\title{
ESTIMAÇÃO DA FRAÇÃO DE RECOMBINAÇÃ̃O E DA FASE DE LIGAÇÃO EM ESPÉCIES DE POLINIZAÇÃO ABERTA: UMA ABORDAGEM BAYESIANA
}

\author{
Júlio CÉSAR PEREIRA
}

Licenciado em Matemática

Orientadora: Prof $\underline{a}$ Dr $\stackrel{a}{-}$ ROSELI APARECIDA LÈNNDRO

Dissertação apresentada à Escola Superior de Agricultura "Luiz de Queiroz", Universidade de São Paulo, para a obtenção do título de Mestre em Agronomia, Área de Concentração: Estatística e Experimentação Agronômica.

P I R A C I C A B A

Estado de São Paulo - Brasil

Novembro - 2004 
Dados Internacionais de Catalogação na Publicação (CIP) DIVISĀO DE BIBLIOTECA E DOCUMENTAÇĀO - ESALQJUSP

Pereira, Júlio César

Estimação da fração de recombinação e da fase de ligação em espécies de polinização aberta: uma abordagem bayesiana / Júlio César Pereira. - - Piracicaba, 2004.

$103 \mathrm{p}$.

Dissertação (Mestrado) - - Escola Superior de Agricultura Luiz de Queiroz, 2004. Bibliografia.

1. Cruzamento 2. Estatística aplicada 3. Inferência bayesiana (inferência estatistica) 4. Mapeamento genético 5 . Método da máxima verossimilhaça 6 . Polinização 7. Progenie vegetal 8. Simulação - Estatistica I. Título

CDD 519.542

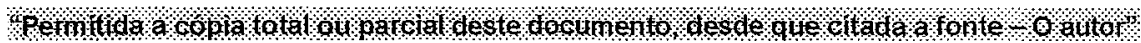




\section{DEDICATÓRIA}

Aos meus pais

Francisco Rogério Pereira e Maria Salete Nunes Pereira e aos meus irmãos Fabiana Nunes Pereira,

João Henrique Pereira e Flávia Nunes Pereira, ofereço.

A Deus, dedico. 
Tu, que habitas sob a proteção do Altíssimo,

que moras à sombra do Onipotente,

dize ao Senhor: "Sois meu refúgio e minha cidadela,

meu Deus, em quem eu confio".

É cle que te livrará do laço do caçador,

e da peste perniciosa.

Ele te cobrirá com suas plumas;

sob suas asas encontrarás refúgio.

Sua fidelidade te será um escudo de proteção.

Tu não temerás os terrores noturnos,

nem a flecha que voa à luz do dia,

nem a peste que se propaga nas trevas,

nem a mal que grassa ao meio-dia.

Caiam mil homens à tua esquerda e dez mil à tua direita:

tu não serás atingido.

Porém, verás com teus próprios olhos,

contemplarás o castigo dos pecadores,

porque o Senhor é teu refúgio.

Escolheste, por asilo, o Altíssimo.

Nenhum mal te atingirá,

nenhum flagelo chegará à tua tenda,

porque aos seus anjos Ele mandou

que te guarden em todos os teus caminhos.

Eles te sustentarão em suas mãos,

para que não tropeces em alguma pedra.

Sobre serpentes e viboras andarás,

calcarás aos pés o leão e o dragão.

"Pois quem se uniu a mim, eu o livrarei;

e o protegerei, pois conhece o meu nome;

na tribulação estarei com ele.

Hei de livrá-lo e o cobrirei de glória.

Será favorecido de longos dias,

e mostrar-lhe-ei a minha salvação.

(SALMO 90). 


\section{AGRADECIMENTOS}

Agradeço a Deus, o autor da vida e ao seu filho Jesus Cristo, Aquele que nos amou acima de tudo e deu Sua própria vida pela nossa.

Às pessoas que contribuíram diretamente para a realização deste trabalho:

À Prof ${ }^{\underline{a}} \operatorname{Dr}^{\underline{a}}$ Roseli Aparecida Leandro, pela orientação, amizade e pela confiança depositada no meu trabalho.

Ao Prof. Dr. Antônio Augusto Franco Garcia, pela amizade, por colaborar na orientação, pelas idéias e participação contínua no desenvolvimento deste trabalho.

À Francine Ragonha, pessoa com quem trabalhei e convivi diariamente durante todo o curso de mestrado, pela amizade, companheirismo, convivência agradável, pelas discussões sempre produtivas e pelas valiosas sugestões.

Ao Éder, pela revisão do trabalho e sugestões.

Ao Gabriel, pelo auxílio no desenvolvimento dos programas computacionas.

À Marta, pelos ensinamentos na área de genética.

À todos os integrantes do Grupo de Estudos Genética-Estatística, coordenado pelo Prof. Dr. Antônio Augusto Franco Garcia e pela Prof ${ }^{\underline{a}} \operatorname{Dr}^{\underline{a}}$ Roseli Aparecida Leandro.

À ESALQ-USP, pela infra-estrutura e pelo apoio concedido através da moradia na Vila Estudantil da Pós Graduação. 
Aos amigos da Vila Estudantil, Anderson e Ana Paula, pessoas capazes de tornar simples momentos em momentos muito especiais e inesquecíveis.

À todos os moradores e ex-moradores da Vila, pelos bons momentos que passamos juntos, em especial à Rosângela, Élio, Wirifran e Henrique.

Aos ex-moradores da Vila pela boa convivência, de maneira especial à Milena Ramires, Raquel e Juan.

À Adriana, pela paciência e compreensão.

Aos amigos do curso de mestrado e doutorado em Estatística e Experimentação Agronômica, em especial à Beth Balanço, Telde, Luciana, João Maurício, Hélio Rubens (Rubilico) e Alfredo.

Ao Moita, pelos conselhos e pelas dicas computacionais.

Ao CNPQ pelo apoio financeiro.

Aos funcionários do Departamento de Ciências Exatas da ESALQUSP, em especial à Solange, Luciane e Jorge.

Aos professores do Departamento de Ciências Exatas da ESALQ-USP, em especial àqueles que foram meus professores e que ainda não agradeci, ao Décio Barbin, Clarice Garcia Borges Demétrio, Édwin Moisés Marcos Ortega e Sílvio Sandoval Zocchi.

Ao meu orientador do curso de graduação, Prof. Dr. Anízio Perissinotto Junior. 


\section{SUMÁRIO}

Página

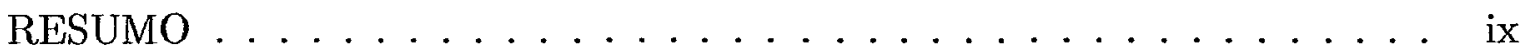

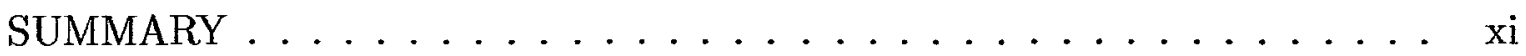

1 INTRODUÇÃO $\ldots \ldots \ldots \ldots \ldots \ldots \ldots$

2 REVISÃO DE LITERATURA . . . . . . . . . . . . 4

2.1 Ligação Genética . . . . . . . . . . . . . . . . . . . . . 4

2.2 Determinação da Ligação $\ldots \ldots \ldots \ldots \ldots$. . . . . . . . . 7

2.3 Construção de Mapas de Ligação $\ldots \ldots \ldots$. . . . . . . . . . 9

2.4 Determinação da Fase de Ligação . . . . . . . . . . . . . . . . . 11

2.5 Estimação das Freqüências de Recombinação com Fase Parental Desconhecida . . . . . . . . . . . . . . . . . . 13

2.6 A Análise de Ligação em Espécies de Polinização Aberta . . . . . . . . 14

2.7 O Teorema de Bayes . . . . . . . . . . . . . . . . . . . . 19

2.7.1 Escolha da Distribuição a priori. . . . . . . . . . . . . . . 21

2.7.2 Distribuições a priori próprias e impróprias . . . . . . . . . . 22

2.7.3 Distribuições a priori Conjugadas. . . . . . . . . . . . . . 22

2.7.4 Distribuições objetivas, distribuições não-informativas . . . . . . . . . . 22

2.7 .5 Distribuição a posteriori . . . . . . . . . . . . . . . . 24

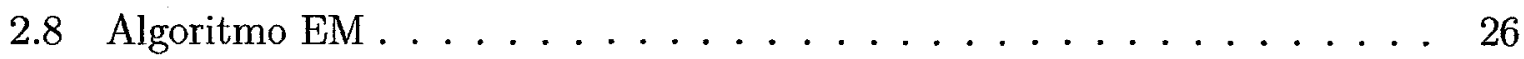

3 MATERIAL E MÉTODOS . . . . . . . . . . . 28

3.1 Material . . . . . . . . . . . . . . . . . 28

3.2 Métodos . . . . . . . . . . . . . . . . . . . . . 29

3.2 .1 Atribuição dos Cromossomos Parentais . . . . . . . . . . . . . . 29 
3.2 .2 A Função de Verossimilhança . . . . . . . . . . . . . . . . . . . 32

3.2.3 Estimação da Fração de Recombinação pelo Método da Máxima Verossimilhança . . . . . . . . . . . . . . . . . 34

3.2.4 Enfoque Bayesiano: Estimação da Freqüência de Recombinação . . 37

3.2 .5 Determinação da Fase de Ligação . . . . . . . . . . . . . . . 40

4 RESULTADOS E DISCUSSÃO . . . . . . . . . . . . . . . 42

4.1 Cruzamentos em que somente um dos genitores é heterozigótico para ambos os locos . . . . . . . . . . . . . . 43

4.2 Cruzamentos em que a segregação é simétrica em ambos os locos . . . . 51

4.3 Cruzamentos em que ambos os locos têm um alelo nulo no mesmo genitor 58

4.4 Outros cruzamentos . . . . . . . . . . . . . . . . 63

4.5 Considerações Gerais . . . . . . . . . . . . . . . . . . . . 70

5 CONCLUSOEES . . . . . . . . . . . . . . . 73

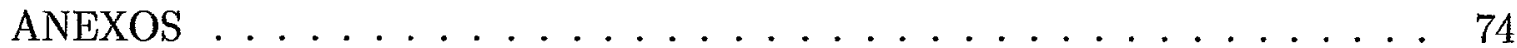

REFERÊNCIAS BIBLIOGRÁFICAS . . . . . . . . . . . . . . . . . 102 


\title{
ESTIMAÇÃO DA FRAÇÃO DE RECOMBINAÇÃ̃O E DA FASE DE LIGAÇÃO EM ESPÉCIES DE POLINIZAÇÃO ABERTA: UMA ABORDAGEM BAYESIANA
}

\author{
Autor: JÚLIO CÉSAR PEREIRA \\ Orientadora: Prof. Dr. ROSELI APARECIDA LEANDRO
}

\section{RESUMO}

A análise de ligação em populações de espécies de polinização aberta, em que não é possível a obtenção de linhagens, é mais complicada do que em populações de cruzamentos controlados em que isso é possível. Este trabalho trata da análise de ligação em progênies resultantes de diferentes cruzamentos entre duas plantas de espécie de polinização aberta, considerando-se dois locos. Dois métodos de estimação para a freqüência de recombinação foram comparados: o método da máxima verossimilhança e um método Bayesiano com o uso de uma priori uniforme. As estimativas da freqüência de recombinação obtidas pelo método Bayesiano, em geral apresentam menor soma de quadrados de resíduos que as estimativas de máxima verossimilhança e os comportamentos das estimativas obtidas pelos dois métodos, 
tornam-se próximos a medida em que o tamanho da progênie aumenta. Além disso, o fato de se estimar a frequêencia de recombinação por um método ou outro não interfere na estimação da fase de ligação (que também é estimada por um método Bayesiano). Assim, o método puramente Bayesiano pode também ser recomendado para a análise de ligação. Uma vez que a abordagem Bayesiana também permite a incorporação de informações a priori fornecidas pelo pesquisador ou com base em artigos já publicados, nota-se que o enfoque Bayesiano pode ser uma alternativa útil em vários casos. 


\title{
ESTIMATION OF RECOMBINATION FREQUENCY AND LINKAGE PHASES IN OUTCROSSING SPECIES: A BAYESIAN APPROACH
}

\author{
Author: JÚLIO CÉSAR PEREIRA \\ Adviser: Prof. Dr. ROSELI APARECIDA LEANDRO
}

SUMMARY

Linkage analysis in outcrossing species populations in which the achievement of lines is not possible is more complicated than in populations of controlled crossings where this is possible. This study deals with linkage analysis in progenies that are result of different crossings between two plants of the outcrossing species, considering two loci. Two methods of estimation for the recombination frequency were compared: the method of maximum likelihood and a Bayesian method with the use of a priori uniform. The recombination frequency estimates obtained by the Bayesian method generally present a smaller sum of squares of residues than the estimates of maximurin likelihood. The performance of the estimates obtained by the two methods become similar inasmuch as the progeny size is increased. Besides, 
the fact of estimating a recombination frequency by one method or the other does not interfere in the estimation of the linkage phase (which is also estimated by a Bayesian method).The purely Bayesian method can therefore also be recommended for linkage analysis. Since the Bayesian approach also allows the incorporation of information furnished a priori by the researcher or based on published articles, one notes that the Bayesian focus would be a useful alternative in various cases. 


\section{INTRODUÇÃO}

O mapeamento genético ocupa uma posição de destaque na área agronômica, pois fornece informações úteis para o melhoramento genético, com importância na obtenção de cultivares com requisitos adequados a interesses agronômicos e industriais. Os mapas genéticos podem ser utilizados para determinar a localização de genes ou regiões genômicas que afetam caracteres simples ou complexos de interesse agronômico (Pastina, 2002).

Apesar do grande desenvolvimento em pesquisas genéticas, as espécies de polinização aberta, em que não é possível a obtenção de linhagens endogâmicas devido a aspectos biológicos ou, até mesmo, devido ao longo tempo necessário para a obtenção desse tipo de material, foram pouco estudadas do ponto de vista do mapeamento genético. Nos últimos anos estudos referentes a essas espécies vem ganhando destaque. Para espécies em que é possível a obtenção de linhagens endogâmicas por meio de autofecundações sucessivas, a análise de ligação é simples, pois é possível distinguir os indivíduos recombinantes e não recombinantes na progênie e, assim, a fase de ligação dos diferentes locos de marcadores é conhecida (Wu, et al., 2002).

Para populações tradicionais de mapeamento tais como $\mathrm{F} 2$ derivadas de autofecundação de indivíduos F1(oriundo de cruzamentos de linhagens) e populações de retrocruzamentos (cruzamento do F1 com um dos pais homozigóticos), marcadores tais como: "restriction fragment length polimorphism" (RFLP), "amplified fragment lenght" (AFLP) e "randomly amplified polimorfic DNA" (RADP) são suficientes para caracterizar os alelos segregante nesse tipo de população. 
As diferenças para a análise de ligação entre a progênies de linhagens endogâmicas e progênies de espécies de polinização aberta são devido ao número de alelos segregando por loco bem como sua fase de ligação. Um cruzamento entre duas plantas de espécie de polinização aberta, podem segregar até quatro alelos por loco, enquanto as fases de ligação são geralmente desconhecidas (Maliepaard, et al., 1997). A maior dificuldade em analisar diferentes tipos de marcadores ao mesmo tempo vem da incerteza da fase de ligação parental entre as marcas (Wu, et al., 2002).

A análise de ligação nas espécies de polinização aberta ${ }^{1}$ podem preferencialmente fazer uso de marcadores moleculares codominantes com alelos múltiplos como microsatélites que apresentam segregação altamente informativa (1:1:1:1). Para locos que possuem a segregação pouco informativa (1:1) e (3:1) pode-se se utilizar os marcadores dominantes como AFLP e RAPD, para locos em que a segregação é do tipo (1:2:1) é possível utilizar qualquer marcador codominante (Wu, et al., 2002).

Maliepaard et al. (1997) dão uma classificação completa de todos os possíveis marcadores genotípicos ou fenotípicos em termos de número e dos tipos de marcadores genéticos e apresentam equações para estimação da fração de recombinação sob fases de ligações particulares em ambos os pais. Dependendo de como diferentes alelos são combinados nos dois pais usados no cruzamento, existem 18 tipos de cruzamentos considerando um único loco e que são classificados em 7 grupos. Dentre esses 18 tipos de cruzamentos alguns são totalmente informativos (a segregação na progênie é $1: 1: 1: 1$ ) e outros são parcialmente informativos (segregação $1: 2: 1,3: 1$ e $1: 1$ ). A análise de ligação entre as marcas, feita duas a duas, considerando todas as possíveis combinações dos 7 grupos, resulta em um total de 28 combinações (Wu et al., 2002).

Wu et al. (2002) desenvolveram um algoritmo geral para estimação simultânea da fração de recombinação e configuração da fase de ligação sobre todas as marcas ligadas, no tipo de população tratada. Nesse algoritmo, a caracterização

\footnotetext{
${ }^{1}$ Sempre que se fala em espécies de polinização aberta, refere-se àquelas em que não é possível a obtenção de linhagens endogâmicas.
} 
das fases de ligação entre os locos na análise de ligação é feita utilizando-se uma abordagem Bayesiana, entretanto as freqüências de recombinação são estimadas por máxima verossimilhança (abordagem clássica).

Nordhein et al. (1983) propõem, em um estudo de ligação genética para dois locos com fase de ligação parental desconhecida, estimadores Bayesianos para a freqüência de recombinação no caso de um retrocruzamento, o qual é um caso particular das 28 combinações.

Nesse trabalho foi estudado todos os 28 tipos de cruzamentos, entre dois locos, apresentados por Maliepaard et al. (1997), comparando o método de estimação Bayesiano, como proposto por Nordhein et al. (1983), com o método da máxima verossimilhança (método clássico). Para isso foram analisadas as propriedades estatísticas das estimativas obtidas por ambos os métodos, a fim de verificar se a abordagem Bayesiana leva alguma vantagem em relação à abordagem clássica. $\mathrm{O}$ algoritmo proposto por Wu et al. (2002) foi utilizado para a caracterização da fase de ligação.

No caso da abordagem Bayesiana, foi atribuída uma distribuição de probabilidade a priori para a freqüência de recombinação. A distribuição a priori permite ao pesquisador, no caso o geneticista, expressar sua opinião, inserir informação, seja ela baseada em dados históricos ou devido a sua expectativa subjetiva basedo em sua experiência, a respeito da freqüência de recombinação. 


\section{REVISÃO DE LITERATURA}

A fim de que o leitor possa entender melhor esse trabalho, é apresentado aqui, de forma didática, o problema biológico que pretende-se ajudar a resolver usando uma abordagem Bayesiana.

\subsection{Ligação Genética}

O conceito de ligação surgiu no início do século XX quando Bateson e Punnett estavam estudando a herança em ervilhas, em relação a dois genes, e perceberam que a segregação de gametas não estava de acordo com a segregação mendeliana. Propuseram, então, que o acoplamento (ligação) físico entre os alelos dominantes e os alelos recessivos, provavelmente, estaria evitando a distribuição independente (Griffths et al., 2002).

Após a idéia de ligação ter sido proposta, Morgan observou um desvio similar nas leis de Mendel quando fazia cruzamentos de moscas. Estudando dois genes, um que afetava a cor do olho ( $p r$ : púrpura e $p r^{+}:$vermelho), e o outro que afetava o tamanho da asa ( $v g$ : vestigal e $v g^{+}:$normal). Os alelos selvagens $p r^{+}$ e $v g^{+}$de ambos os genes são dominantes (Griffths et al., 2002). Morgan cruzou, inicialmente, moscas $p r^{+} p r^{+} v g^{+} v g^{+}$com $p r p r v g v g$.

$$
\begin{array}{cccc} 
& p r^{+} p r^{+} v g^{+} v g^{+} & \times & p r p r v g v g \\
\text { gametas } & p r^{+} v g^{+} & \downarrow & p r v g \\
F 1: & & p r^{+} p r v g^{+} v g &
\end{array}
$$

A seguir, fez um cruzamento teste com fêmeas duplo homozigotas da geração F1. 


$$
\begin{array}{rllll} 
& p r^{+} p r v g^{+} v g & \times & p r p r v g v g \\
& & \downarrow & \\
p r^{+} p r v g^{+} v g & p r^{+} p r v g v g & & p r p r v g^{+} v g \quad \text { pr prvg } v g
\end{array}
$$

Os resultados obtidos por Morgan na geração F2 eram muito diferentes daqueles esperados pela proporção mendeliana $1: 1: 1: 1$ indicando portanto ligação entre os genes. As duas classes com maiores freqüências foram $p r^{+} p r v g^{+} v g$ e pr pr vg vg, originalmente introduzidas pelas moscas parentais e homozigotas.

O cruzamento teste é muito importante. De fato, um genitor (o testador) contribui apenas com gametas constituídos de alelos recessivos (pr pr vgvg), os fenótipos da progênie revelam a contribuição do outro genitor duplamente heterozigoto. Assim, a análise pode concentrar-se, na meiose, em um genitor esquecendo-se o outro (Griffths et al., 2002).

O cruzamento teste revela as combinações alélicas de um dos pais no F1, mostrando que a ligação pode ser deduzida pela autofecundação de F1. Revela, ainda que há uma proporção $1: 1$ entre os dois tipos parentais e, também, entre os dois tipos não parentais. Esse tipo de ligação é chamado de ligação em associação, quando os genes estão ligados em associação e denota-se por $\frac{p r^{+} v g^{+}}{p r v g}$ ou $\frac{A B}{a b}$ para dois genes quaisquer $A$ e $B$.

Morgan supôs que as combinações de alelos trazidos como genitores homozigotos no primeiro cruzamento podiam vir trocadas (neste caso cada genitor é homozigoto para um alelo dominante e para um recessivo):

$$
\begin{array}{cccc} 
& p r^{+} p r^{+} v g v g & \times & p r p r v g^{+} v g^{+} \\
\text {gametas } & p r^{+} v g & \downarrow & p r v g^{+} \\
F 1: & & p r^{+} p r v g^{+} v g &
\end{array}
$$

Em seguida fez o cruzamento teste e obteve a progênie F2. 


$$
\begin{aligned}
& p r^{+} p r v g^{+} v g \quad \times \quad p r p r v g v g \\
& \downarrow \\
& p r^{+} p r v g^{+} v g \quad \text { prpr } v g^{+} v g \quad \text { prprvg } g^{+} v g \quad \text { prprvgvg }
\end{aligned}
$$

Novamente os resultados obtidos eram diferentes da segregação mendeliana independente $(1: 1: 1: 1)$. Agora as classes com maiores freqüências são aquelas que têm só um alelo dominante, não como antes, dois alelos dominantes ou dois recessivos. Mas ainda aqui, as maiores classes são das combinações alélicas parentais, ou seja, que foram trazidas para $\mathrm{F} 1$ pelas moscas parentais. Desse cruzamento teste, também pode-se deduzir a ligação e este tipo de ligação é chamada de ligação em repulsão denotada por $\frac{p r^{+} v g}{p r v g^{+}}$, ou $\frac{A b}{a B}$ para dois genes $A$ e $B$ quaisquer.

Para explicar esse fenômeno, Morgan sugeriu que os genes que controlam o fenótipo estão situados no mesmo par de cromossomos. A localização de dois genes no mesmo par cromossômico é chamada de ligação. Quando se fala em ligação, é comum referir-se à fase de ligação, a qual pode ser associação ou repulsão.

Assim, no caso de ligação em associação quando $p r$ e $v g$ são introduzidos de um genitor, eles estão situados no mesmo cromossomo, enquanto $p r^{+}$e $v g^{+}$ estão em cromossomos homológos de outro genitor (Figura 1). No caso da repulsão, um alelo dominante de um gene está sobre o mesmo cromossomo que o alelo recessivo do outro gene. A ligação explica porque as combinações alélicas de P (parental) permanecem juntas (Griffths et al., 2002).

Para explicar o aparecimento de combinações não parentais, Morgan sugeriu que quando os cromossomos homólogos se pareiam na meiose as cromátides não-irmãs podem trocar partes em um processo chamado "Crossing-Over" (Figura 2). As duas novas combinações são chamadas de produtos de "crossing-over" (Griffths et al., 2002). 


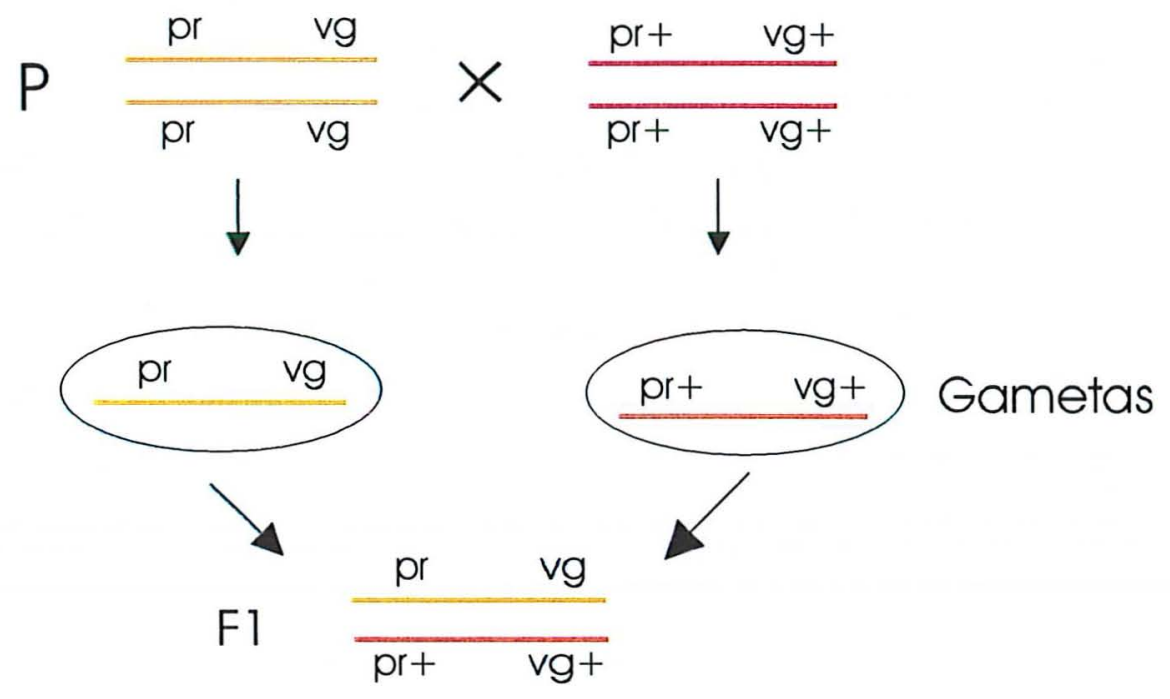

Figura 1 - Herança simples de dois pares de alelos situados no mesmo par de cromossomos

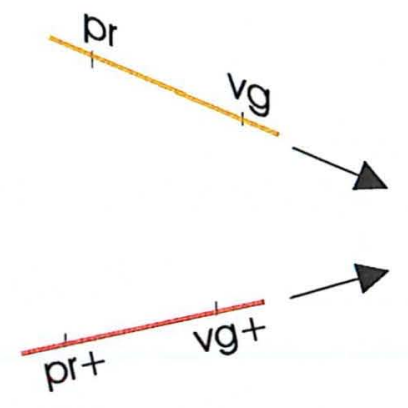

Cromossomos parentais

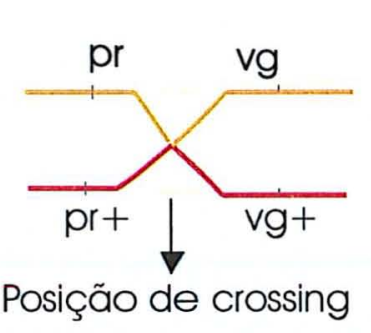

Meiose

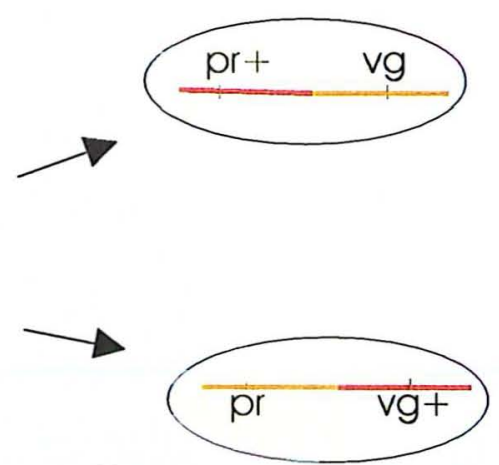

Cromossomos com crossing

Figura 2 - Ocorrência de "crossing-over" durante a meiose

\subsection{Determinação da Ligação}

O principal teste para determinar se dois genes estão ligados é baseado no conceito de recombinação.

A recombinação meiótica é qualquer processo que gere um produto 
haplóide com um genótipo diferente de ambos os genótipos haplóides que constituem a célula meiótica diplóide. Para detectar os gametas recombinantes em um ciclo de vida diplóide precisa-se conhecer os gametas iniciais; para isso é preferível ter genitores "puros". Além disso, não se pode detectar diretamente os recombinantes finais; é necessário fazer cruzamento teste com indivíduos diplóides e observar sua progênie (Griffiths et al., 2002).

Se a progênie de um cruzamento teste for constituída de um produto recombinante da meiose ela também é chamada de recombinante. Os recombinantes podem ser produzidos por segregação independente e "crossing-over".

A Figura 3 ilustra a segregação mendeliana independente considerando o cruzamento teste. Na segregação mendeliana, as duas classes recombinantes sempre constituem $50 \%$ da progênie sendo $25 \%$ de cada tipo de recombinante.

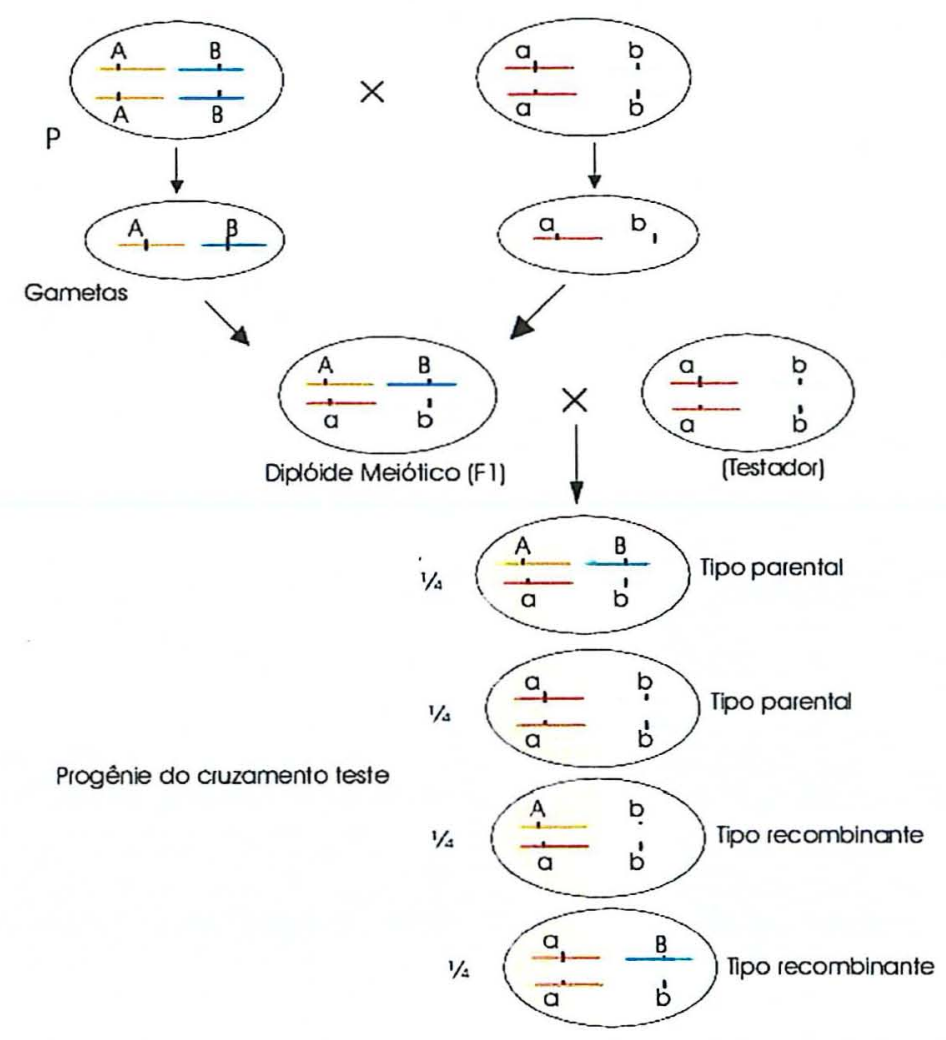

Figura 3 - Segregação mendeliana independente

Se em um cruzamento teste for observado uma frequiência de recom- 
binação de $50 \%$ pode-se deduzir que os dois genes em estudo segregam de forma independente, e a interpretação que se dá é que os dois genes estão em pares cromossômicos distintos. No entanto, deve-se observar que: genes que estão muito separados no mesmo par cromossômico podem agir independentemente e produzir o mesmo resultado (Griffiths et al., 2002).

Os recombinantes também são produzidos quando duas cromátides não-irmãs fazem "crossing-over". Não há "crossing-over" entre dois genes específicos em todas as meioses, mas quando ocorre o "crossing-over" metade dos produtos destas meioses são recombinantes. A meiose sem "crossing-over" entre os genes em estudo produz apenas genótipos parentais.

Quando dois genes estão muito próximos sobre o mesmo par cromossômico a ocorrência de "crossing-over" é menos freqüente, isso torna a segregação independente praticamente impossível e produz uma freqüência de recombinação significativamente mais baixa do que $50 \%$ (Figura 4). A freqüência de recombinação que surge de genes ligados varia de 0 a $50 \%$ dependendo da sua proximidade. (Griffiths et al., 2002).

\subsection{Construção de Mapas de Ligação}

Morgan, estudando vários genes ligados, percebeu que a quantidade de "crossing-over" entre eles diferem, e imaginou que estas variações de freqüência de "crossing-over" pudessem indicar as freqüências reais que separam genes nos cromossomos. O estudante de graduação Sturtevant, a pedido de Morgan estudou esse fato e desenvolveu um método para descrever as relações entre genes, que ainda é usado hoje em dia. Ele percebeu que as variações nas intensidades de ligação, já atribuídas por Morgan às diferenças na separação espacial dos genes, ofereceram a oportunidade de se determinar as seqüências na dimensão linear de um cromossomo. Foi então, que Sturtevant produziu o primeiro mapa cromossômico, sugerindo o uso da porcentagem de recombinantes como um indicador quantitativo da distância linear entre dois genes em um Mapa Genético ou Mapa de Ligação (Griffiths et al., 2002). 


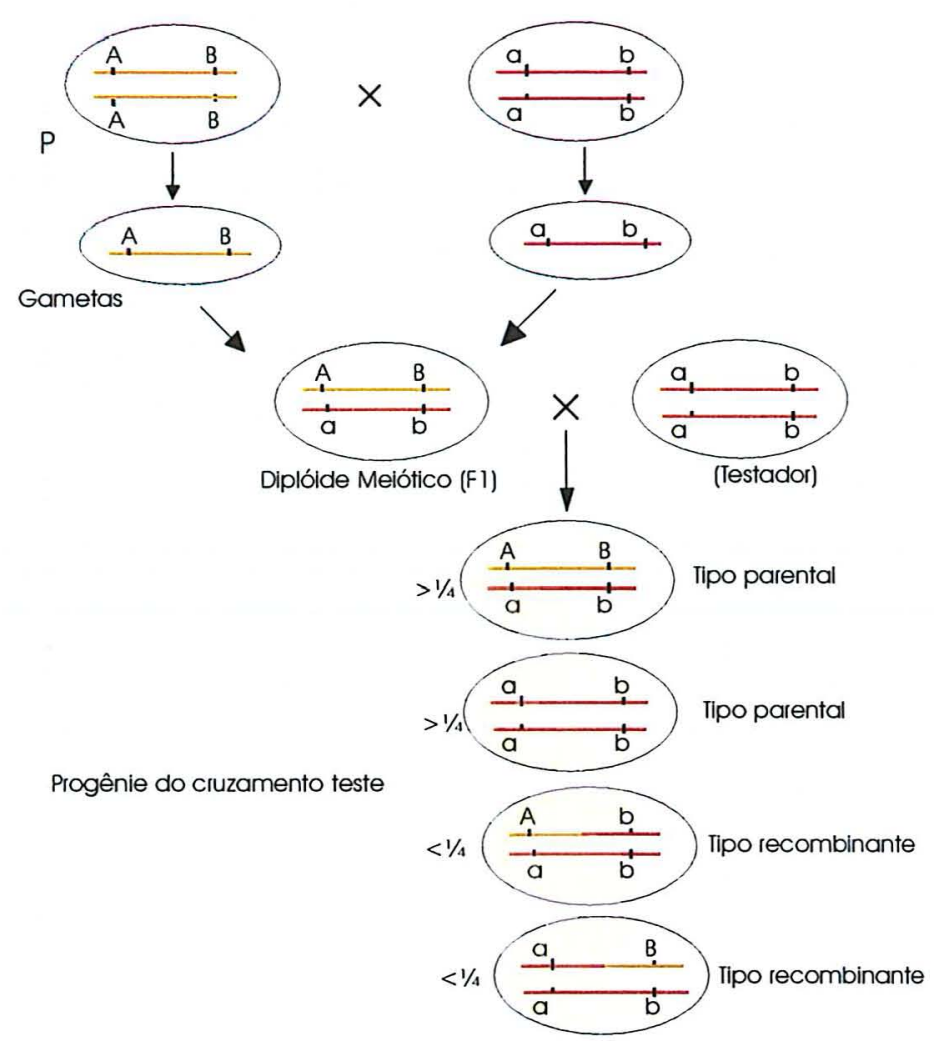

Figura 4 - Genes ligados, freqüência de recombinação menor que 50\%

Sturtevant postulou uma certa proporcionalidade: quanto maior a distância entre os genes ligados, maior a chance de que as cromátides não-irmãs façam "crossing-over" na região entre os genes e, assim, maior a proporção de recombinantes que seriam produzidos (Griffiths, et al. 2002). Foi definido, então, que uma unidade de mapa genético em centimorgan (cM) equivale a aproximadamente $1 \%$ de recombinação quando os marcadores estão bem próximos, mas podem diferir da porcentagem de recombinação quando estão mais distantes devido à ocorrência de "crossing-over" duplo, triplo, etc. O lugar no mapa, e no cromossomo, onde o gene se situa é chamado locos gênico (Cristofani, 1997).

A Figura 5 traz um exemplo de um mapa genético, construído para dados da progênie de um cruzamento em que foram considerados 5 locos. Nesse exemplo a distância entre os genes é expressa em Morgan. 


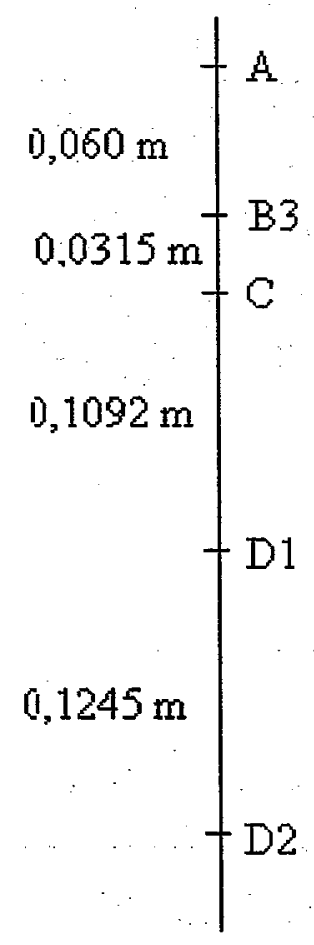

Figura 5 - Mapa genético construído para dados simulados referente a 5 locos

\subsection{Determinação da Fase de Ligação}

Existem situações em que experimentos práticos de mapeamento genético com cruzamentos controlados são inviáveis devido ao longo tempo de geração ou do custo elevado (Nordhein et al., 1983). Assim, em muitos experimentos práticos de mapeamento genético, as fases de ligação não são conhecidas a priori. É o caso das espécies de polinização aberta.

Para progênies de retrocruzamento com modelo considerando dois locos, para que se tenha informação sobre a fase de ligação, um dos parentais deve ser heterozigoto para ambos os locos (Pastina, 2002). Sendo, então, os locos $A \mathrm{e}$ $B$, um dos parentais deve ser $A a B b$. No entanto, em casos onde um dos parentais é heterozigoto para um loco e o outro parental é heterozigoto para o outro loco $(A a b b \times a a B b)$, a progênie não fornece informação sobre as fases de ligação. Já para dados de cruzamentos múltiplos, as fases de ligação podem ser diferentes de 
cruzamento para cruzamento. Entretanto, uma vez determinada a fase de ligação para cada cruzamento, as análises de ligação podem ser feitas através de ferramentas estatísticas, como as funções de verossimilhança (Liu, 1998):

$$
\begin{gathered}
L_{\text {Associação }}=L(r) \\
L_{\text {Repulsão }}=L(1-r)
\end{gathered}
$$

em que:

$L_{\text {Associação }}=L(r)$ é a função de verossimilhança, considerando a ligação em associação;

$L_{\text {Repulsão }}=L(1-r)$ é a função de verossimilhança, considerando a ligação em repulsão e

$r$ é a freqüência de recombinação entre os locos.

Para casos de retrocruzamentos, a estimativa da freqüência de recombinação de uma das fases de ligação pode ser diretamente obtida da outra através da relação:

$$
\widehat{r}_{R}=1-\widehat{r}_{A}
$$

em que:

$\widehat{r}_{R}$ é a estimativa da freqüência de recombinação entre locos em repulsão e $\widehat{r}_{A}$ é a estimativa da freqüência de recombinação entre locos em associação.

Como para casos de retrocruzamentos, a função de verossimilhança é simétrica em torno de $r=0,5$ para ambas as fases de ligação, o teste estatístico para razão de verossimilhança é o mesmo nas duas fases e a estimativa da freqüência de recombinação pode ser obtida por transformação. Assim, se:

$$
\operatorname{Pr}\left[\chi_{1}^{2} \geq G\right] \leq \alpha \text { e } \widehat{r}<0,5
$$

o loco estará em fase de associação, sendo:

$\alpha$ : o nível de significância;

$G$ : o logaritmo da razão de verossimilhanças;

$\widehat{r}$ : a estimativa da fração de recombinação utilizando o modelo de associação. 
Contudo, caso:

$$
\operatorname{Pr}\left[\chi_{1}^{2} \geq G\right] \leq \alpha \quad \text { e } \quad \widehat{r}>0,5
$$

a fase de ligação será de repulsão. Entretanto, se o teste for não significativo, a mesma não poderá ser determinada (Liu, 1998).

\subsection{Estimação das Freqüências de Recombinação com Fase Parental Desconhecida}

Como ressaltado na seção anterior, existem situações em que é inviável trabalhar com cruzamentos controlados, para os quais a fase de ligação parental é conhecida. Tendo isso em consideração, Nordheim et al. (1983) propõem um estudo para estimação da freqüência de recombinação em que a fase parental é desconhecida.

Para esse estudo o modelo adotado foi o modelo apresentado na eq. (1) para dois locos, sendo que um dos parentais é heterozigoto em ambos os locos $(\mathrm{AaBb})$ e o outro parental é homozigoto (aabb).

$$
\operatorname{Pr}(k \mid n, r)=\left\{\begin{array}{cc}
\left(\begin{array}{c}
n \\
k
\end{array}\right)\left[r^{k}(1-r)^{n-k}+r^{n-k}(1-r)^{k}\right] & 0 \leq k<\frac{n}{2} \\
\frac{1}{2}\left(\begin{array}{c}
n \\
k
\end{array}\right)\left[r^{k}(1-r)^{n-k}+r^{n-k}(1-r)^{k}\right] & k=\frac{n}{2}
\end{array}\right.
$$

em que $n$ é o tamanho amostral (número de gametas), $k$ é o número de observações na menor classe (associação ou repulsão). A função de verossimilhança pode ser escrita como:

$$
L(r \mid n, k) \propto r^{k}(1-r)^{n-k}+r^{n-k}(1-r)^{k} .
$$

Foram considerados três métodos de estimação das freqüências de recombinação, a saber: o método da máxima verossimilhança, o método Bayesiano e um método "ad hoc" (Nordheim et al., 1983).

No método Bayesiano, foi considerada uma distribuição a priori não informativa para o parâmetro $r$ e uma priori informativa, representando a crença de 
que a segregação é independente, com um pico da distribuição de probabilidade a priori em $r=0,5$.

O estimador de Bayes é a média para $r$ em relação à distribuição a posteriori. O estimador Bayesiano com uso de uma distribuição a priori não informativa é dado por:

$$
\widehat{r}_{1}=\frac{k+1}{n+2} I_{0,5}(k+2, n-k+1)+\frac{n-k+1}{n+2} I_{0,5}(n-k+2, k+1)
$$

em que $I_{x}(a, b)$ é a função beta incompleta.

O estimador Bayesiano com uso da distribuição a priori informativa é dado por:

$$
\widehat{r}_{2}=\frac{\left[\beta 0,5^{n}+2(1-\beta) \int_{0}^{0,5} r L(r \mid n, k) d r\right]}{\left[\beta 0,5^{n-1}+2(1-\beta) \int_{0}^{0,5} L(r \mid n, k) d r\right]}
$$

$\mathrm{O}$ estimador natural "ad hoc" $\widehat{r}_{3}$ consiste em tomar o quociente entre o número de gametas $(k)$ da menor classe e o número total de gametas $(n)$ :

$$
\widehat{r}_{3}=\frac{k}{n}
$$

O estimador de máxima verossimilhança $\widehat{r}_{4}$ é o valor de $r$ que maximiza $L(r \mid n, k)$, em geral este valor pode ser encontrado numericamente.

Os quatro estimadores das freqüências de recombinação foram comparados pelos autores, sendo $\widehat{r}_{1}$ o que apresentou melhor resultado, tendo como principal critério de comparação o Quadrado Médio do Resíduo. Na maior parte do intervalo dos possíveis valores de $r$, o estimador $\widehat{r}_{1}$ foi o que apresentou menor Quadrado Médio do Resíduo.

\subsection{A Análise de Ligação em Espécies de Polinização Aberta}

As diferenças para a análise de ligação entre progênies de cruzamentos de linhagens e progênies de espécie de polinização aberta são devido ao número de alelos segregantes por loco bem como o conhecimento da fase de ligação entre os 
alelos. Essas diferenças tornam a análise de ligação mais complicada nesse último caso.

Populações segregando como um retrocruzamento e F2 são obtidas por meio de cruzamento de linhagens homozigóticas. Assim, todos os locos segregam somente para dois alelos, e todos os alelos de um mesmo pai estão em associação na geração F1. Em cruzamentos entre plantas de espécie de polinização aberta podem segregar para até 4 alelos por loco, enquanto que a fase de ligação é geralmente desconhecida.

Dependendo de como os diferentes alelos são combinados nos dois pais utilizados num cruzamento, existem 18 tipos de possíveis cruzamentos para um loco (Tabela 1). Baseado no padrão de marcas apresentados pelos genitores e pela progênie, esses tipos de cruzamentos podem ser classificados em sete grupos conforme a Tabela 1 (Maliepaard et al., 1997).

Maliepaard et al. (1997) apresentaram uma visão geral de todas as possíveis configurações dos marcadores moleculares em cruzamentos com espécies de polinização aberta, mostrando uma classificação completa de todos os possíveis marcadores genotípicos e fenotípicos em termos do número e tipo de marcadores. Apresentam também equações para a estimação da fração de recombinação considerando cada fase de ligação em particular para dois locos e fórmulas para o cálculo do $L O D$ Score(logaritmo na base 10 da razão de verossimilhanças) para todos os casos. Tais fórmulas são utilizadas para testar a ligação entre um par de locos. Para os casos que não é possível encontrar um estimador analítico, propõem a utilização do algoritmo EM para a estimação da fração de recombinação.

Para realizar a análise de ligação entre dois locos arbitrários, deve-se considerar todas as possíveis combinações dos sete grupos de marcadores. Teoricamente, existem 28 combinações (Wu et al., 2002). A Tabela 2 apresenta todas as combinações, duas a duas, entre dois locos, para um representante de cada um dos 7 grupos apresentados na Tabela 1; os cruzamentos são representados por números, cruzamentos com números repetidos são equivalentes. 
Tabela 1. Possíveis tipos de cruzamentos para um marcador, padrão de marcas dos genitores e da progênie

\begin{tabular}{|c|c|c|c|c|c|c|c|c|}
\hline & \multirow{2}{*}{\multicolumn{2}{|c|}{ Tipo de Cruzamento }} & \multicolumn{3}{|c|}{ Pais } & \multicolumn{3}{|c|}{ Progênie } \\
\hline & & & Cruzamento & Banda observada & & Banda Observada & Segregaçãa & No. de fenótipos \\
\hline \multirow[t]{4}{*}{ A } & & 1 & $a b \times c d$ & $a b \times c d$ & assimétrico & $\mathrm{ac}, \mathrm{ad}, \mathrm{bc}, \mathrm{bd}$ & $1: 1: 1: 1$ & 4 \\
\hline & & 2 & $a b \times a c$ & $a b \times a c$ & assimétrico & $a, a c, b a, b c$ & $1: 1: 1: 1$ & 4 \\
\hline & & 3 & $a b \times c o$ & $a b \times c$ & assimétrico & $a c, a, b c, b$ & 1:1:1:1 & 4 \\
\hline & & 4 & $a o \times b o$ & $a \times b$ & assimétrico & $a b, a, b, o$ & $1: 1: 1: 1$ & 4 \\
\hline \multirow[t]{3}{*}{ B } & $B 1$ & 5 & $a b \times a o$ & $a b \times a$ & assimétrico & $a b, 2 a, b$ & $1: 2: 1$ & 3 \\
\hline & $\mathrm{B} 2$ & 6 & aox ab & $a \times a b$ & assimétrico & $a b, 2 a, b$ & $1: 2: 1$ & 3 \\
\hline & B3 & 7 & $a b \times a b$ & $a b \times a b$ & simétrico & $a, 2 a b, b$ & $1: 2: 1$ & 3 \\
\hline C & & 8 & ao $\times$ ao & $a \times a$ & simétrico & $3 a, 0$ & $3: 1$ & 2 \\
\hline \multirow[t]{10}{*}{ D } & D1 & 9 & $a b \times c c$ & $a b \times c$ & assimétrico & $a c, b c$ & 1:1 & 2 \\
\hline & & 10 & $a b \times a a$ & $a b \times a$ & assimétrico & $a, a b$ & $1: 1$ & 2 \\
\hline & & 11 & $a b \times 0 o$ & $a b \times 0$ & assimétrico & $a, b$ & 1:1 & 2 \\
\hline & & 12 & box aa & $b \times a$ & assimétrico & $a b, a$ & $1: 1$ & 2 \\
\hline & & 13 & ao $\times$ oo & $a \times 0$ & assimétrico & $a, o$ & $1: 1$ & 2 \\
\hline & D2 & 14 & $c c \times a b$ & $c \times a b$ & assimétrico & $a c, b c$ & 1:1 & 2 \\
\hline & & 15 & $a a \times a b$ & $a \times a b$ & assimetrico & $a, a b$ & 1:1 & 2 \\
\hline & & 16 & $a o \times a b$ & $\mathbf{a} \times \mathbf{a b}$ & assimétrico & $a, b$ & $1: 1$ & 2 \\
\hline & & 17 & $a a \times$ bo & $a \times b$ & assimétrico & $a b, a$ & 1:1 & 2 \\
\hline & & 18 & $00 \times$ ao & $a \times a$ & assimétrico & $a, o$ & 1:1 & 2 \\
\hline
\end{tabular}

Fonte: Wu et al. (2002)

Os cruzamentos da Tabela 2, são denotados também pelas letras indicando o grupo ao qual pertencem na Tabela 1. No Anexo A11 são apresentados esses cruzamentos da Tabela 2 (Maliepaard et al., 1997), sua notação em termos dos grupos ao qual pertencem na Tabela 1 (Wu et al., 2002), bem como a notação utilizada neste trabalho. Assim, quando se estuda um cruzamento do tipo 1 (na notação da Tabela 2), por exemplo, está estudando-se os cruzamentos dos tipos $D 1 D 1$ e $D 2 D 2$ (na notação da Tabela 1), mas, como o estudo de ligação para esses dois cruzamentos são análogos, apenas 1 deles será considerado. A notação utilizada será, por exemplo, $D 1 D 1(1)$, em que $D 1 D 1$ indica que os dois locos são do tipo $D 1$ (Tabela 1) e o número 1 entre parenteses indica a que grupo pertence na Tabela 2.

Wu et al. (2002), num cruzamento, denotam um pai por $P$ e outro por $Q$, os cromossomos em cada pai por $P_{1}$ e $P_{2}, Q_{1}$ e $Q_{2}$, respectivamente. Então, 
Tabela 2. Possíveis tipos de cruzamentos entre dois pares de locos

\begin{tabular}{lccccccc}
\hline Loco 1 & $a b \times a a$ & $a a \times a b$ & $a b \times a b$ & $a b \times c d$ & $a o \times a o$ & $a b \times a o$ & $a o \times a b$ \\
\hline$a b \times a a$ & 1 & $*$ & 2 & 3 & 4 & 5 & 6 \\
$a a \times a b$ & $(1)$ & $(2)$ & $(3)$ & $(4)$ & $(6)$ & $(5)$ \\
$a b \times a b$ & & 7 & 8 & 9 & 10 & $(10)$ \\
$a b \times c d$ & & & 11 & 12 & 13 & $(13)$ \\
$a o \times a o$ & & & & 14 & 15 & $(15)$ \\
$a b \times a o$ & & & & & 16 & 17 \\
$a o \times a b$ & & & & & & $(17)$ \\
\hline
\end{tabular}

Fonte: Maliepaard et al. (1997)

para um tipo de cruzamento em particular, considerando dois locos, existem quatro pares de cromossomos parentais e os cruzamentos da Tabela 1 podem ser definidos em termos dos pares de cromossomos parentais e dos fenótipos observados.

A combinação de $\mathrm{D}_{1}$ com $\mathrm{D}_{2}$, que na Tabela 2 é indicado por “* ", não fornece informação para distinguir recombinantes dos não recombinantes como mostra a Figura 6 em que os gametas parentais e recombinantes são iguais. Além disso, os quatro tipos de arranjos para esse cruzamento coincidem. Portanto, a análise de ligação não pode ser realizada apenas entre esses dois grupos. Para os demais casos não existem esses problemas. Assim, somente tipos de segregação, onde pelo menos um dos pais é heterozigoto em ambos os locos, são considerados para a análise de ligação.

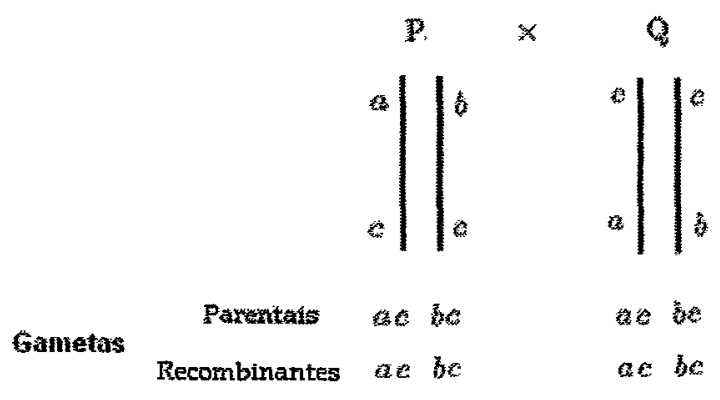

Figura 6 - Cruzamento do tipo $D_{1}$ combinado com $D_{2}$ 
Para a construção de mapas genéticos, quando só se dispõe de marcadores dos tipos D1 e/ou D2, é utilizada a estratégia de "double-pseudotestcross", em que, se um indivíduo for heterozigótico para um marcador e outro indivíduo tiver genótipo nulo, isto é, outras formas alélicas não detectadas, a progênie F1 segrega na proporção 1:1 para presença e ausência de bandas. Assim, é construído um mapa de ligação com marcadores que segregam para cada genitor, ou seja, são construídos dois mapas individuais (Grattapaglia \& Sederoff, 1994).

Um processo para determinação da fase de ligação baseado na progênie é apresentado por Maliepaad et al. (1997): estima-se a freqüência de recombinação sob as diferentes fases de ligação e deduz a fase baseando-se nas estimativas com $L O D$ Score significativo e que estão dentro do espaço paramétrico $\Theta=[0 ; 0,5]$. Se a fase de ligação entre um par de marcas não pode ser determinada por esse método, propõem que seja determinada indiretamente através da combinação com alguma marca vizinha que contenha um tipo de segregação mais informativa.

Wu et al. (2002) desenvolveram um algoritmo geral para a estimação simultânea da freqüiência de recombinação e da fase de ligação sobre todas as marcas ligadas em espécie de polinização aberta. Nesse algoritmo a caracterização da fase de ligação é baseada na distribuição de probabilidade a posteriori do arranjo dos alelos para dois marcadores em dois cromossomos homólogos em cada pai condicionado aos fenótipos observados, assumindo distribuição a priori uniforme para a fase de ligação. Entretanto, estimam-se as freqüências de recombinação através do método da máxima verossimilhança.

A quantidade de informação obtida nos diversos tipos de cruzamentos é estudada, analiticamente e por simulação, é apresentado, também, uma aproximação para o cálculo de intervalos de confiança para a freqüência de recombinação estimada que pode ser aplicada para todos os cruzamentos (Maliepaard et al., 1997). Estes autores realizaram, também, um estudo das propriedades estatísticas dos estimadores da frequência de recombinação para todas as situações. São apresentados gráficos dos valores esperados pelos valores estimados da freqüência de recombinação 
para todos os dados simulados, a fim de estudar o viés do estimador de máxima verossimilhança. Isso é feito para as estimativas das freqüências de recombinação que têm um $L O D$ Score significativo, ou seja, maior que 3 . O viés é também estudado analiticamente para alguns estimadores. Verificou-se que para uma população de tamanho infinito os estimadores de máxima verossimilhança não são viciados. Ainda, apresenta-se as funções de informação relativa ao cruzamento $A A(11)$ para todos os cruzamentos. Fez-se o estudo da variância para a freqüência de recombinação usando o inverso da função informação de Fisher e também apresentam a variância estimada por simulação. Apresentam, ainda, intervalos de confiança para as estimativas da freqüência de recombinação.

Os cruzamentos que apresentam maiores problemas na análise de ligação são aqueles que envolvem locos do tipo C (Tabela 1), as estimativas de máxima verossimilhança da freqüência de recombinação para esses tipos de cruzamentos são mais viciadas. Conseqüêntemente, a função informação relativa ao cruzamento $A A(11)$ desses cruzamentos é em geral menor que a dos demais (Maliepaard et al., 1997).

Maliepaard et al. (1997), mostram que vários cruzamentos, considerando dois locos, diferem quanto a precisão da estimação da freqüência de recombinação, o poder da detecção da ligação e a possibilidade da estimação da fase de ligação em ambos os pais.

\subsection{O Teorema de Bayes}

O teorema de Bayes, é a chave de toda estatística Bayesiana (Smith, 1991). Permite combinar um conhecimento prévio sobre um parâmetro $\boldsymbol{\theta}$ e atualizar informações continuamente sobre o parâmetro $\boldsymbol{\theta}$ conforme as observações são coletadas.

Supõe-se que $\boldsymbol{y}^{\prime}=\left(y_{1}, \ldots, y_{n}\right)$ é um vetor de $n$ observações com distribuição de probabilidade $\boldsymbol{f}(\boldsymbol{y} \mid \boldsymbol{\theta})$, que depende de $k$ parâmetros $\boldsymbol{\theta}^{\prime}=\left(\theta_{1}, \ldots, \theta_{k}\right)$. 
Supõe-se ainda que $\boldsymbol{\theta}$ tem uma distribuição de probabilidade $\pi(\boldsymbol{\theta})$. Então

$$
f(\boldsymbol{y} \mid \boldsymbol{\theta}) \pi(\boldsymbol{\theta})=f(\boldsymbol{y}, \boldsymbol{\theta})
$$

Dadas as observações $\boldsymbol{y}$, a distribuição condicional de $\boldsymbol{\theta}$ é:

$$
\pi(\boldsymbol{\theta} \mid \boldsymbol{y})=\frac{f(\boldsymbol{y}, \boldsymbol{\theta})}{f(\boldsymbol{y})}=\frac{f(\boldsymbol{y} \mid \boldsymbol{\theta}) \pi(\boldsymbol{\theta})}{f(\boldsymbol{y})}
$$

em que $f(\boldsymbol{y})=E[f(\boldsymbol{y} \mid \boldsymbol{\theta})]=\sum_{\boldsymbol{\theta}} f(\boldsymbol{y} \mid \boldsymbol{\theta}) \pi(\boldsymbol{\theta})$, a soma de todos os possíveis valores de $\boldsymbol{\theta}$ no caso em que $\boldsymbol{\theta}$ é discreto, e $f(\boldsymbol{y})=\boldsymbol{E}[\boldsymbol{f}(\boldsymbol{y} \mid \boldsymbol{\theta})]=\int_{\boldsymbol{\theta}} f(\boldsymbol{y} \mid \boldsymbol{\theta}) \pi(\boldsymbol{\theta}) d \boldsymbol{\theta}$, a integral definida num intervalo de valores admissíveis de $\boldsymbol{\theta}$ no caso em que $\boldsymbol{\theta}$ é contínuo. $E[f()$.$] é a esperança matemática em relação à distribuição \pi(\boldsymbol{\theta})$. Assim pode-se escrever a eq. (2) como

$$
\pi(\boldsymbol{\theta} \mid \boldsymbol{y})=c f(\boldsymbol{y} \mid \boldsymbol{\theta}) \pi(\boldsymbol{\theta})
$$

em que $c^{-1}=f(\boldsymbol{y})$.

A eq. (2) ou eq. (3) é o que se chama de Teorema de Bayes, $\pi(\boldsymbol{\theta})$ é a distribuição a priori de $\boldsymbol{\theta}$. Essa distribuição diz o que é conhecido a respeito do parâmetro $\boldsymbol{\theta}$ antes do conhecimento dos dados; $\pi(\boldsymbol{\theta} \mid \boldsymbol{y})$ é a distribuição a posteriori; $c$ é a constante normalizadora. Observa-se que omitindo a constante normalizadora o teorema de Bayes pode ser escrito como:

$$
\pi(\boldsymbol{\theta} \mid \boldsymbol{y}) \propto f(\boldsymbol{y} \mid \boldsymbol{\theta}) \pi(\boldsymbol{\theta})
$$

O teorema de Bayes afirma que a distribuição de probabilidade para $\boldsymbol{\theta}$ depois que os dados $(\boldsymbol{y})$ forem observados é proporcional ao produto da distribuição de probabilidade a priori para $\boldsymbol{\theta}$ e a verossimilhança para $\boldsymbol{\theta}$ dado os dados $(\boldsymbol{y})$ (eq. (4))(Box \& Tiao, 1992).

A função $f(\boldsymbol{y} \mid \boldsymbol{\theta})$ que aparece no teorema de Bayes é chamada de função de verossimilhança, também denotada por $L(\boldsymbol{\theta} \mid \boldsymbol{y})$. É através da função de verossimilhança que os dados podem modificar o conhecimento a priori de $\boldsymbol{\theta}$.

A distribuição de probabilidade a priori, $\pi(\theta)$, representa o que é conhecido ou a crença a respeito dos parâmetros desconhecidos antes que os dados 
sejam observados. Segundo Leandro (2001), a distribuição a priori tem um papel importante na inferência Bayesiana, já que pode ser usada para representar o conhecimento prévio ou ignorância relativa a respeito do parâmetro.

\subsubsection{Escolha da Distribuição $a$ priori.}

Segundo Smith (1991), a especificação da densidade a priori depende da crença e da experiência individual do pesquisador, e em geral, não é tarefa fácil converter tal crença ou experiência em forma de uma distribuição de probabilidade.

Dois procedimentos para transformar o conhecimento a priori em distribuição de probabilidade a priori são apresentados.

1. Uma das formas de ajustar a distribuição a priori é basear-se nas freqüências relativas.

Supõe-se que se tem um histograma com as freqüências relativas do parâmetro $\theta$ nos diversos intervalos, em uma situação semelhante a que está sendo estudada no momento. A partir desse histograma, ajusta-se uma curva adequada que vai representar a distribuição a priori. Essa técnica é direta, simplesmente visa produzir uma densidade que reflita a forma de uma freqüência de distribuição histórica (Smith, 1991).

2. Uma outra forma de especificar a distribuição a priori é basear-se nas expectativas do pesquisador.

$\mathrm{Na}$ ausência dos dados anteriores não se pode fazer o ajuste da priori como no item 1. Dessa maneira, a distribuição a priori é ajustada com base na expectativa subjetiva do pesquisador.

Considerou-se aqui, a escolha de uma distribuição a priori para um único parâmetro. A escolha da distribuição a priori conjunta para dois ou mais parâmetros é direta desde que as prioris para cada parâmetro possam ser consideradas independentes, mas pode apresentar dificuldades se existir dependência entre os parâmetros (Smith, 1991). 


\subsubsection{Distribuições a priori próprias e impróprias}

A distribuição de probabilidade a priori $\pi(\theta)$ não é necessariamente uma distribuição de probabilidade própria.

Diz-se que uma distribuição de probabilidade $f(x)$ é própria quando satisfaz a seguinte propriedade:

$$
\begin{aligned}
& f(x)>0 \text { no seu domínio de definição e } \\
& \sum_{x} f(x)=1 \text { para variável aleatória discreta, } \\
& \int_{x} f(x) d x=1 \text { para variável aleatória contínua. }
\end{aligned}
$$

Como exemplo de uma distribuição de probabilidade a priori imprópria, considere a função constante $\pi(\theta)=k,-\infty<\theta<\infty, k>0$. Esta. função é uma densidade imprópria, pois $\int_{-\infty}^{\infty} \pi(\theta) d \theta=k \int_{-\infty}^{\infty} d \theta$ não existe.

\subsubsection{Distribuições a priori Conjugadas.}

Se $\boldsymbol{F}$ é uma classe de funções $L(\theta \mid y)$, e $\boldsymbol{P}$ é uma classe de distribuições a priori para $\theta$, então a classe $\boldsymbol{P}$ é conjugada a $\boldsymbol{F}$ se $\pi(\theta \mid y) \in \boldsymbol{P}$ para toda $L(\theta \mid y) \in \boldsymbol{F}$ e $\pi(y) \in \boldsymbol{P}$ (Gelman et al., 2003).

\subsubsection{Distribuições objetivas, distribuições não-informativas}

Para julgar os dados em relação a uma priori de referência "neutra", o pesquisador utiliza o que comumente é chamado "princípio do júri". Os casos são tratados em um tribunal diante de um júri o qual é cuidadosamente escolhido de tal forma que não possua vínculo ou conexão com os principais interessados nem com os eventos do caso em questão (Leandro, 2001). A inteñição é garantir claramente que a informação extraída dos dados ou depoimentos possa ser assumida como idéias que 
dominarão a informação a priori para que os membros do júri possam chegar a um veredicto final.

Priori de referência é uma distribuição conveniente para ser utilizada como padrão a priori. A princípio pode ser dominada, ou não, pela verossimilhança ou informação presente fornecida pelos dados ou experimento, porém, na literatura em geral (Box \& Tiao, 1992), as prioris são dominadas pelos dados representados através da função de verossimilhança. Em algumas situações, o pesquisador sentirá que a informação disponível para avaliar a distribuição a priori não existe, ou ainda, quando ele deseja expressar, através da distribuição a priori, a sua indiferença ou ignorância com relação ao parâmetro $\theta$, existe a necessidade de explicitar, definir regras para selecionar, construir distribuições a priori para representar esse "conhecimento pobre" ou ignorância. Existe uma grande discussão referente a esse estado de espírito. É importante ressaltar que nunca se pode estar em completo estado de ignorância. O problema é como expressar a idéia do pouco conhecimento a respeito do parâmetro a priori em relação ao que os dados têm a contar.

Quando o valor de um parâmetro é completamente desconhecido, Jeffreys (1961) propôs duas regras para a escolha da distribuição a priori, as quais, segundo ele, atingem os casos mais comuns. Ele estabeleceu que:

1. se o parâmetro pode assumir qualquer valor em um domínio finito ou $(-\infty, \infty)$, uma distribuição a priori deveria ser considerada como uma distribuição uniforme. No caso de o parâmetro pertencer ao intervalo $(-\infty, \infty)$ essa distribuição não seria própria no sentido que sua integral no domínio não seria um.

2. no caso em que o parâmetro só pode assumir valores positivos, isto é, no intervalo $(0, \infty)$, então, a distribuição a priori do seu logaritmo deveria ser considerada como uniforme também em $(-\infty, \infty)$.

Prova-se que (Box \& Tiao, 1992): 
Regra de Jeffreys para o caso uniparamétrico: A distribuição a priori para um único parâmetro $\theta$ é aproximadamente não informativa se for proporcional à raiz quadrada da medida de informação de Fisher.

Regra de Jeffreys para o caso multiparamétrico: A distribuição a priori para um conjunto de parâmetros é proporcional à raiz quadrada do determinante da matriz de informação de Fisher.

\subsubsection{Distribuição a posteriori}

A inferência Bayesiana baseia-se na transferência de uma distribuição a priori para $\theta, \pi(\theta)$, para uma distribuição a posteriori para $\theta, \pi(\theta \mid y)$, a qual pode ser vista como a crença que se associa ao parâmetro desconhecido $\theta$ depois que os dados foram observados(Smith,1991).

Uma característica geral da inferência Bayesiana é que a distribuição a posteriori está centrada em um ponto que representa um compromisso entre a informação a priori e os dados, e essa relação é, em grande parte, controlada pelos dados conforme o tamanho amostral aumenta.

A distribuição de probabilidade a posteriori para $\theta, \pi(\theta \mid y)$, contém todas as informações atualizadas sobre o parâmetro $\theta$ e o seu gráfico dá uma boa descrição do processo inferencial. Entretanto, deseja-se às vezes obter resumos numéricos de interesse de $\pi(\theta \mid y)$; os mais comuns são: média, moda(s), mediana e estimativas intervalares (intervalos de credibilidade e região HPD "highest posterior density"):

1. A média é a esperança a posteriori do parâmetro $\theta$ e é definida por:

$$
\widehat{\theta}=\int_{-\infty}^{\infty} \theta \pi(\theta \mid y) d \theta
$$

e é única.

Observação: se o parâmetro $\theta$ for discreto deve-se substituir a integral pelo somatório. 
2. A moda, $\theta^{*}$, pode ser interpretada como o valor mais provável dadas as observações e é definida por:

$$
\pi\left(\theta^{*}\right)=\sup _{\Theta} \pi(\theta \mid y)
$$

em que $\Theta$ representa o espaço paramétrico.

3. A mediana, $\widetilde{\theta}$ é o ponto pertencente ao espaço paramétrico $\Theta$ satisfazendo a seguinte propriedade:

$$
\int_{-\infty}^{\widetilde{\theta}} \pi(\theta \mid y) d \theta=\int_{\tilde{\theta}}^{-\infty} \pi(\theta \mid y) d \theta
$$

quando o parâmetro $\theta$ for contínuo. Se $\theta$ for discreto, deve-se substituir a integral pelo somatório.

4. Dada a distribuição de probabilidade a posteriori, diz-se que $(a, b)$ é um intervalo de credibilidade a posteriori $100(1-\alpha) \%$ de $\theta$ se

$$
\int_{a}^{b} \pi(\theta \mid y) d \theta=1-\alpha \quad(0<\alpha<1)
$$

(Smith, 1991).

5. Em geral, podem-se encontrar muitos intervalos de credibilidade $(100-\alpha) \%$ para um valor específico de $\alpha$. Um outro método de resumir a incerteza a posteriori é calcular a região HPD "highest posterior density": região de valores que contém $100(1-\alpha) \%$ da probabilidade a posteriori tal que, se $\theta_{1}$ pertence à região e $\theta_{2}$ não pertence, então, $\pi\left(\theta_{1}\right) \geq \pi\left(\theta_{2}\right)$, para quaisquer $\theta_{1}, \theta_{2}$ pertencentes ao espaço paramétrico.

A região HPD e o intervalo de credibilidade para $\theta$ coincidem se a distribuição a posteriori é simétrica e unimodal.

A distribuição hipotética bimodal apresentada na Figura 7 permite fazer uma comparação interessante entre intervalo de credibilidade e a região HPD. O intervalo de credibilidade nesse exemplo inclui a área de probabilidade nula no centro da distribuição e a região HPD compreende dois intervalos disjuntos (Gelman et al., 2003). 

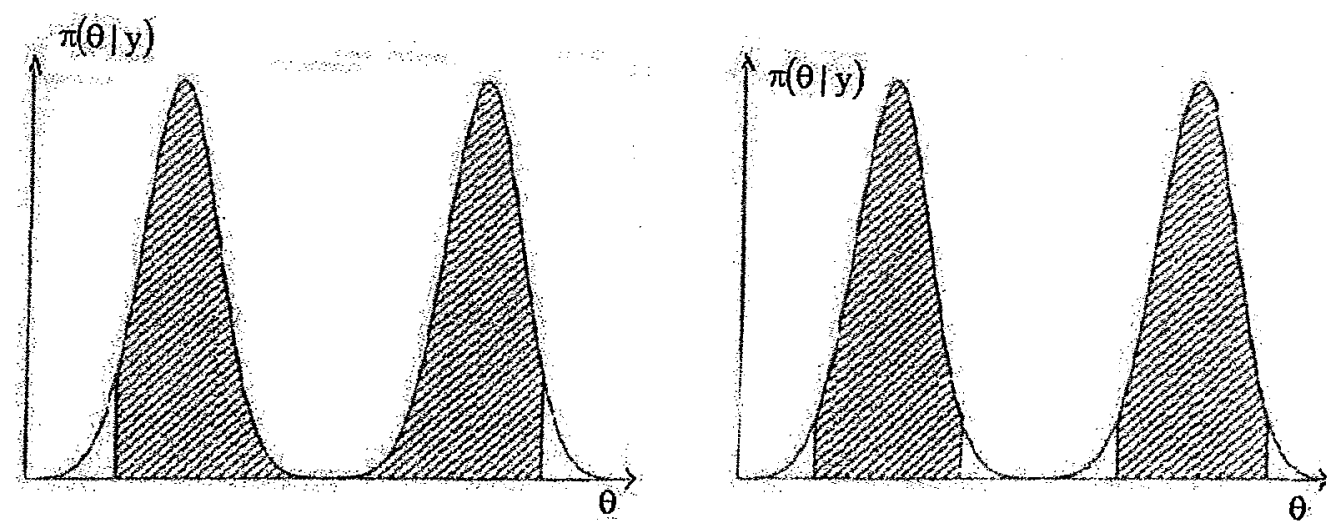

Figura 7 - Intervalo de Credibilidade à esquerda e região HPD à direita

\subsection{Algoritmo EM}

O algoritmo EM (Esperança - Maximização) é um método iterativo para obtenção de estimativas de máxima verossimilhança. Tem sido muito usado em análises de mapeamento genético. Tal abordagem tem se mostrado muito poderosa para obtenção de estimativas de máxima verossimilhança quando as observações consistem de dados incompletos.

O algoritmo EM faz uma clara distinção entre os dados observados $Y$ que são incompletos e os dados completos $X$, não observáveis. Alguma função $t(X)=Y$ associa $X$ e $Y$. Representando $X$ como $(Y, Z)$, sendo $Z$ os dados "ausentes", então, $t$ é uma projeção em direção ao componente $Y$ de $X$. Os dados "ausentes" podem significar mais do que dados não observados no senso comum. De fato, a definição de $X$ deve ser feita em função do problema a ser resolvido. A idéia geral é tomar $X$ de forma que a obtenção de estimativas de máxima verossimilhança torne-se trivial para os dados completos.

Assume-se que os dados completos tenham uma densidade de probabilidade $f(X \mid \theta)$ que é uma função do vetor de parâmetros $\theta$ e de $X$.

No passo E (esperança) calcula-se a esperança condicional 


$$
Q\left(\boldsymbol{\theta} \mid \boldsymbol{\theta}_{n}\right)=E[\ln f(X \mid \boldsymbol{\theta}) \mid Y, \boldsymbol{\theta}]
$$

em que $\boldsymbol{\theta}_{n}$ é o valor estimado atual de $\boldsymbol{\theta}$.

No passo M (maximização), maximiza-se $Q\left(\boldsymbol{\theta} \mid \boldsymbol{\theta}_{n}\right)$ em relação a $\boldsymbol{\theta}$.

Este procedimento fornece uma nova estimativa para $\boldsymbol{\theta}_{n}$ representada por $\boldsymbol{\theta}_{n+1}$. Os dois passos são repetidos até haver convergência (Lange, 1997). 


\section{MATERIAL E MÉTODOS}

\subsection{Material}

Foram utilizados um total de 6926 conjuntos de dados simulados, representando os dados de populações hipotéticas de uma espécie de polinização aberta, para cruzamentos considerando dois locos. Os tamanhos de progênies considerados foram $n=100$ (um tamanho usual na prática) e $n=50$, considerando que possa existir uma perda de $50 \%$ dos dados. Tentou-se com isso estudar um caso comum $(\mathrm{n}=100)$ e outro imaginando uma perda exagerada de dados. Possivelmente, o pesquisador encontrará na prática situações intermediárias entre essas. Tais dados foram simulados no pacote R.1.9.0 (Anexo A2). Os cruzamentos para os quais os dados foram simulados são todos os cruzamentos da Tabela 2.

Os dados foram gerados da seguinte maneira:

(i) considerou-se uma partição regular $\boldsymbol{P}$, de passo $h=0,01$ do espaço paramétrico $\Theta=[0 ; 0,5]$ (intervalo dos possíveis valores da freqüência de recombinação, $r$ );

(ii) para cada valor de $r$ pertencente a partição $\boldsymbol{P}$, simulou-se um conjunto de dados referente a uma combinação particular dos tipos de marcadores, baseando-se nas freqüências fenotípicas esperadas de cada cruzamento, para cada um dos 4 possíveis tipos de arranjos dos alelos nos dois locos.

Os pacotes Maple 6 e R 1.9.0 foram também utilizados para construção de gráficos, no auxílio dos cálculos das estimativas de freqüências de recombinação e das funções de verossimilhança. 


\subsection{Métodos}

\subsubsection{Atribuição dos Cromossomos Parentais}

Considerou-se uma população de espécie de polinização aberta, considerando-se dois locos, em que quatro alelos podem segregar em um único loco. O número de alelos pode variar de loco para loco. Assumiu-se que os alelos $a, b, c, d$ são codominantes entre si (cada alelo expressa um fenótipo) e dominantes em relação ao alelo nulo o, ou seja, o fenótipo do heterozigoto é o mesmo do homozigoto para o alelo dominante (Wu et al., 2002).

Considerando-se os cruzamentos da Tabela 1, denotando-se um dos pais por $\mathrm{P}$ e o outro pai por $\mathrm{Q}$ e os dois cromossomos em cada pai por $\mathrm{P}_{1}$ e $\mathrm{P}_{2}, \mathrm{Q}_{1} \mathrm{e}$ $\mathrm{Q}_{2}$, respectivamente, então, para um marcador particular independente do seu tipo, existem quatro possíveis Pares de Cromossomos Parentais (PCP) na progênie, $\mathrm{P}_{1} \mathrm{Q}_{1}$, $\mathrm{P}_{1} \mathrm{Q}_{2}, \mathrm{P}_{2} \mathrm{Q}_{1}, \mathrm{P}_{2} \mathrm{Q}_{2}$ (Figura 8).

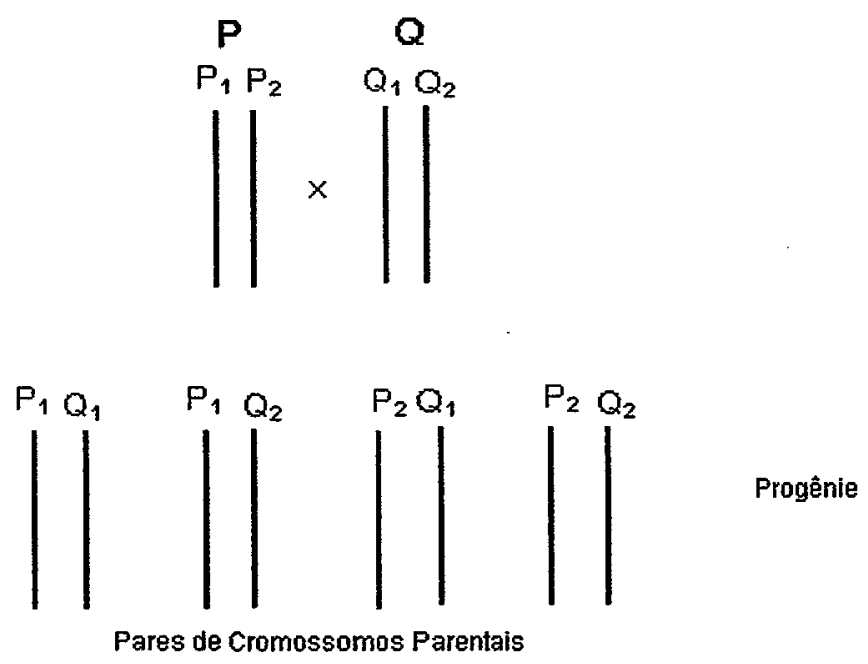

Figura 8 - Pares de cromossomos parentais na progênie para um único loco 
Os grupos da Tabela 1 podem ser definidos em termos da correspondência entre os genótipos PCP's e os fenótipos observados.

Assumindo que os cromossomos parentais são atribuídos como $P_{1} \| P_{2}$ e $Q_{1} \| Q_{2}$, em que $\|$ representa um par de cromossomos homólogos, a fase de ligação entre os alelos do primeiro loco $\left(M^{1}\right)$ e segundo loco $\left(M^{2}\right)$ pode ser determinada designando os alelos alternativos do segundo loco para um cromossomo homólogo diferente, dado um arranjo dos alelos no primeira loco. Tem-se assim, um total de quatro arranjos $\left(A_{w}, w=1, \ldots, 4\right)$ (associação - associação, associação - repulsão, repulsão - associação, repulsão - repulsão) para os dois pais como ilustrado na Figura 9. Em cada arranjo, o atributo do primeiro loco não muda.
P. $x$
$\mathrm{Q}$

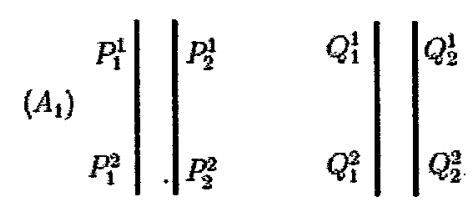
$\begin{array}{ll}\left.A_{2}\right) & P_{1}^{1} \\ & P_{1}^{2}\end{array}|| \begin{array}{ll}P_{2}^{1} & Q_{1}^{1} \\ P_{2}^{2} & Q_{2}^{2}\end{array}||_{\frac{1}{Q_{1}^{2}}}$
$\begin{array}{ll}\left(A_{3}\right) & \\ & P_{1}^{2}\end{array}|| \begin{array}{ll}P_{2}^{1} & Q_{1}^{1} \\ & \\ P_{1}^{2} & Q_{1}^{2}\end{array}|| \begin{aligned} & Q_{2}^{1} \\ & Q_{2}^{2}\end{aligned}$
$\begin{array}{ll}\left(A_{4}\right) & P_{1}^{1} \\ & P_{2}^{2}\end{array}|| \begin{array}{ll}P_{2}^{1} & Q_{1}^{1} \\ P_{1}^{2} & Q_{2}^{2}\end{array}|| \begin{aligned} & Q_{2}^{1} \\ & Q_{1}^{2}\end{aligned}$

Figura 9 - Possíveis configurações das fases de ligação para dois pais em um cruzamento considerando dois locos. 
Assumiu-se que os dois pais num cruzamento têm a mesma fração de recombinação entre locos correspondentes. Denota-se a fração de recombinação entre o primeiro e a segundo loco, $M^{1}$ e $M^{2}$, por $r^{12}$. A probabilidade condicional do genótipo PCP de $M^{2}$ na progênie dado o genótipo PCP de $M^{1}$, é a probabilidade de transição de eventos de recombinação $h_{w}^{12}$ (elemento da matriz $H_{w}^{12}$ ) entre os dois locos para o genótipo PCP. A probabilidade de transição e o número $d_{w}^{12}$ (elemento da matriz $D_{w}^{12}$ ) de eventos de recombinação ocorrendo entre os dois locos para o $w$-ésimo arranjo pode ser expressa na forma matricial (Wu et al., 2002):

Para o arranjo $1\left(A_{1}\right)$ têm-se as matrizes:

$H_{1}^{12}=\left[\begin{array}{cccc}\left(1-r^{12}\right)^{2} & r^{12}\left(1-r^{12}\right) & r^{12}\left(1-r^{12}\right) & \left(r^{12}\right)^{2} \\ r^{12}\left(1-r^{12}\right) & \left(1-r^{12}\right)^{2} & \left(r^{12}\right)^{2} & r^{12}\left(1-r^{12}\right) \\ r^{12}\left(1-r^{12}\right) & \left(r^{12}\right)^{2} & \left(1-r^{12}\right)^{2} & r^{12}\left(1-r^{12}\right) \\ \left(r^{12}\right)^{2} & r^{12}\left(1-r^{12}\right) & r^{12}\left(1-r^{12}\right) & \left(1-r^{12}\right)^{2}\end{array}\right], D_{1}^{12}=\left[\begin{array}{cccc}0 & 1 & 1 & 2 \\ 1 & 0 & 2 & 1 \\ 1 & 2 & 0 & 1 \\ 2 & 1 & 1 & 0\end{array}\right]$

para o arranjo $2\left(A_{2}\right)$ :

$H_{2}^{12}=\left[\begin{array}{cccc}r^{12}\left(1-r^{12}\right) & \left(1-r^{12}\right)^{2} & \left(r^{12}\right)^{2} & r^{12}\left(1-r^{12}\right) \\ \left(1-r^{12}\right)^{2} & r^{12}\left(1-r^{12}\right) & r^{12}\left(1-r^{12}\right) & \left(r^{1} 2\right)^{2} \\ \left(r^{12}\right)^{2} & r^{12}\left(1-r^{12}\right) & r^{12}\left(1-r^{12}\right) & \left(1-r^{12}\right)^{2} \\ r^{12}\left(1-r^{12}\right) & \left(r^{12}\right)^{2} & \left(1-r^{12}\right)^{2} & r^{12}\left(1-r^{12}\right)\end{array}\right], D_{2}^{12}=\left[\begin{array}{cccc}1 & 0 & 2 & 1 \\ 0 & 1 & 1 & 2 \\ 2 & 1 & 1 & 0 \\ 1 & 2 & 0 & 1\end{array}\right]$

para o arranjo $3\left(A_{3}\right)$ :

$H_{3}^{12}=\left[\begin{array}{cccc}r^{12}\left(1-r^{12}\right) & \left(r^{12}\right)^{2} & \left(1-r^{12}\right)^{2} & r^{12}\left(1-r^{12}\right) \\ \left(r^{12}\right)^{2} & r^{12}\left(1-r^{12}\right) & r^{12}\left(1-r^{12}\right) & \left(1-r^{12}\right)^{2} \\ \left(1-r^{12}\right)^{2} & r^{12}\left(1-r^{12}\right) & r^{12}\left(1-r^{12}\right) & \left(r^{12}\right)^{2} \\ \left(1-r^{12}\right)^{2} & r^{12}\left(1-r^{12}\right) & \left(r^{12}\right)^{2} & r^{12}\left(1-r^{12}\right)\end{array}\right], D_{3}^{12}=\left[\begin{array}{cccc}1 & 2 & 0 & 1 \\ 2 & 1 & 1 & 0 \\ 0 & 1 & 1 & 2 \\ 1 & 0 & 2 & 1\end{array}\right]$ 
para o arranjo $4\left(A_{4}\right)$ :

$$
H_{4}^{12}=\left[\begin{array}{cccc}
\left(r^{12}\right)^{2} & r^{12}\left(1-r^{12}\right) & r^{12}\left(1-r^{12}\right) & \left(1-r^{12}\right)^{2} \\
r^{12}\left(1-r^{12}\right) & \left(r^{12}\right)^{2} & \left(1-r^{12}\right)^{2} & r^{12}\left(1-r^{12}\right) \\
r^{12}\left(1-r^{12}\right) & \left(1-r^{12}\right)^{2} & \left(r^{12}\right)^{2} & r^{12}\left(1-r^{12}\right) \\
\left(1-r^{12}\right)^{2} & r^{12}\left(1-r^{12}\right) & r^{12}\left(1-r^{12}\right) & \left(r^{12}\right)^{2}
\end{array}\right], D_{4}^{12}=\left[\begin{array}{cccc}
2 & 1 & 1 & 0 \\
1 & 2 & 0 & 1 \\
1 & 0 & 2 & 1 \\
0 & 1 & 1 & 2
\end{array}\right] ;
$$

Os elementos das matrizes $H_{w}^{12}, w=1, \ldots, 4$ são obtidos da seguinte maneira: para as linhas das matrizes $H_{w}^{12}$ são colocados os possíveis genótipos do primeiro loco na seguinte ordem $\left(P_{1}^{1} Q_{1}^{1}, P_{1}^{1} Q_{2}^{1}, P_{2}^{1} Q_{1}^{1}, P_{2}^{1} Q_{2}^{1}\right)$ e para as colunas das matrizes são colocados os possíveis genótipos do segundo loco $\left(P_{1}^{2} Q_{1}^{2}, P_{1}^{2} Q_{2}^{2}, P_{2}^{2} Q_{1}^{2}, P_{2}^{2} Q_{2}^{2}\right)$ nessa ordem. Os elementos da matriz vão representar os eventos de recombinação entre os genótipos correspondentes considerando um arranjo em particular. Por exemplo, considerando o primeiro arranjo $\left(A_{1}\right)$, o elemento $h_{1_{11}}^{12}$ da primeira linha e primeira coluna da matriz $H_{1}^{12}$ está relacionando os genótipos $P_{1}^{1} Q_{1}^{1}$ do primeiro loco e $P_{1}^{2} Q_{1}^{2}$ do segundo loco. Como não é necessária a recombinação (no caso do primeiro arranjo), para se obter o gameta $P_{1}^{1} P_{1}^{2}$ temse, a probabilidade de $\left(1-r^{12}\right)$ de acontecer esse evento de não recombinação, e como também não é necessária a recombinação para obter-se o gameta $Q_{1}^{1} Q_{1}^{2}$ tem-se, também, uma probabilidade de $\left(1-r^{12}\right)$ de acontecer esse evento. Como esses dois eventos são independentes, então, tem-se a probabilidade $\left(1-r^{12}\right)^{2}$ (no caso do arranjo 1) de se obter os gametas $P_{1}^{1} P_{1}^{2}$ e $Q_{1}^{1} Q_{1}^{2}$ que constituem o genótipo $P_{1}^{1} P_{1}^{2} Q_{1}^{1} Q_{1}^{2}$. Assim, o elemento $h_{1_{11}}^{12}$ da matriz $H_{1}^{12}$ é dado por $h_{1_{11}}^{12}=\left(1-r^{12}\right)^{2}$. Os demais foram obtidos de forma análoga.

\subsubsection{A Função de Verossimilhança}

Assumindo que os dados de todos os $\mathrm{N}$ genótipos são independentes, em que $N$ é o tamanho da progênie, tem-se a seguinte função de verossimilhança (Wu et al., 2002): 


$$
P\left(M \mid A_{w}^{2}\right)=\prod_{j=1}^{N} \boldsymbol{m}_{i_{1} j}^{T} \boldsymbol{I}_{p_{1}}^{T} \boldsymbol{H}_{w}^{12} \boldsymbol{I}_{p_{2}} \boldsymbol{m}_{i_{2} j}=\prod_{j=1}^{N} \boldsymbol{m}_{i_{1} j}^{T} \boldsymbol{P}_{w}^{12} \boldsymbol{m}_{i_{2} j}
$$

em que, $\boldsymbol{m}_{i k j}$ é o vetor $p_{k}$-dimensional da variável indicadora para o marcador $k$; $I_{p_{k}}$ é uma matriz de incidência $\left(4 \times p_{k}\right)$ relacionando o genótipo PCP ao fenótipo, o qual pode ser designado para qualquer um dos quatro arranjos alélicos como

para cruzamento com marcador do tipo $A$,

$$
\boldsymbol{I}_{p_{A}}=\left[\begin{array}{llll}
1 & 0 & 0 & 0 \\
0 & 1 & 0 & 0 \\
0 & 0 & 1 & 0 \\
0 & 0 & 0 & 1
\end{array}\right]
$$

$$
\boldsymbol{I}_{p_{B_{1}}}^{T}=\left[\begin{array}{cccc}
1 & 1 & 0 & 0 \\
0 & 0 & 1 & 0 \\
0 & 0 & 0 & 1
\end{array}\right]
$$

para cruzamento com marcador do tipo $B_{1}$,

$$
\boldsymbol{I}_{p_{B_{2}}}^{T}=\left[\begin{array}{llll}
1 & 0 & 1 & 0 \\
0 & 1 & 0 & 0 \\
0 & 0 & 0 & 1
\end{array}\right]
$$

para cruzamento com marcador do tipo $B_{2}$,

$$
\boldsymbol{I}_{p_{B_{3}}}^{T}=\left[\begin{array}{cccc}
1 & 0 & 0 & 0 \\
0 & 1 & 1 & 0 \\
0 & 0 & 0 & 1
\end{array}\right]
$$

para cruzamento com marcador do tipo $B_{3}$,

$$
\boldsymbol{I}_{p_{C}}^{T}=\left[\begin{array}{llll}
1 & 1 & 1 & 0 \\
0 & 0 & 0 & 1
\end{array}\right]
$$

para cruzamento com marcador do tipo $C$, 


$$
\boldsymbol{I}_{p_{D_{1}}}^{T}=\left[\begin{array}{llll}
1 & 1 & 0 & 0 \\
0 & 0 & 1 & 1
\end{array}\right]
$$

para cruzamento com marcador do tipo $D_{1}$, e

$$
\boldsymbol{I}_{p_{D_{2}}}^{T}=\left[\begin{array}{llll}
1 & 0 & 1 & 0 \\
0 & 1 & 0 & 1
\end{array}\right]
$$

para cruzamento com marcador do tipo $D_{2}$.

$\boldsymbol{H}_{\boldsymbol{w}}^{12}$ é a matriz de probabilidade de transição do genotipo PCP do marcador $M^{1}$ para $M^{2}, \boldsymbol{P}_{\boldsymbol{w}}^{12}=\boldsymbol{I}_{p_{1}}^{T} \boldsymbol{H}_{\boldsymbol{w}}^{12} \boldsymbol{I}_{p_{2}}$ é uma matriz $\left(p_{1} \times p_{2}\right)$ da probabilidade de transição do marcador $M^{1}$ para $M^{2}$ a nível fenotípico, e $T$ denota a transposta de um vetor ou matriz.

A função de verossimilhança de cada cruzamento, foi obtida através de um programa implementado no pacote Maple 6 (Anexo A).

\subsubsection{Estimação da Fração de Recombinação pelo Método da Máxima Verossimilhança}

O método de estimação apresentado aqui é baseado no artigo de Wu et al. (2002), que por sua vez sistematizaram o artigo de maliepaard et al. (1997).

Considerando um arranjo em particular para o segundo marcador $M^{2}$, a fração de recombinação entre marcadores $M^{1}$ e $M^{2}$ foi estimada maximizando o logaritmo da função de verossimilhança em relação a $r^{12}$ resolvendo a equação

$$
\frac{\partial}{\partial r^{12}} \ln \left[P\left(M \mid A_{w}^{2}\right)\right]=0
$$

A estimativa de máxima verossimilhança para $r^{12}$, foi obtida por um processo iterativo basedo na esperança (E) e maximização (M) o qual é denominado algoritmo EM. As equações gerais sob o passo $\{\tau+1\}$ são dadas a seguir:

Passo E. Para o passo $\{\tau\}$, usando a matriz $\boldsymbol{H}_{w}^{12\{\tau\}}$ baseado na estimativa atual, calcula-se o número esperado de eventos recombinantes entre quaisquer dois marcadores $M^{1}$ e $M^{2}$ para a progênie $j$ sob o arranjo $A_{w}^{2}$ 


$$
c_{i_{1} i_{2} j}^{w\{\tau+1\}}=\frac{\boldsymbol{m}_{i_{1} j}^{T}\left[\boldsymbol{I}_{p_{1}}^{t}\left(D_{w}^{12} \circ \boldsymbol{H}_{w}^{12\{\tau\}}\right) \boldsymbol{I}_{p_{2}}\right] \boldsymbol{m}_{i_{2} j}}{\boldsymbol{m}_{i_{1} j}^{T} \boldsymbol{P}_{w}^{12\{\tau\}} \boldsymbol{m}_{i_{2} j}}
$$

em que $D_{w}^{12}$ é uma matriz $(4 \times 4)$ e "o"denota o produto elemento a elemento de matrizes (produto de Hadamard).

Passo M. Calcula-se $r_{w}^{12\{\tau+1\}}$ sob o arranjo $A_{w}^{2}$ usando a equação

$$
r_{w}^{12\{\tau+1\}}=\frac{1}{2 N} \sum_{j=1}^{N} \sum_{i_{1}=1}^{p_{1}} \sum_{i_{2}=1}^{p_{2}} c_{i_{1} i_{2} j}^{w\{\tau+1\}}
$$

Este processo iterativo foi repetido entre as equações (7) e (8) até $r_{w}^{12}$ convergir para um valor estável. Tal valor estável representa a estimativa de máxima verossimilhança para a fração de recombinação entre os marcadores $M^{1}$ e $M^{2}$ para o arranjo $A_{w}^{2}$.

Com os dados simulados, foram estimadas as freqüências de recombinação pelo método da máxima verossimilhança. Para a obtenção dessas estimativas o algoritmo EM foi implementado no pacote R 1.9.0 (Anexo A3). Foram construídos gráficos dos valores estimados contra valores esperados da freqüência de recombinação, a fim de verificar o comportamento das estimativas e identificar um possível viés. Os intervalos de confiança para as estimativas de máxima verossimilhança foram calculados, para isso usou-se intervalos de confiança aproximados. Foi também, calculada a soma de quadrados dos resíduos dos valores estimados em relação aos valores esperados obtendo-se, assim, uma medida da variabilidade das estimativas de máxima verossimilhança em relação aos verdadeiros valores de $r$.

As estimativas de máxima verossimilhança das freqüências de recombinação, obtidas dos dados simulados, foram utilizadas ainda para testar a ligação entre locos. O teste de ligação aplicado foi o LRT (teste da razão de verossimilhança). O Teste da Razão de Verossimilhanças

O teste da razão de verossimilhança é dado por

$$
L R T=-2 \log \left(\frac{L(r)}{L(\hat{r})}\right)
$$


ou seja, é o ln da razão de verossimilhanças multiplicado por -2 .

Em geral é difícil encontrar a distribuição amostral exata de $L R T$. Mas, em muitas situações a distribuição de $L R T$ se aproxima da distribuição $\chi_{(1)}^{2}$, ou seja,

$$
L R T=-2 \log \left(\frac{L(r)}{L(\hat{r})}\right) \approx \chi_{(1)}^{2} .
$$

O teorema central do limite pode ser utilizado para estabelecer a eq. (10) quando os dados são variáveis aleatórias identicamente distribuídas, $X_{1}, X_{2}, \ldots, X_{n}$.

Pode ser mostrado que sob algumas condições de regularidade

$$
\lim _{n \longrightarrow \infty} P\left(L R T \leq d \mid r=r_{0}\right)=P\left(\chi_{(1)}^{2} \leq d\right), \forall d>0
$$

A condição mais importante na eq. (11) é que os $X_{i}, i=1, \ldots, n$ não devem depender de $r$. Também é assumido que $r$ é um ponto interior do espaço paramétrico. A distribuição $\chi_{1}^{2}$ é a distribuição limite de $L R T$ para todos os valores paramétricos interiores $r_{0}$, mas o tamanho amostral necessário para obter a precisão razoável pode depender de $r_{0}$ (Kalbfleisch, 1985).

Define-se,também, o LOD Score como (Liu, 1998):

$$
L O D=\log _{10}\left(\frac{L(\hat{r})}{L(r)}\right)
$$

Por exemplo, para um valor de $L O D$ igual a 3 , tem-se, $3=\log _{10}\left(\frac{L(\hat{r})}{L(r)}\right) \Longrightarrow$ $10^{3}=\frac{L(\hat{r})}{L(r)} \Longrightarrow 10^{3} L(r)=L(\hat{r})$, o que indica que " $\hat{r}$ é 1000 vezes mais provável que $r "$.

Para testar a ligação, define-se:

$$
H_{0}: r=0,5 \text { (não ligação) }
$$

$$
H_{1}: r<0,5 \text {. }
$$


Calcula-se o LRT e rejeita-se $H_{0}$ quando $P\left(\chi_{1}^{2} \geq L R T\right) \leq 0,05$.

\subsubsection{Enfoque Bayesiano: Estimação da Freqüência de Recombinação}

É apresentado aqui o método Bayesiano de estimação da freqüência de recombinação.

Como distribuição a priori para a freqüência de recombinação foi utilizada a distribuição uniforme:

$$
\pi(r)=\left\{\begin{array}{lc}
2, & 0 \leq r \leq 0,5 \\
0, & \text { caso contrário }
\end{array}\right.
$$

$\mathrm{O}$ uso dessa priori não priveligia nenhum valor de $r$, ou seja, todos os valores de $r$ a princípio são igualmente prováveis.

A distribuição a priori uniforme foi combinada com a função de verossimilhança de cada cruzamento, obtendo-se assim, as distribuições a posteriori:

$$
\pi(r \mid \boldsymbol{M}) \propto \pi(r) \pi(\boldsymbol{M} \mid r),
$$

em que, $\pi(r \mid \boldsymbol{M})$ é a distribuição a posteriori de $r, \pi(r)$ é a distribuição a priori e $\pi(\boldsymbol{M} \mid r)$ é a função de verossimilhança.

Das distribuições a posteriori obtidas na eq. (13) foram calculadas as estimativas de Bayes para freqüência de recombinação, que são dadas pela esperança a posteriori de $r$ eq. (14).

$$
\hat{r}=\int_{\Theta} r \pi(r \mid \boldsymbol{M}) d r
$$

Com os dados simulados, foram estimadas as freqüências de recombinação pelo método Bayesiano. Tais estimativas foram obtidas utilizando o pacote R 1.9.0 para a realização dos cálculos (Anexo A3).

Foram construídos gráficos dos valores estimados contra valores esperados da freqüência de recombinação, a fim de verificar o comportamento das estimativas de Bayes. Os intervalos de credibilidade foram obtidos para essas estimativas, 
foi também calculada a soma de quadrados dos resíduos dos valores estimados, em relação aos valores esperados obtendo-se, assim, uma medida da variabilidade das estimativas de Bayes em relação aos verdadeiros valores de $r$.

As estimativas de Bayes das freqüências de recombinação, obtidas dos dados simulados, foram utilizadas ainda para testar a ligação entre locos. Para isso foi aplicado um teste de hipóteses Bayesiano baseado no fator de Bayes.

\section{Teste de Hipótese Bayesiano}

Seja $r$ um parâmetro pertencente ao espaço paramétrico $\Theta$. Deseja-se saber se $r \in \Theta_{0}$ ou $r \in \Theta_{1}$ em que

$$
\Theta_{0} \bigcup \Theta_{1}=\Theta \text { e } \Theta_{0} \bigcap \Theta_{1}=\emptyset
$$

Sendo assim, definem-se as hipóteses:

$$
\begin{aligned}
& H_{0}: r \in \Theta_{0} \\
& H_{1}: r \in \Theta_{1}
\end{aligned}
$$

$\mathrm{Na}$ abordagem Bayesiana tudo o que se precisa fazer é calcular as probabilidades a posteriori (Lee, 1997):

$$
p_{0}=P\left(r \in \Theta_{0} \mid \boldsymbol{y}\right) ; p_{1}=P\left(r \in \Theta_{1} \mid \boldsymbol{y}\right)
$$

em que $\boldsymbol{y}$ representa os dados, e decidir entre $H_{0}$ e $H_{1}$. Observa-se que $p_{0}+p_{1}=1$.

É necessário considerar também

$$
\pi_{0}=P\left(r \in \Theta_{0}\right) \text { e } \pi_{1}=P\left(r \in \Theta_{1}\right),
$$

isto é, probabilidades a priori. Observa-se, também, que $\pi_{0}+\pi_{1}=1$.

Define-se a vantagem a priori de $H_{0}$ contra $H_{1}$ como $\frac{\pi_{0}}{\pi_{1}}$ e a vantagem a posteriori de $H_{0}$ contra $H_{1}$ como $\frac{p_{0}}{p_{1}}$. 
Observa-se que, se a vantagem a priori está próxima de 1 então $H_{0}$ é tão provável quanto $H_{1}$ a priori. Enquanto que se a razão é grande (maior que 1) considera-se $H_{0}$ mais provável que $H_{1}$. Contudo, se a razão é pequena (menor que 1) considera-se $H_{0}$ improvável. A mesma interpretação se dá à posteriori.

$\mathrm{O}$ fator de Bayes em favor de $H_{0}$ contra $H_{1}$ é definido por

$$
B=\frac{p_{0} / p_{1}}{\pi_{0} / \pi_{1}}
$$

Se $\Theta_{0}=\left\{r_{0}\right\}$ e $\Theta_{1}=\left\{r_{1}\right\}$ para algum $r_{0}$ e algum $r_{1}$, tem-se, $p_{0} \propto$ $\pi_{0} p\left(\boldsymbol{y} \mid r_{0}\right)$ e $p_{1} \propto \pi_{1} p\left(\boldsymbol{y} \mid r_{1}\right)$ o que implica que $\frac{p_{0}}{p_{1}}=\frac{\pi_{0} p\left(\boldsymbol{y} \mid r_{0}\right)}{\pi_{1} p\left(\boldsymbol{y} \mid r_{1}\right)}$. Logo, o fator de Bayes a favor de $H_{0}$ contra $H_{1}$ é

$$
B=\frac{p_{0} / p_{1}}{\pi_{0} / \pi_{1}}=\frac{\pi_{0} p\left(\boldsymbol{y} \mid r_{0}\right) / \pi_{1} p\left(\boldsymbol{y} \mid r_{1}\right)}{\pi_{0} / \pi_{1}} .
$$

Assim, $B$ é a razão de verossimilhança de $H_{0}$ contra $H_{1}$, que pode ser interpretada como a vantagem de $H_{0}$ contra $H_{1}$ que é dada pelos dados.

Entretanto, a interpretação não é tão simples quando $H_{0}$ e $H_{1}$ são compostas por mais que um elemento. Assim, define-se

$$
\rho_{0}(r)=\frac{p(r)}{\pi(r)} \text { para } r \in \Theta_{0} \text { e } \rho_{1}(r)=\frac{p(r)}{\pi(r)} \text { para } r \in \Theta_{1},
$$

em que $p(r)$ é a densidade a posteriori de $r ; \rho_{0}$ é a restrição de $p(r)$ para $\Theta_{0}$ e $\rho_{1}$ é a restrição de $p(r)$ para $\Theta_{1}$. Tem-se, então, $p_{0}=P\left(r \in \Theta_{0} \mid \boldsymbol{y}\right)=\int_{r \in \Theta_{0}} p(r) p(\boldsymbol{y}) d r \propto$ $\int_{r \in \Theta_{0}} p(r \mid \boldsymbol{y}) d r=\pi_{0} \int_{r \in \Theta_{0}} p(\boldsymbol{y} \mid r) \rho_{0}(r) d r$.

Semelhantemente, $p_{1} \propto \pi_{1} \int_{r \in \Theta_{1}} p(r) p(\boldsymbol{y} \mid r) d r$. Portanto, o fator de Bayes é:

$$
B=\frac{p_{0} / p_{1}}{\pi_{0} / \pi_{1}}=\frac{\int_{r \in \Theta_{0}} p(\boldsymbol{y} \mid r) \rho_{0}(r) d r}{\int_{r \in \Theta_{1}} p(\boldsymbol{y} \mid r) \rho_{1}(r) d r}
$$

o qual é a razão de verossimilhanças ponderadas por $\rho_{0}$ e $\rho_{1}$ de $\Theta_{0}$ e $\Theta_{1}$.

Para testar a ligação define-se as hipóteses:

$$
H_{0}: r \in[0,45 ; 0,5] \text { (não ligação), }
$$




$$
H_{1}: r \in[0 ; 0,45)
$$

Apesar da não ligação ocorrer somente quando $r=0,5$, considerou-se que os locos não estão ligados quando $r \in[0,45 ; 0,5]$, pois, para se detectar ligação quando se tem um valor de $r$ nesse intervalo é necessário uma amostra muito grande. Como em geral não se trabalha com amostras tão grandes é razoável fazer essa suposição. Assim, calculou-se o fator de Bayes, $B$, quando $B<1$ rejeitou-se $H_{0}$ e aceitou-se que os marcadores estão ligados.

\subsubsection{Determinação da Fase de Ligação}

O método para a determinação da fase de ligação apresentado aqui é um método Bayesiano.

Um arranjo apropriado e, portanto, a fase de ligação mais apropriada entre dois marcadores para ambos os pais, pode ser determinado calculando a probabilidade a posteriori condicionada aos dados eq. (15). O arranjo correspondente a maior probabilidade a posteriori representa a fase de ligação mais provável entre os dois marcadores.

Seja $A_{w}^{2}$, o $w$-ésimo arranjo dos alelos do segundo marcador $M^{2}$ dado que a atribuição cromossômica para o primeiro marcador $M^{1}$ é fixa. Seja $\boldsymbol{M}=$ $\left(M_{1}, M_{2}\right)^{T}$ os dados para os dois marcadores. De acordo com o teorema de Bayes, a probabilidade a posteriori de $A_{w}^{2}$ dado $\boldsymbol{M}$ é expressa como

$$
P\left(A_{w}^{2} \mid \boldsymbol{M}\right)=\frac{P\left(A_{w}^{2}\right) P\left(\boldsymbol{M} \mid A_{w}^{2}\right)}{\sum_{w=1}^{4} P\left(A_{w}^{2}\right) P\left(\boldsymbol{M} \mid A_{w}^{2}\right)}=\frac{P\left(\boldsymbol{M} \mid A_{w}^{2}\right)}{\sum_{w=1}^{4} P\left(\boldsymbol{M} \mid A_{w}^{2}\right)},
$$

em que $P\left(A_{w}^{2}\right)$ é a probabilidade a priori de $A_{w}^{2}, w=1, \ldots, 4$. Tal distribuição de probabilidade é a uniforme discreta, e $P\left(\boldsymbol{M} \mid A_{w}^{2}\right)$ é a verossimilhança de $\boldsymbol{M}$ dado o arranjo $A_{w}^{2}$ (Wu, et al., 2002).

Esse método foi empregado para a determinação da fase de ligação, no caso em que as freqüências de recombinação foram estimadas pela esperança a 
posteriori (enfoque bayesiano), obtendo-se assim um método puramente Bayesiano. O mesmo método de determinação da fase de ligação foi também utilizado, quando as estimativas da freqüência de recombinação foram obtidas pela máxima verossimilhança, como proposto por Wu et al. (2002).

O programa para a determinação da fase de ligação adequada, foi implementado do pacote R 1.9.0 (Anexo A4). 


\section{RESULTADOS E DISCUSSÃO}

É importante conhecer as várias propriedades estatísticas dos estimadores das frequiências de recombinação para todos os tipos de cruzamentos, sob todos os arranjos, descrevendo o quão próximas estão dos valores verdadeiros. Tipos de segregação diferem no poder de deteç̧ão da ligação. Para a construção de um mapa de ligação completo, é necessário que a ligação seja detectada para um número suficientemente grande de marcas para algum nível de significância. Quando a ligação é detectada entre um par de locos, não implica que a estimativa seja precisa (Maliepaard et al., 1997).

A fim de obter uma medida da variabilidade das estimativas da freqüência de recombinação, foi calculada a Soma dos Quadrados dos Resíduos (SQR) dos valores estimados, em relação aos valores esperados (valores verdadeiros), tanto para progênies de tamanho 50 quanto para as de tamanho 100. Foram também construídos os gráficos dos valores estimados, pelos métodos Bayesiano (B) e da máxima verossimilhança (M.V.) contra os valores esperados.

Dentre os gráficos apresentados, foram incluídos os gráficos contendo somente as estimativas significativas das freqüências de recombinação, as quais foram testadas utilizando o teste da razão de verossimilhança (LRT), no caso das estimativas de máxima verossimilhança, e o fator de Bayes, no caso das estimativas Bayesianas.

Na Tabela 2 são apresentadas 28 combinações entre dois locos. Dentre as 28 combinações, 17 são essencialmente distintas (Maliepaard et al., 1997). Foram analizados 1 cruzamento de cada um dos 17 grupos de combinações distintas, ou seja, dos grupos de cruzamentos equivalentes quanto à análise de ligação foi analisado 
apenas 1 de cada grupo.

Os resultados das simulações, bem como os gráficos e intervalos de confiança foram apresentados somente para alguns cruzamentos sob alguns dos arranjos. Para os cruzamentos e arranjos que apresentaram resultados, gráficos e intervalos de confiança semelhantes ao de outros, de modo que não alterassem as conclusões não foram mostrados.

\subsection{Cruzamentos em que somente um dos genitores é heterozigótico para ambos os locos}

Nos casos em que os cruzamentos possuem somente um dos genitores heterozigótico para ambos os locos: $D 1 D 1(1)$ (ambos os locos são do tipo $a b \times a a$ ), $D 1 B 3(2)$ (um dos locos é do tipo $a b \times a a$ e o outro é do tipo $a b \times a b$ ), $D 1 A(3)$ (um dos locos é do tipo $a b \times a a$ e o outro é do tipo $a b \times c d$ ), $D 1 C(4)$ (um dos locos é do tipo $a b \times a a$ e o outro é do tipo $a a \times a a), D 1 B 1(5)($ um dos locos é do tipo $a b \times a a$ e o outro é do tipo $a b \times a o$ ) e $D 2 B 1(6)($ um dos locos é do tipo $a a \times a b$ e o outro é do tipo $a b \times a o$ ). Como somente um dos genitores é heterozigoto para ambos os locos, os arranjos $A 1$ (associação-associação) e $A 2$ (associação-repulsão), bem como, A3(repulsão-associação) e $A 4$ (repulsão-repulsão) são equivalentes. Segundo Maliepaard et al. (1997), aqui sempre $\hat{r}_{A 1}=1-\hat{r}_{A 3}$, ou seja, o estimador da freqüência de recombinação sob o arranjo $A 1$ ou $A 2$ é igual a 1 menos o estimador sob os arranjos $A 3$ ou $A 4$. Naturalmente, somente as estimativas menores ou iguais a 0,5 são valores admissíveis para a freqüência de recombinação. Se o Lod Score é significativo o arranjo com estimativa admissível é escolhido (Maliepaard et al.,1997).

Como esperado, em simulações considerando-se os arranjos $A 1$ e $A 2$, quando foi estimada a freqüência de recombinação pelo método da máxima verossimilhança, utilizando o algoritmo EM, foram obtidos valores significativos admissíveis para a freqüência de recombinação, sob os arranjos $A 1$ e $A 2$, e não admissíveis sob os arranjos $A 3$ e $A 4$. O contrário foi obtido quando os arranjos $A 3$ e $A 4$ foram utilizados 
na simulação, ou seja, valores admissíveis para a freqüência de recombinação foram obtidos sob os arranjos $A 3$ e $A 4$ e inadimissíveis sob os arranjos $A 1$ e $A 2$. A estimação do arranjo pode ser feita através da probabilidade a posteriori condicionada aos dados eq.(15) considerando-se a estimativa admissível. O arranjo com maior probabilidade a posteriori e com estimativa admissível foi tomado como o correto.

As estimativas de Bayes, calculada pela esperança a posteriori da freqüência de recombinação, são sempre valores pertencentes ao espaço paramétrico $\Theta=[0 ; 0,5]$. Portanto todas as estimativas de Bayes são admissíveis. Assim, para simulações sob os arranjos $A 1$ e $A 2$, obteve-se valores admissíveis para as estimativas de Bayes sob os arranjos $A 1$ e $A 2$; estimativas sob os arranjos $A 3$ e $A 4$ resultaram em valores próximos a 0,5 . Para simulações sob os arranjos $A 3$ e $A 4$, as estimativas sob os arranjos, $A 1$ e $A 2$ é que são valores próximos a 0,5 . O arranjo correto, quando se estima a freqüência de recombinação pelo método Bayesiano, é aquele que tem a maior probabilidade a posteriori, a qual é obtida através da eq. (15).

Observa-se que, para esses tipos de cruzamentos é sempre possível determinar o arranjo. A diferença na estimação do arranjo, quando se usa o método da M.V. para estimar a freqüência de recombinação e o método de Bayes, é que no primeiro caso determina-se o arranjo pela maior probabilidade a posteriori e pela estimativa admissível, no segundo, é possível fazer isso considerando, apenas, a maior probabilidade a posteriori.

Para esses tipos de cruzamentos, a SQR diminuiu à medida que o tamanho amostral aumentou, independentemente do método utilizado (Tabelas 3,4 , $5,6,7$ e 8 ), exceto para o arranjo $A 4$ do cruzamento $A D 1(3)$ no caso das estimativas de Bayes, em que, a SQR teve um pequeno aumento quando se aumentou o tamanho da progênie (Tabela 5). Essa exceção pode ser devida ao conjunto de dados simulado.

As SQR's das estimativas de Bayes são sempre menores que as SQR's das estimativas de M.V., tanto para o tamanho de progênie 50 quanto para o tamanho 100 (Tabelas 3, 4, 5, 6, 7 e 8), indicando que as estimativas de Bayes estão menos dispersas em relação aos valores verdadeiros que as estimativas de M.V.. 
A diferenças entre as SQR's das estimativas de M.V. e de Bayes diminuíram com o aumento do tamanho da progênie de 50 para 100, exceto para o arranjo $A 3$ do cruzamento $D 1 B 1(5)$ (Tabela 7 ).

Tabela 3. SQR para as estimativas de máxima verossimilhança e Bayesianas da freqüência de recombinação em cruzamento do tipo $D 1 D 1(1)$ (isto é, cruzamento em que ambos os locos são do tipo $a b \times a a)$

\begin{tabular}{ccccccc}
\hline & \multicolumn{3}{c}{$\mathrm{N}=50$} & & \multicolumn{3}{c}{$\mathrm{N}=100$} \\
Arranjo & E.M.V. & E.B. & Diferença & E.M.V. & E.B. & Diferença \\
\hline A1 & 0,2136 & 0,1728 & 0,0408 & 0,0853 & 0,0642 & 0,0211 \\
A2 & 0,2094 & 0,1582 & 0,1936 & 0,1114 & 0,0947 & 0,0167 \\
A3 & 0,1397 & 0,1289 & 0,0108 & 0,1039 & 0,1008 & 0,0031 \\
A4 & 0,1884 & 0,1066 & 0,0818 & 0,0814 & 0,0721 & 0,0093 \\
\hline
\end{tabular}

E.M.V. - Estimativa de Máxima Verossimilhança; E.B. - Estimativa de Bayes

Tabela 4. SQR para as estimativas de máxima verossimilhança e Bayesianas de freqüência de recombinação em cruzamento do tipo $B 3 D 1(2)$ (isto é, cruzamento em que um loco é do tipo $a b \times a b$ e outro é do tipo $a b \times a a)$

\begin{tabular}{ccccccc}
\hline & \multicolumn{3}{c}{ N=50 } & \multicolumn{3}{c}{$\mathrm{N}=100$} \\
Arranjo & E.M.V. & E.B. & Diferença & E.M.V. & E.B. & Diferença \\
\hline A1 & 0,3324 & 0,2318 & 0,1006 & 0,1967 & 0,1340 & 0,0627 \\
A2 & 0,4293 & 0,2558 & 0,1735 & 0,1408 & 0,1270 & 0,0138 \\
A3 & 0,3764 & 0,2705 & 0,1059 & 0,1207 & 0,0959 & 0,0248 \\
A4 & 0,5419 & 0,3214 & 0,2205 & 0,1649 & 0,1394 & 0,0255 \\
\hline
\end{tabular}

E.M.V. - Estimativa de Máxima Verossimilhança; E.B. - Estimativa de Bayes 
Tabela 5. SQR para as estimativas de máxima verossimilhança e Bayesianas de freqüência de recombinação em cruzamento do tipo $A D 1(3)$ (isto é, cruzamento em que um loco é do tipo $a b \times c d$ e o outro é do tipo $a b \times a a$ )

\begin{tabular}{ccccccc}
\hline & \multicolumn{3}{c}{$\mathrm{N}=50$} & & \multicolumn{3}{c}{$\mathrm{N}=\mathbf{1 0 0}$} \\
Arranjo & E.M.V. & E.B. & Diferença & E.M.V. & E.B. & Diferença \\
\hline A1 & 0,1377 & 0,1126 & 0,0251 & 0,0735 & 0,0601 & 0,0134 \\
A2 & 0,2051 & 0,1451 & 0,0600 & 0,1000 & 0,0966 & 0,0034 \\
A3 & 0,1629 & 0,0921 & 0,0708 & 0,1042 & 0,0918 & 0,0124 \\
A4 & 0,1620 & 0,1139 & 0,0481 & 0,1570 & 0,1253 & 0,0317 \\
\hline
\end{tabular}

E.M.V. - Estimativa de Máxima Verossimilhança; E.B. - Estimativa de Bayes

Tabela 6. SQR para as estimativas de máxima verossimilhança e Bayesianas de freqüência de recombinação em cruzamento do tipo $C D 1(4)$ (isto é, cruzamento em que um loco é do tipo ao $\times$ ao e o outro é do tipo $a b \times a a$ )

\begin{tabular}{ccccccc}
\hline & \multicolumn{3}{c}{ N=50 } & \multicolumn{3}{c}{$\mathrm{N}=100$} \\
Arranjo & E.M.V. & E.B. & Diferença & E.M.V. & E.B. & Diferença \\
\hline A1 & 0,4990 & 0,2684 & 0,2306 & 0,2845 & 0,2032 & 0,0813 \\
A2 & 0,6954 & 0,4164 & 0,2790 & 0,2534 & 0,1958 & 0,0576 \\
A3 & 0,4818 & 0,3365 & 0,1453 & 0,2668 & 0,1657 & 0,1011 \\
A4 & 0,4586 & 0,3104 & 0,1482 & 0,3110 & 0,2288 & 0,0822 \\
\hline
\end{tabular}

E.M.V. - Estimativa de Máxima Verossimilhança; E.B. - Estimativa de Bayes 
Tabela 7. SQR para as estimativas de máxima verossimilhança e Bayesianas de freqüência de recombinação em cruzamento do tipo $B 1 D 1(5)$ (isto é, cruzamento em que um loco é do tipo $a b \times a o$ e o outro é do tipo $a b \times a a$ )

\begin{tabular}{ccccccc}
\hline & \multicolumn{3}{c}{$\mathrm{N}=50$} & & \multicolumn{3}{c}{$\mathrm{N}=100$} \\
Arranjo & E.M.V. & E.B. & Diferença & E.M.V. & E.B. & Diferença \\
\hline A1 & 0,1520 & 0,1162 & 0,0358 & 0,0961 & 0,0931 & 0,0030 \\
A2 & 0,1751 & 0,1386 & 0,0365 & 0,1032 & 0,0855 & 0,0177 \\
A3 & 0,1540 & 0,1386 & 0,0154 & 0,1360 & 0,1073 & 0,0287 \\
A4 & 0,1809 & 0,1489 & 0,0320 & 0,0759 & 0,0653 & 0,0106 \\
\hline
\end{tabular}

E.M.V. - Estimativa de Máxima Verossimilhança; E.B. - Estimativa de Bayes

Tabela 8. SQR para as estimativas de máxima verossimilhança e Bayesianas de freqüência de recombinação em cruzamento do tipo $B 1 D 2(6)$ (isto é, cruzamento em que um dos locos é do tipo $a b \times a o$ e o outro do tipo $a a \times a b$ )

\begin{tabular}{ccccccc}
\hline & \multicolumn{3}{c}{$\mathrm{N}=50$} & & \multicolumn{3}{c}{$\mathrm{N}=100$} \\
Arranjo & E.M.V. & E.B. & Dierença. & E.M.V. & E.B. & Diferença \\
\hline A1 & 0,3750 & 0,2560 & 0,1190 & 0,1757 & 0,1424 & 0,0333 \\
A2 & 0,3038 & 0,2402 & 0,0636 & 0,1809 & 0,1260 & 0,0549 \\
A3 & 0,3471 & 0,2040 & 0,1431 & 0,1192 & 0,0828 & 0,0364 \\
A4 & 0,3061 & 0,2210 & 0,0851 & 0,1658 & 0,1315 & 0,0343 \\
\hline
\end{tabular}

E.M.V. - Estimativa de Máxima Verossimilhança; E.B. - Estimativa de Bayes 
Além da SQR, pode-se notar nos gráficos que quando o tamanho da progênie aumenta de 50 para 100 as estimativas de M.V. e de Bayes se aproximam mais da reta identidade, ou seja, se aproximam mais dos valores verdadeiros das freqüências de recombinação $(r)$. Esse fato é ilustrado para o cruzamento do tipo $D 1 D 1(1)$ sob o arranjo $A 1$ na Figura 10, que mostra os gráficos das estimativas e das estimativas significativas de M.V. e de Bayes para uma progênie de tamanho 50, e na Figura 11 em que a progênie considerada é de tamanho 100.

Freqüência de Recombinação

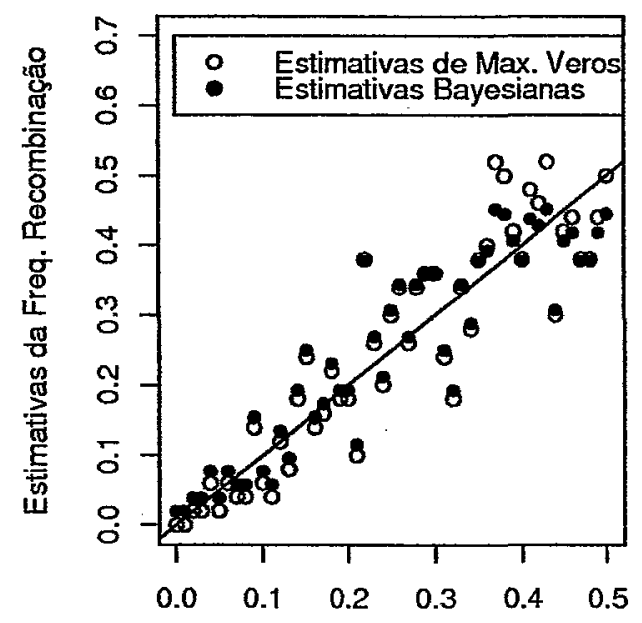

Freqüência de Recombinação

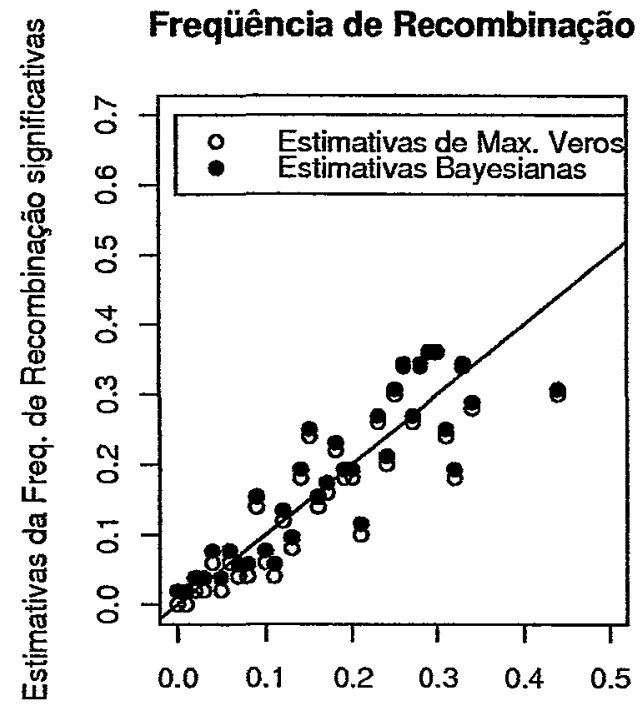

Freqüência de Recombinação

Figura 10 - Estimativas das freqüências de recombinação - cruzamento D1D1(1) arranjo A1 - progênie de tamanho 50

Pode-se notar, ainda nas Figuras 10 e 11, que as estimativas de Bayes e de M.V. se aproximam umas das outras quando se aumenta o tamanho da progênie (ver, também, A5).

Os gráficos dos valores estimados pelo método da M.V. e de Bayes com os respectivos intervalos de confiança $95 \%$ e de credibilidade $95 \%$, são apresentados para o cruzamento D1B3(2) sob o arranjo $A 3$ (Figuras 12 e 13). Foram obtidos os intervalos de confiança $95 \%$ e de credibilidade $95 \%$ para todas as estimativas de M.V. e de Bayes respectivamente, para tamanhos de progênies 50 e 100, sob os 
Freqüência de Recombinação

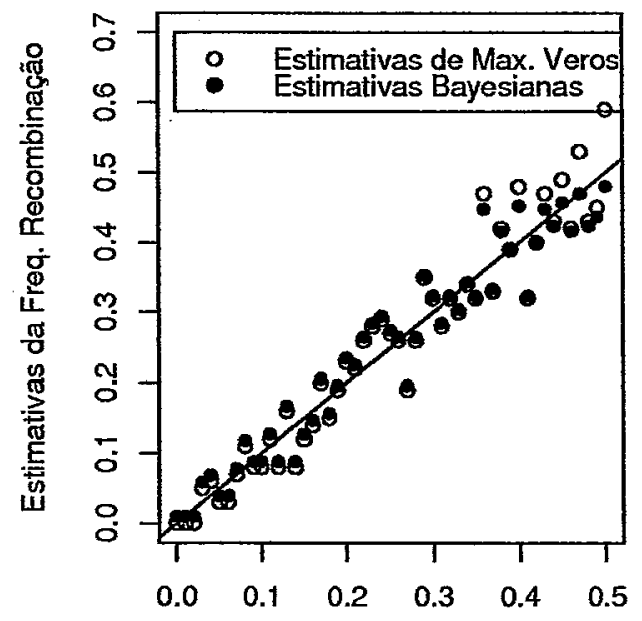

Freqüência de Recombinação
Freqüência de Recombinação
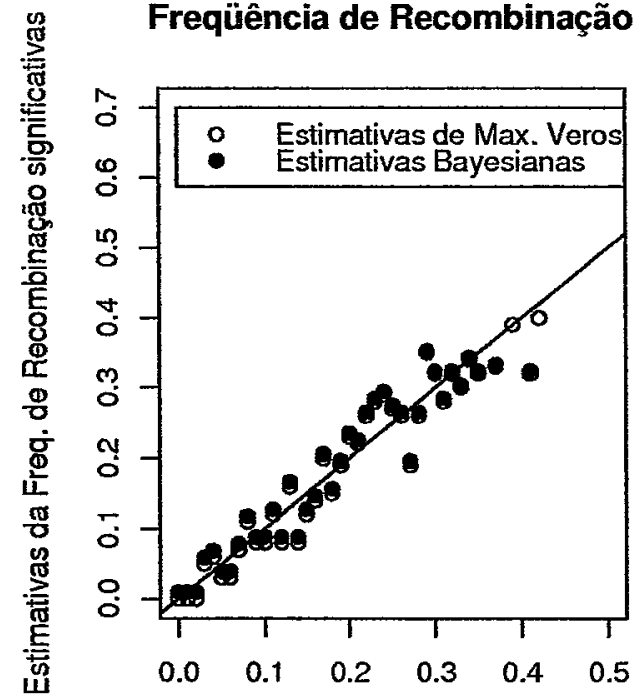

Freqüência de Recombinação

Figura 11 - Estimativas das freqüências de recombinação - cruzamento D1D1(1) arranjo A1 - progênie de tamanho 100

quatro diferentes arranjos, para todos os cruzamentos discutidos aqui. No Anexo A6 são apresentados, para o cruzamento $D 1 B 3(2)$ sob o arranjo $A 3$, com tamanho de progênie 50, os valores das estimativas de M.V. e de Bayes, os intervalos de confiança 95\% e de credibilidade $95 \%$ e, também, as estimativas de M.V. que tiveram o teste de ligação significativo. 

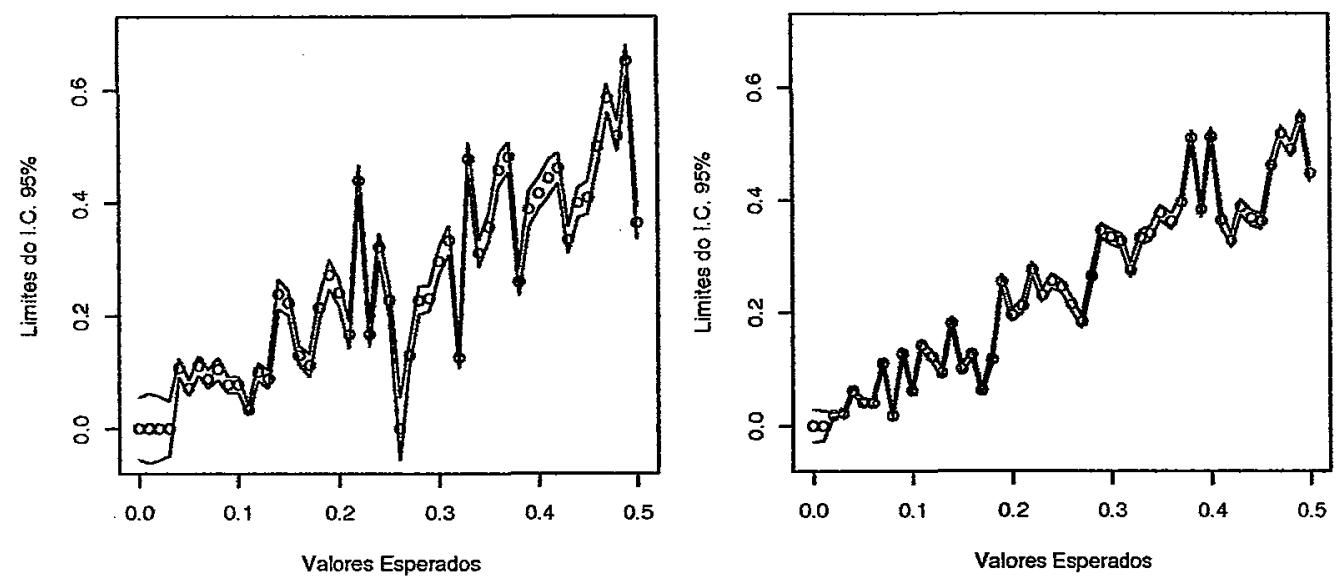

Figura 12 - Limites inferior e superior dos intervalos de confiança para as estimativas de M.V. das freqüências de recombinação - cruzamento $D 1 B 3(2)$ arranjo $A 3$ - progênie de tamanhos 50(à esquerda) e 100(à direita)
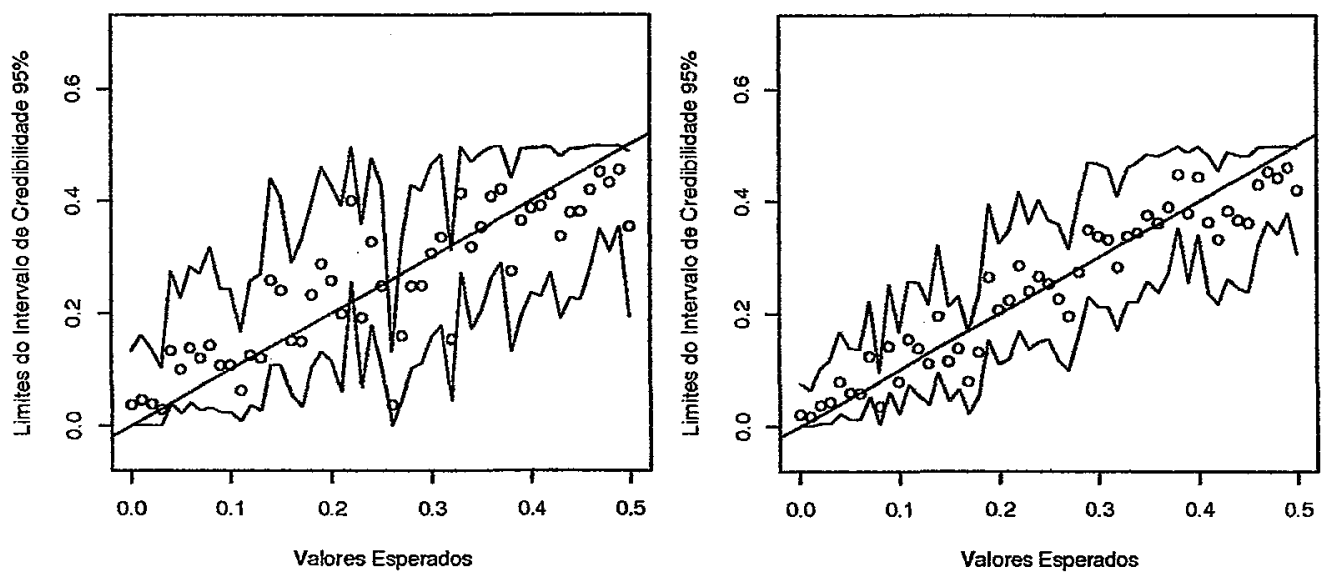

Figura 13 - Limites inferior e superior dos intervalos de credibilidade para as estimativas de Bayes das freqüências de recombinação - cruzamento $D 1 B 3(2)$ - arranjo $A 3$ - progênie de tamanhos 50(à esquerda) e 100(à direita) 


\subsection{Cruzamentos em que a segregação é simétrica em ambos os locos}

Considerando os cruzamentos onde ambos os locos têm um tipo de segregação simétrica: $B 3 B 3(7)$ (ambos os locos são do tipo $a b \times a b$ ), $B 3 C(9)$ (um dos locos é do tipo $a b \times a b$ e o outro é do tipo $a b \times a o$ ) e $C C(14)$ (ambos os locos são do tipo $a o \times a o$ ).

Segundo Maliepaard et al. (1997) os estimadores de M.V. para os arranjos $A 2$ e $A 3$ são idêndicos. Assim a escolha entre $A 2$ e $A 3$ não pode ser feita, também $\hat{r}_{A 1}=1-\hat{r}_{A 4}$.

Se os arranjos são $A 1$ ou $A 4$ para os cruzamentos $B 3 B 3(7)$ e $B 3 C(9)$, então, as estimativas de M.V. são imaginárias (números complexos) (cruzamento $B 3 B 3(7)$ ), ou em torno de 0,5 (cruzamento $B 3 C(9)$ ) com um LOD Score muito pequeno. Assim, para os cruzamentos $B 3 B 3(7)$ e $B 3 C(9)$ os arranjos $A 1$ e $A 4$ podem ser distinguidos um do outro, bem como de $A 2$ e $A 3$ (Maliepaard et al., 1997).

Considerando os cruzamentos $B 3 B 3(7)$ e $B 3 C(9)$, as estimativas de M.V., obtidas através do algoritmo EM, sob os arranjos $A 2$ e $A 3$ são sempre iguais, isto é, $\hat{r}_{A 2}=\hat{r}_{A 3}$. Nas simulações sob os arranjos $A 1$ e $A 4$ as estimativas sob os arranjos $A 2$ e $A 3$ são valores em torno de 0,5 ; estimativas sob o arranjo para o qual os dados foram simulados são admissíveis e as estimativas sob o arranjo restante é maior que 0,5 . Além disso, as probabilidades a posteriori dos arranjos $A 1$ e $A 4$ são as maiores. Nas simulações sob os arranjos $A 2$ e $A 3$, esses dois arranjos têm as maiores probabilidades a posteriori que os arranjos $A 1$ e $A 4$, e também, $P(A 2 \mid M)=$ $P(A 3 \mid \boldsymbol{M})$, como $\hat{r}_{A 2}=\hat{r}_{A 3}$, esses dois arranjos não podem ser distinguidos. Assim, se o arranjo com a maior probabilidade a posteriori é $A 1$ ou $A 4$, o arranjo pode ser determinado, caso contrário é necessário estimar o arranjo através de locos vizinhos, ou seja, um loco que esteja ligado com esses e que possua um tipo de segregação mais informativa.

As estimativas de Bayes sob os arranjos $A 2$ e $A 3$ são sempre iguais. 
Nas simulações sob o arranjo $A 1$, as estimativas sob $A 1$ são valores admissiveis e as estimativas sob os arranjos $A 2, A 3$ e $A 4$ estão próximas de 0,5 ; o arranjo com a maior probabilidade a posteriori é $A 1$. Nas simulações sob o arranjo $A 4$, as estimativas sob os arranjos $A 1, A 2$ e $A 3$ estão próximas de 0,5 e as estimativas sob $A 4$ são valores admissíveis; o arranjo com a maior probabilidade a posteriori é A4. Nas simulações sob os arranjos $A 2$ e $A 3$, eles têm maiores probabilidades a posteriori que $A 1$ e $A 4$ e essas probabilidades são iguais. Assim, o arranjo pode ser determinado se a maior probabilidade a posteriori for para o arranjo $A 1$ ou $A 4$. Caso contrário, não se pode distinguir entre os arranjos $A 2$ e $A 3$, sendo necessário estimar o arranjo através de locos vizinhos.

$\mathrm{O}$ cruzamento $C C(14)$, é simétrico e ambos os locos têm um alelo nulo em ambos os pais. Aqui se o arranjo é $A 1$ (simulações feitas sob o arranjo A1), as estimativas de M.V. para os arranjos $A 2$ e $A 3$ são imaginárias enquanto que as estimativas sob o arranjo $A 4$ são maiores que 0,5 . Entretanto, se os arranjos são $A 2$, $A 3$, e $A 4$, então, todas as estimativas são admissíveis, exceto para o arranjo $A 1$, com LOD Score idêntico. Assim, para o cruzamento do tipo $C C(14)$ somente o arranjo $A 1$ pode ser distinguido de $A 2, A 3$ e $A 4$. Para estimar a fase de ligação, nesse caso; é necessário combinar com outras marcas com tipo de segregação mais informativa (Maliepaard et al., 1997).

Considerando ainda o cruzamento $C C(14)$, se o arranjo é $A 1$, isto é, nas simulações feitas sob $A 1$, as estimativas de M.V. sob os arranjos $A 2$ e $A 3$ estão em torno de 0,5 e sob $A 4$ são maiores que 0,5 , enquanto que sob o arranjo $A 1$ são valores admissíveis. Os arranjos $A 1$ e $A 4$ têm as maiores probabilidades a posteriori. Nas simulações sob os outros arranjos $(A 2, A 3$, e $A 4)$, todas as estimativas são admissíveis, exceto sob o arranjo $A 1$, em que as estimativas são maiores que 0,5 . Aqui, somente o arranjo $A 1$ pode ser distinguido dos demais. É necessário determinar o arranjo com locos vizinhos.

As estimativas Bayesianas da freqüência de recombinação, são valores admissíveis sob o arranjo $\mathrm{A} 1$ e valores próximos de 0,5 sob os arranjos $A 2, A 3$ e $A 4_{\text {r }}$ 
quando as simulações são feitas sob o arranjo A1. Nesse caso o arranjo com a maior probabilidade a posteriori é $A 1$. Para as simulações feitas sob os arranjos $A 2, A 3 \mathrm{e}$ $A 4$, as estimativas sob esses arranjos são admissíveis e sob o arranjo $A 1$ são valores próximos de 0,5 . Assim, somente o arranjo $A 1$ pode ser distinguido dos demais. É necessário determinar o arranjo através de locos vizinhos.

Deve ser notado que existe alguma incerteza na caracterização dos arranjos entre dois marcadores de um cruzamento do tipo simétrico $B 3 B 3(7), B 3 C(9)$, e $C C(14)$. Tal incerteza pode ser removida combinando esses marcadores com um marcador do tipo não simétrico exceto $D 1$ ou $D 2$ (Wu et al., 2002).

Para os cruzamentos $B 3 B 3(7)$ e $B 3 C(9)$, sempre quando aumentou-se o tamanho da progênie de 50 para 100 a SQR diminuiu tanto para as estimativas de M.V. quanto para as estimativas de Bayes (Tabelas 9 e 10). No caso do arranjo $A 3$ do cruzamento $C C(14)$ a $\mathrm{SQR}$ das estimativas de Bayes teve um pequeno aumento quando se aumentou o tamanho da progênie de 50 para 100. As SQR's para os arranjos $A 1, A 2$ e $A 4$, desse cruzamento, diminuiíram quando se aumentou o tamanho da progênie (Tabela 11).

As SQR's das estimativas de Bayes são menores que as SQR's das estimativas de M.V. para progênies de tamanhos 50 e 100. Houve apenas uma exceção, o arranjo $A 2$ do cruzamento $B 3 B 3(7)$ para a progênie de tamanho 50 (Tabela 9).

As diferenças entre as SQR's das estimativas de Bayes e as SQR's das estimativas de M.V. diminuiram quando aumentou-se o tamanho da progênie de 50 para 100, exceto para o arranjo $A 2$ dos cruzamentos $B 3 B 3(7)$ e $C C(14)$ (Tabelas 9 e 11). Essa exceção ocorreu, pois, quando aumentou-se o tamanho da progênie a SQR das estimativas de Bayes teve uma redução maior que a SQR das estimativas de M.V., aumentando a diferença quando o tamanho da progênie era 100. 
Tabela 9. SQR para as estimativas de máxima verossimilhança e Bayesianas de freqüência de recombinação em cruzamento do tipo $B 3 B 3(7)$ (isto é, cruzamento em que ambos os locos são do tipo $a b \times a b$ )

\begin{tabular}{ccccccc}
\hline & \multicolumn{3}{c}{ N=50 } & \multicolumn{3}{c}{$\mathrm{N}=100$} \\
Arranjo & E.M.V. & E.B. & Diferença & E.M.V. & E.B. & Diferença \\
\hline A1 & 0,1097 & 0,0939 & 0,0158 & 0,0661 & 0,0552 & 0,0109 \\
A2 & 0,2149 & 0,2415 & $-0,0266$ & 0,1963 & 0,1563 & 0,0400 \\
A3. & 0,2431 & 0,2270 & 0,0161 & 0,0905 & 0,0788 & 0,0117 \\
A4 & 0,1215 & 0,1073 & 0,0142 & 0,0740 & 0,0643 & 0,0097 \\
\hline
\end{tabular}

E.M.V. - Estimativa de Máxima Verossimilhança; E.B. - Estimativa de Bayes

Tabela 10. SQR para as estimativas de máxima verossimilhança e Bayesianas de freqüência de recombinação em cruzamento do tipo $B 3 C(9)$ (isto é, cruzamento em que um loco é do tipo $a b \times a b$ e o outro é do tipo $a o \times a o)$

\begin{tabular}{ccccccc}
\hline & \multicolumn{3}{c}{$\mathrm{N}=50$} & & \multicolumn{3}{c}{$\mathrm{N}=100$} \\
Arranjo & E.M.V. & E.B. & Diferença & E.M.V. & E.B. & Diferença \\
\hline A1 & 0,2119 & 0,1607 & 0,0512 & 0,1461 & 0,1223 & 0,0238 \\
A2 & 0,7008 & 0,5027 & 0,1981 & 0,3385 & 0,2770 & 0,0615 \\
A3 & 0,6902 & 0,4853 & 0,2049 & 0,5240 & 0,3483 & 0,1757 \\
A4 & 0,2749 & 0,1598 & 0,1151 & 0,1240 & 0,1141 & 0,0099 \\
\hline
\end{tabular}

E.M.V. - Estimativa de Máxima Verossimilhança; E.B. - Estimativa de Bayes 
Tabela 11. SQR para as estimativas de máxima verossimilhança e Bayesianas de freqüência de recombinação em cruzamento do tipo $C C(14)$ (isto é, cruzamento em que ambos os locos são do tipo $a o \times a o$ )

\begin{tabular}{ccccccc}
\hline & \multicolumn{3}{c}{$\mathrm{N}=50$} & & \multicolumn{3}{c}{$\mathrm{N}=100$} \\
Arranjo & E.M.V. & E.B. & Diferença & E.M.V. & E.B. & Diferença \\
\hline A1 & 0,2836 & 0,1823 & 0,1013 & 0,1725 & 0,1601 & 0,0124 \\
A2 & 0,8869 & 0,7107 & 0,1762 & 0,6749 & 0,4075 & 0,2674 \\
A3 & 0,6100 & 0,4333 & 0,61 & 0,5609 & 0,4711 & 0,0898 \\
A4 & 0,9266 & 0,4655 & 0,4611 & 0,5256 & 0,3101 & 0,2155 \\
\hline
\end{tabular}

E.M.V. - Estimativa de Máxima Verossimilhança; E.B. - Estimativa de Bayes

Pode ser visto nas Figuras 14 e 15, que quando o tamanho da progênie aumenta de 50 para 100 as estimativas de M.V. e de Bayes se aproximam dos verdadeiros valores de $r$ e se aproximam entre si (ver, também, A7).

As Figuras 16 e 17 mostram os gráficos dos valores estimados pelo método da M.V. e de Bayes com os respectivos intervalos de confiança e de credibilidade para o cruzamento $C C(14)$ sob o arranjo $A 4$. Para algumas das estimativas de M.V., sob os arranjos $A 2$ e $A 3$ dos cruzamentos $B 3 B 3(7), B 3 C(9)$ e $C C(14)$, não foi possível calcular os intervalos de confiança. Isso ocorreu, porque o cálculo do intervalo de confiança aproximado faz uso da raiz quadrada da Informação observada de Fisher que pode assumir valores negativos. Contudo, nos casos onde não foi possível calcular os intervalos de confiança, as estimativas eram não significativas pelo Teste da Razão de Verossimilhança. Esse fato é ilustrado para o cruzamento $B 3 B 3(7)$, sob o arranjo $A 3$ (ver A8). 
Freqüência de Recombinação

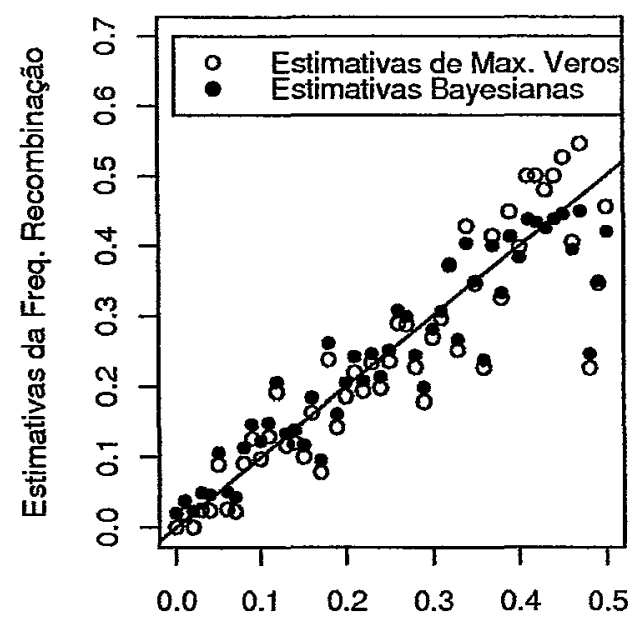

Freqüência de Recombinação

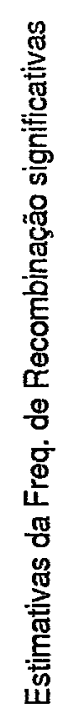

\section{Freqüência de Recombinação}

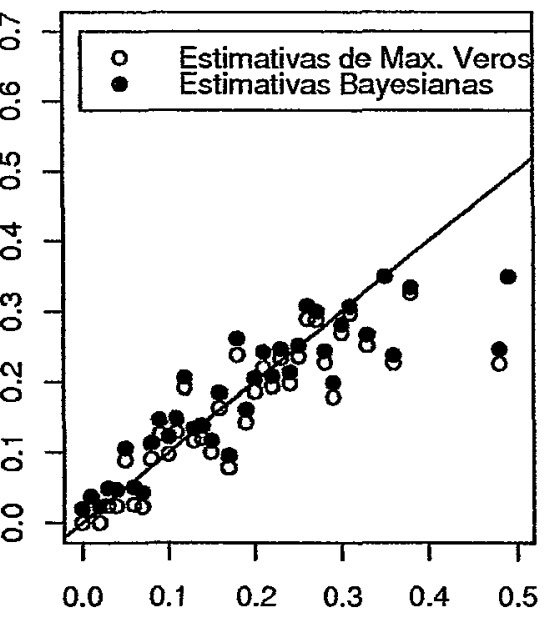

Freqüência de Recombinação

Figura 14 - Estimativas das freqüências de recombinação - cruzamento B3C(9) - arranjo A4 - progênie de tamanho 50

Freqüência de Recombinação

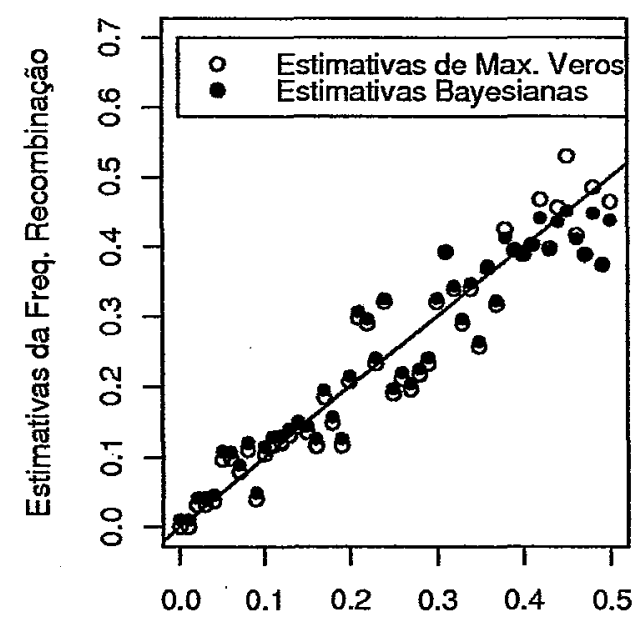

Freqüência de Recombinação

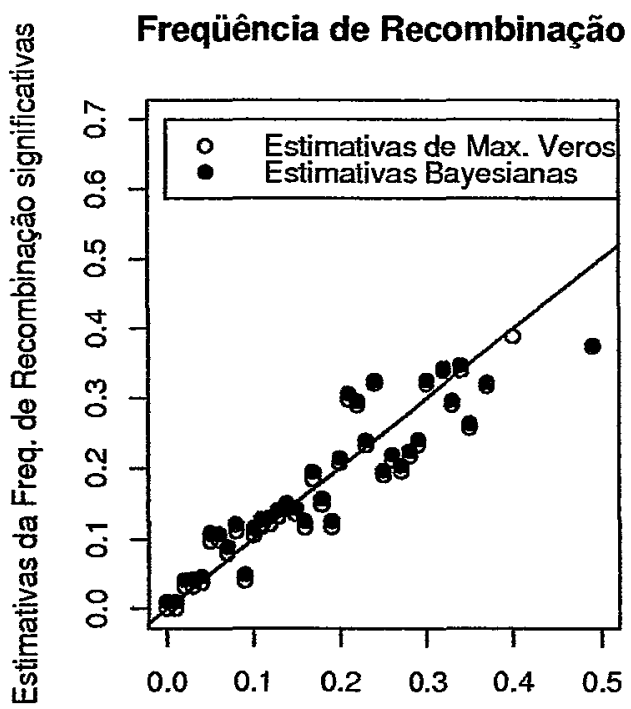

Freqũência de Recombinação

Figura 15 - Estimativas das freqüências de recombinação - cruzamento B3C(9) - arranjo A4 - progênie de tamanho 100 

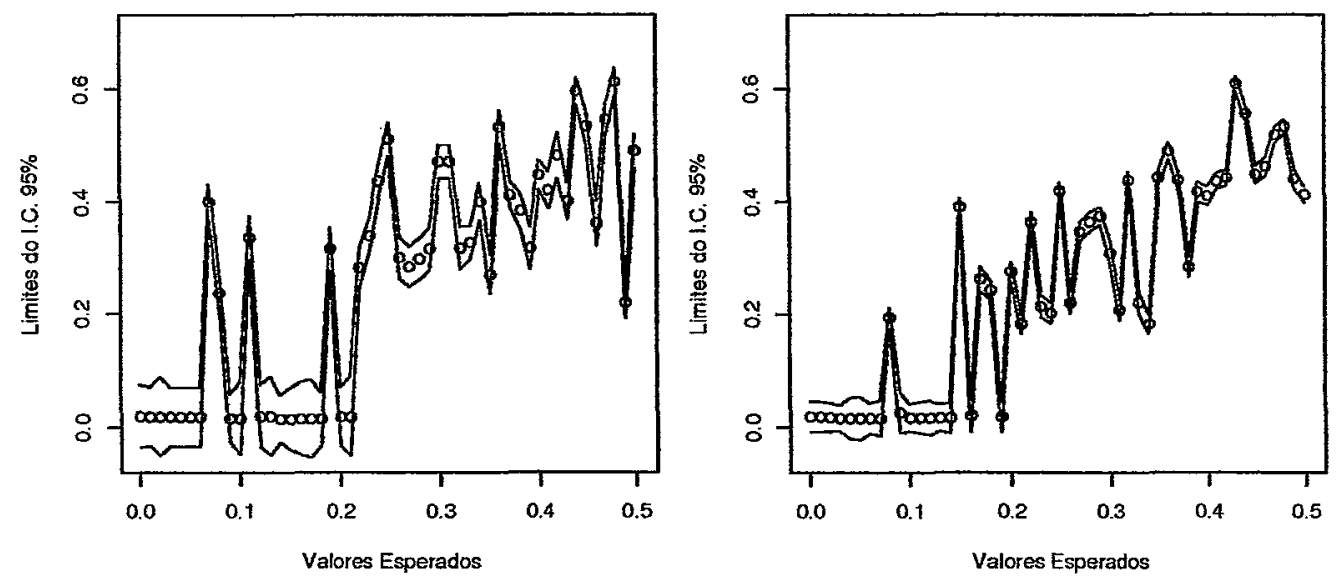

Figura 16 - Limites inferior e superior dos intervalos de confiança para as estimativas de M.V. das freqüências de recombinação - cruzamento $C C(14)$ - arranjo $A 4$ - progênie de tamanhos 50(à esquerda) e 100(à direita)
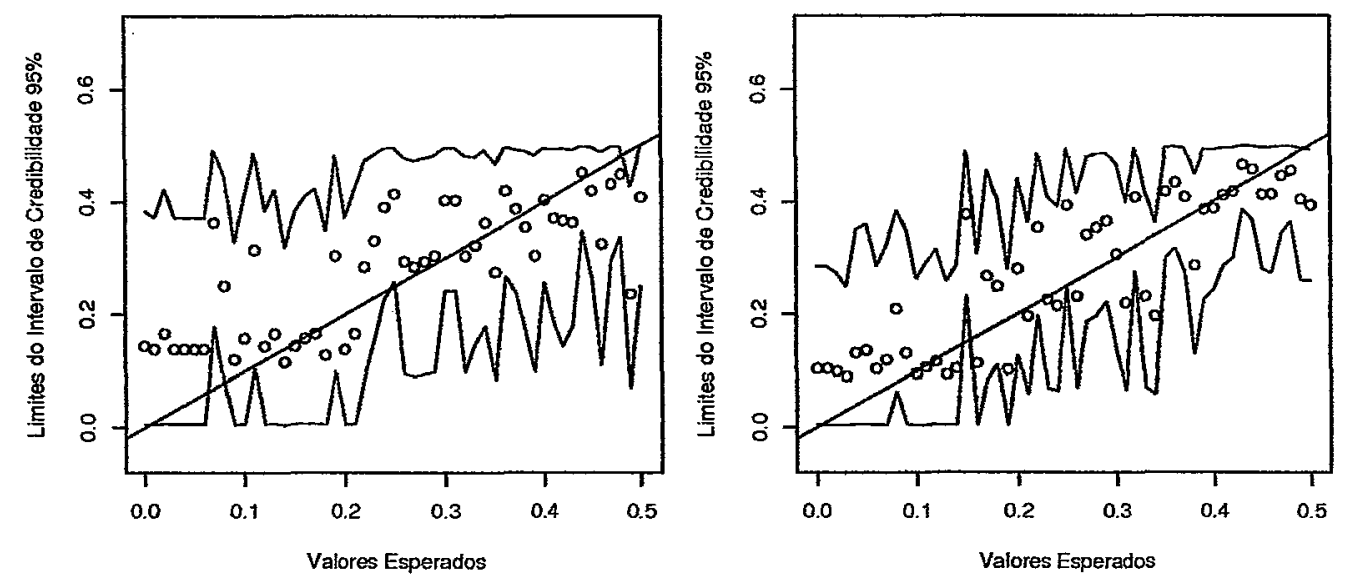

Figura 17 - Limites inferior e superior dos intervalos de credibilidade para as estimativas de Bayes das freqüências de recombinação - cruzamento $C C(14)$ - arranjo $A 4$ - progênie de tamanhos 50(à esquerda) e 100(à direita) 


\subsection{Cruzamentos em que ambos os locos têm um alelo nulo no mesmo genitor}

Analisando os tipos de cruzamentos onde ambos os locos têm um alelo nulo no mesmo genitor: cruzamentos $C B 1(15)$ (um dos locos é do tipo ao $\times$ ao e o outro é do tipo $a b \times a o$ ) e $B 1 B 1(16)$ (ambos os locos são do tipo $a b \times a o$ ). Segundo Maliepaard et al. (1997), considerando os estimadores de M.V. para esses cruzamentos, sempre $\hat{r}_{A 1}=1-\hat{r}_{A 4}$ e $\hat{r}_{A 2}=1-\hat{r}_{A 3}$.

Se os locos estão em associação no primeiro genitor (arranjos $A 1$ e $A 2)$, então, a estimativa para a fase correta tem o menor valor e um alto $L O D$ Score, enquanto as outras duas estimativas são maiores que 0,5 . Se, entretanto, os locos estão em repulsão no primeiro genitor (arranjos $A 3$ e $A 4$ ), então, as estimativas sob os arranjos $A 3$ e $A 4$ são aproximadamente iguais com Lod Score similar, enquanto que as outras duas estimativas são maiores que 0,5 . Assim, os arranjos $A 1$ e $A 2$ podem ser distinguidos entre si e de $A 3$ e $A 4$. Contudo, simulações de $A 3$ e $A 4$ mostram que em mais de $95 \%$ dos casos significativos a fase correta foi estimada, sendo prudente verificar a fase de ligação através de locos vizinhos (Maliepaard et al., 1997).

Se o arranjo é $A 1$ ou $A 2$, isto é, nas simulações feitas sob esses arranjos, as estimativas de M.V. obtidas através do algoritmo EM, sob os arranjos $A 3$ e $A 4$ são maiores que 0,5 e sob os arranjos $A 1$ e $A 2$ são admissíveis. Se o arranjo é $A 3$ ou $A 4$ ocorre o contrário, as estimativas de M.V. sob os arranjos $A 1$ e $A 2$ são maiores que 0,5 e sob os arranjos $A 3$ e $A 4$ são estimativas admissíveis. Nas simulações sob o arranjo $A 1$ os arranjos com maiores probabilidades a posteriori são $A 1$ e $A 4$, $P(A 1 \mid M)=P(A 4 \mid M)$. Em simulações sob o arranjo $A 2$ os arranjos com maior probabilidade a posteriori são $A 2$ e $A 3, P(A 2 \mid \boldsymbol{M})=P(A 3 \mid \boldsymbol{M})$, isso só não ocorreu para $4 \%$ dos dados simulados. Assim, nas simulações sob, $A 1$ e $A 2$ o arranjo pode ser determinado corretamente através da probabilidade a posteriori dos arranjos e da estimativa admissível. Entretanto, nas simulações sob $A 3$ e $A 4$, o arranjo correto foi estimado em somente $89 \%$ dos casos. Como já sugerido por Maliepaard et al. 
(1997) é conveniente verificar o arranjo através de locos vizinhos.

Quanto às estimativas de freqüência de recombinação pelo método de Bayes, se o arranjo é $A 1$ ou $A 2$ as estimativas sob $A 3$ e $A 4$ são valores próximos de 0,5; se o arranjo é $A 3$ ou $A 4$, as estimativas sob $A 1$ e $A 2$ são valores próximos de 0,5 .

Nas simulações sob $A 1$ e $A 2$ o arranjo foi estimado corretamente, quando a freqüência de recombinação foi estimada pelo método Bayeseiano, mas nas simulações sob $A 3$ e $A 4$ não foi sempre possível, sendo prudente verificar o arranjo através de locos vizinhos.

Para os cruzamentos $B 1 C(15)$ e $B 1 B 1(16)$, sempre que se aumentou o tamanho da progênie de 50 para 100, as SQR's das estimativas de M.V., assim como, as SQR's das estimativas de Bayes diminuíram. As SQR's das estimativas de Bayes são sempre menores que as SQR's das estimativas de M.V. (Tabelas 12 e 13).

As diferenças entre as SQR's das estimativas de M.V. e as SQR's das estimativas de Bayes tornaram-se menores quando se aumentou o tamanho da progênie de 50 para 100, exceto para o arranjo $A 4$ do cruzamento $B 1 B 1(16)$ (Tabela 13). Essa exceção ocorreu, pois, ambas as SQR's diminuíram quando se aumentou o tamanho da progênie, mas, a SQR das estimativas de Bayes diminuiu mais que a SQR das estimativas de M.V..

Pode ser visto graficamente que, quando se aumentou o tamanho da progênie de 50 para 100 as estimativas M.V. e de Bayes se aproximaram umas das outras e, também, dos verdadeiros valores do parâmetro. Esse fato é ilustrado nas Figuras 18 e 19 para o cruzamento do tipo $B 1 C(15)$ sob o arranjo $A 1$. 
Tabela 12. SQR para as estimativas de máxima verossimilhança e Bayesianas da freqüência de recombinação em cruzamento do tipo $B 1 C(15)$ (isto é, cruzamentos em que um dos locos é do tipo $a b \times a o$ e o outro é do tipo $a o \times a o$ )

\begin{tabular}{ccccccc}
\hline & \multicolumn{3}{c}{ N=50 } & \multicolumn{3}{c}{$\mathrm{N}=100$} \\
Arranjo & E.M.V. & E.B. & Diferença & E.M.V. & E.B. & Diferença \\
\hline A1 & 0,2794 & 0,2332 & 0,0462 & 0,1928 & 0,0917 & 0,0110 \\
A2 & 0,2070 & 0,1713 & 0,0357 & 0,1005 & 0,0735 & 0,0270 \\
A3 & 0,5059 & 0,3092 & 0,1967 & 0,1605 & 0,1185 & 0,0420 \\
A4 & 0,6224 & 0,4220 & 0,2004 & 0,1872 & 0,1198 & 0,0674 \\
\hline
\end{tabular}

E.M.V. - Fstimativa de Máxima Verossimilhança; F.B. - Fstimativa de Bayes

Tabela 13. SQR para as estimativas de máxima verossimilhança e Bayesianas de freqüência de recombinação em cruzamento do tipo $B 1 B 1(16)$ (isto é, cruzamentos em que ambos os locos são do tipo $a b \times a o$ )

\begin{tabular}{ccccccc}
\hline & \multicolumn{3}{c}{ N=50 } & \multicolumn{3}{c}{$N=100$} \\
Arranjo & E.M.V. & E.B. & Diferença & E.M.V. & E.B. & Diferença \\
\hline A1 & 0,1210 & 0,0941 & 0,0269 & 0,0690 & 0,0601 & 0,0089 \\
A2 & 0,2668 & 0,2383 & 0,0285 & 0,2064 & 0,1895 & 0,0169 \\
A3 & 0,2488 & 0,2323 & 0,0165 & 0,0999 & 0,0949 & 0,0050 \\
A4 & 0,1633 & 0,1516 & 0,0117 & 0,0794 & 0,0597 & 0,0197 \\
\hline
\end{tabular}

E.M.V. - Estimativa de Máxima Verossimilhança; E.B. - Estimativa de Bayes 


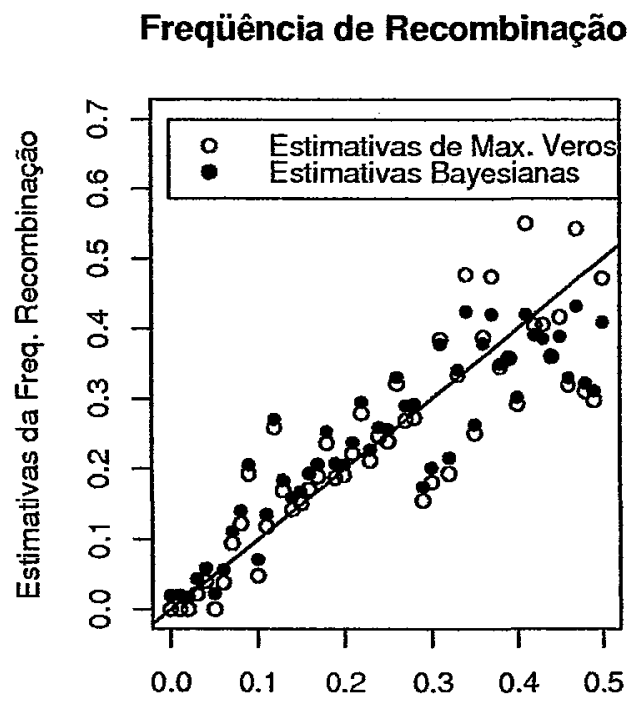

Freqũência de Recombinação

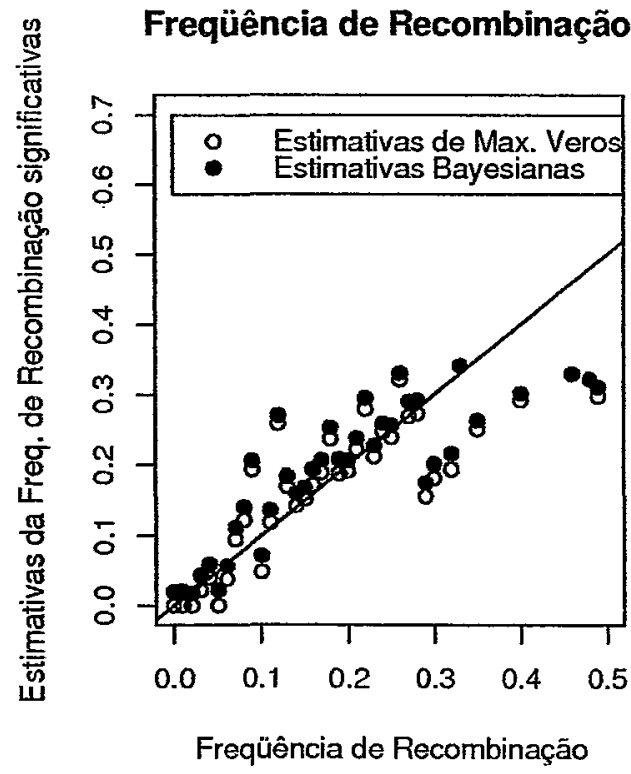

Freqüência de Recombinação

Figura 18 - Estimativas das freqüências de recombinação - cruzamento B1C(15) arranjo A1 - progênie de tamanho 50
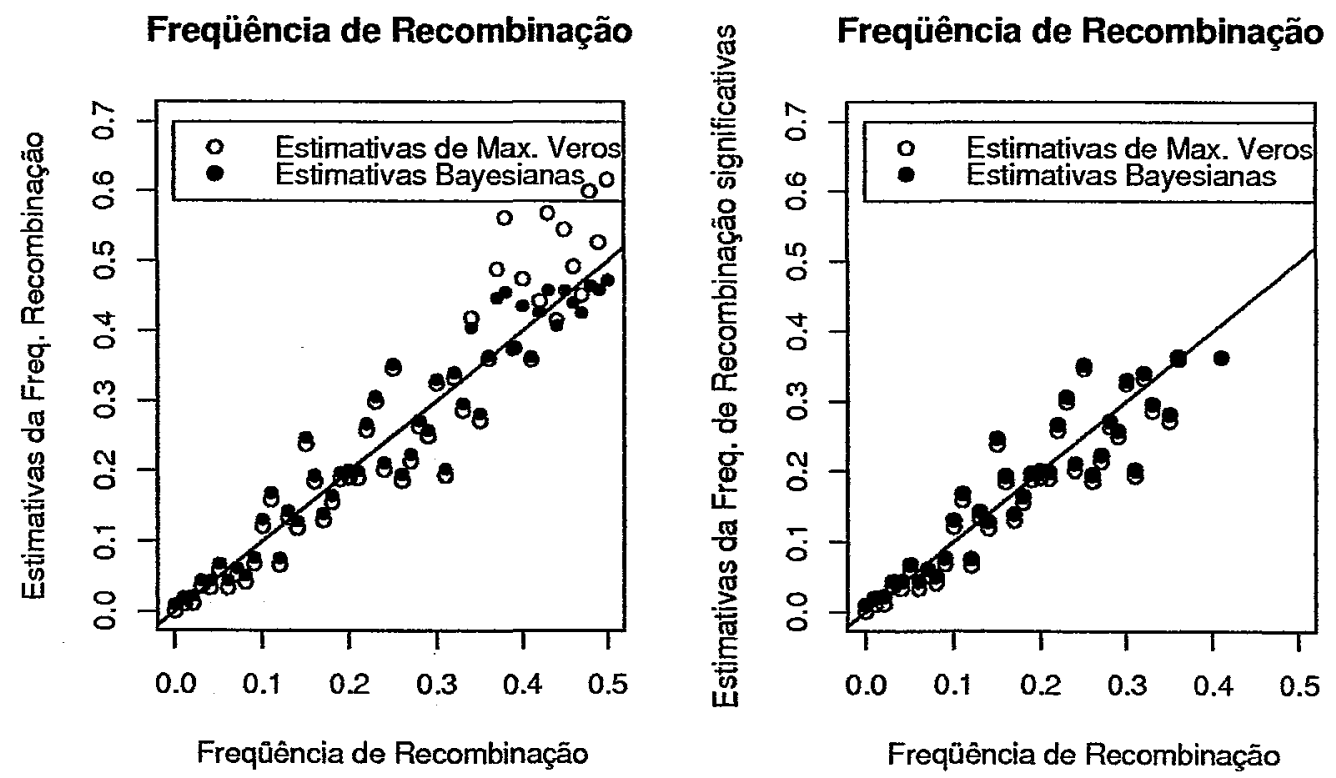

Figura 19 - Estimativas das freqüências de recombinação - cruzamento B1C(15) arranjo A1 - progênie de tamanho 100 
Os intervalos de confiança $95 \%$ e de credibilidade $95 \%$ para as estimativas de M.V. e de Bayes respectivamente são apresentados nas Figuras 20 e 21 para o cruzamento $B 1 B 1(16)$, sob o arranjo $A 1$.
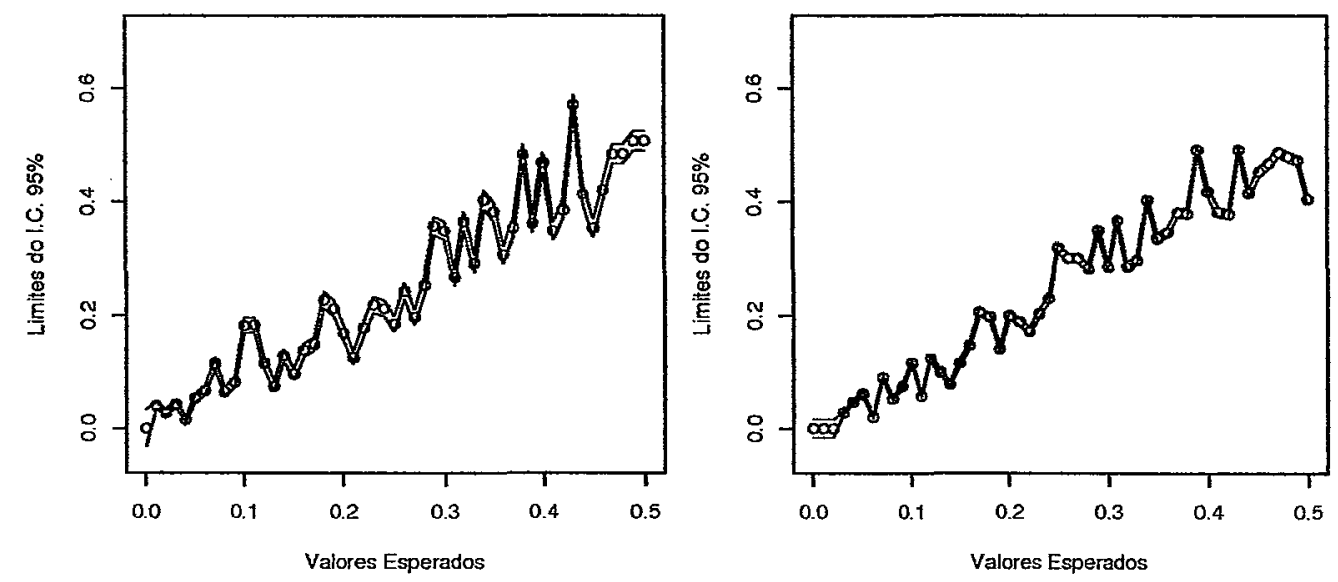

Figura 20 - Limites inferior e superior dos intervalos de confiança para as estimativas de M.V. das freqüências de recombinação - cruzamento $B 1 B 1(16)$ arranjo $A 1$ - progênie de tamanhos 50(à esquerda) e 100(à direita)
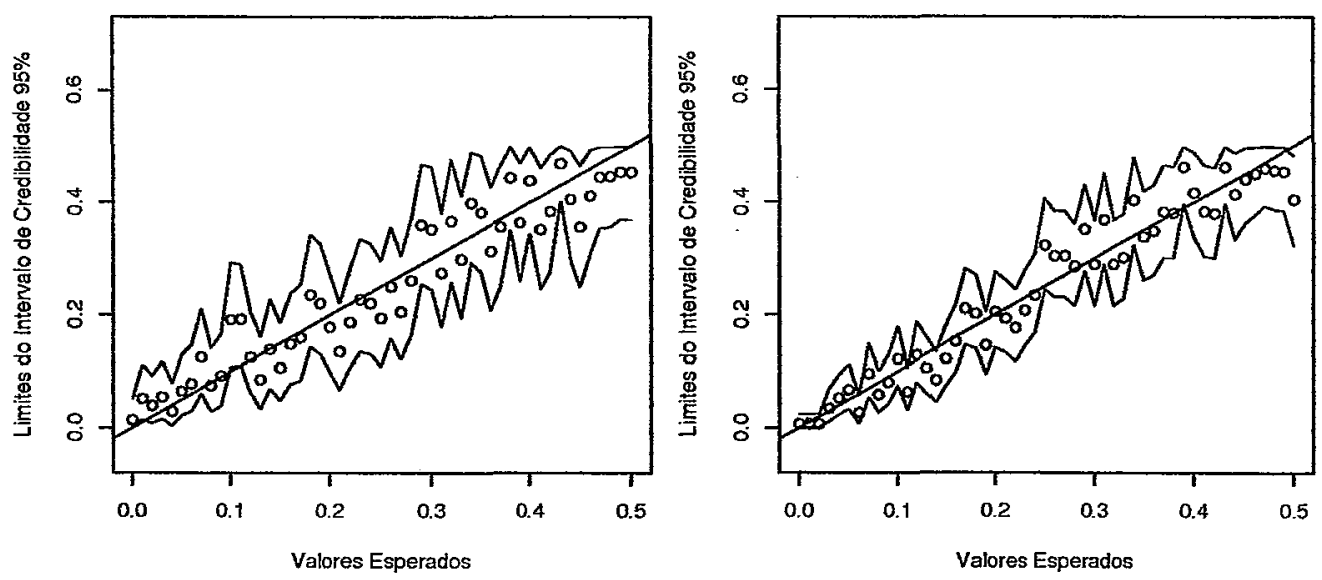

Figura 21 - Limites inferior e superior dos intervalos de credibilidade para as estimativas de Bayes das freqüências de recombinação - cruzamento $B 1 B 1(16)$ - arranjo $A 1$ - progênie de tamanhos 50(à esquerda) e 100(à direita) 
São apresentados no Anexo A9 os valores das estimativas de M.V. e de Bayes, com os respectivos valores dos limites inferior e superior dos intervalos de confiança e credibilidade, juntamente com os valores das estimativas significativas de M.V. e de Bayes. Tais valores são referentes aos dados simulados para o cruzamento $B 1 B 1(16)$ sob o arranjo $A 1$ para uma progênie de tamanho 100.

\subsection{Outros cruzamentos}

Os cruzamentos restantes: $A B 3(8)$ (um dos locos é do tipo $a b \times c d$ e o outro é do tipo $a b \times a b$ ), B1B3(10)(um dos locos é do tipo $a b \times a o$ e o outro é do tipo $a b \times a b), A A(11)$ (ambos os locos são do tipo $a b \times c d$ ),$A C(12)$ (um dos locos é do tipo $a b \times c d$ e o outro é do tipo $a o \times a o), A B 1(13)($ um dos locos é do tipo $a b \times c d$ e o outro é do tipo $a b \times a o$ ) e $B 1 B 2(17)$ (um dos locos é do tipo $a b \times a o$ e o outro é do tipo $a o \times a b$ ) segundo Maliepaard et al. (1997), fornecem informação suficiente para estimar a fase de ligação. Para os estimadores de máxima verossimilhança, sempre $\hat{r}_{A 1}=1-\hat{r}_{A 4} \mathrm{e} \hat{r}_{A 2}=1-\hat{r}_{A 3}$, conduzindo a duas estimativas admissíveis. A estimativa com a fase correta praticamente sempre tem o mesmo valor e um LOD Score grande, considerando que as outras estimativas são ou próximas de $0,5(A B 3(8), A A(11)$, $A C(12), B 1 B 2(17))$ ou entre a menor estimativa e $0,5(B 1 B 3(10)$ e $A B 1(13))$.

Nas simulações sob o arranjo $A 1$ e $A 4$, as freqüências de recombinação estimadas, pelo método da M.V. através do algoritmo EM, para os arranjos $A 2 \mathrm{e}$ A3 estão em torno de 0,5 , as estimativas sob o arranjo para o qual os dados foram simulados são valores admissíveis ( $A 1$ ou $A 4$ ), e as estimativas sob o arranjo restante (A1 ou A4) são valores maiores que 0,5 . Quando as simulações são feitas sob os arranjos $A 2$ e $A 3$, obtém-se as estimativas sob $A 1$ e $A 4$ em torno de 0,5 , estimativas admissíveis sob o arranjo para o qual os dados foram simulados, e valores maiores que 0,5 para as estimativas sob o arranjo restante. A determinação do arranjo é feita pela maior probabilidade a posteriori entre os arranjos e pelas estimativas admissíveis das freqüências de recombinação. Assim, o arranjo com maior probabilidade a posteriori e para o qual as estimativas das freqüências de recombinação são valores entre $0 \mathrm{e}$ 
0,5 é o arranjo indicado.

Quanto às estimativas Bayesianas da freqüência de recombinação, sempre as estimativas sob o arranjo para o qual os dados foram simulados são valores admissíveis, enquanto que as estimativas sob os demais arranjos são valores próximos de 0,5. E mais, as probabilidades a posteriori dos arranjos para os quais os dados foram simulados sempre são as maiores. Logo, o arranjo é determinado somente pela probabilidade a posteriori.

Não foi possível implementar o algoritmo EM para o cruzamento $A A(11)$, logo, não foram obtidas estimativas de M.V. para esse caso. $\mathrm{O}$ que foi afirmado aqui referente as estimativas de Bayes é válido, também, para o cruzamento $A A(11)$. No entanto, no que se refere às estimativas de M.V. não se pode afirmar com certeza que é válido para esse caso, mas, segundo Maliepaard et al. (1997) é sempre possível determinar o arranjo para esse tipo de cruzamento quando se estima a freqüência de recombinação por máxima verossimilhança. Além disso, esse é o caso mais informativo, pois, ambos os locos segregam na proporção (1:1:1:1) (Wu, et al., 2002).

Para os cruzamentos $A B 3(8), B 1 B 3(10), A C(12), A B 1(13)$, sempre que aumentou-se o tamanho da progênie de 50 para 100 as SQR's das estimativas de M.V. e de Bayes diminuíram (Tabelas 14, 15, 16 e 17). No cruzamento $B 1 B 2(17)$, somente para o arranjo $A 3$, quando aumentou-se o tamanho da progênie de 50 para 100 as SQR's das estimativas de M.V. também aumentaram (Tabela 18).

As SQR's das estimativas de Bayes são menores que as SQR's das estimativas de M.V., tanto para tamanhos de progênie iguais a 50, quanto para tamanhos iguais a 100. Houve apenas duas exceções, uma no caso do cruzamento do tipo $A B 3(8)$, em que a SQR das estimativas de Bayes é maior que a SQR das estimativas de M.V., para uma progênie de tamanho 50 sob o arranjo $A 3$; outra para o cruzamento $A B 1(13)$, em que, sob os arranjos $A 1$ e $A 2$ (progênie de tamanho 100), a SQR das estimativas de Bayes também é maior que a SQR das estimativas de M.V. (Tabelas 14 e 17). 
As diferenças entre as SQR's das estimativas de M.V. e as SQR's das estimativas de Bayes diminuíram quando o tamanho amostral aumentou de 50 para 100 , para os cruzamentos $B 1 B 3(10), A C(12)$ e $A B 1(13)$ (Tabelas 15,16 e 17). No caso dos arranjos $A 1$ e $A 2$ do cruzamento $A B 1(13)$, essas diferenças são negativas para uma progênie de tamanho 100 (Tabela 17). Isso ocorreu, pois, subtraíu-se a SQR das estimativas de Bayes da SQR das estimativas de M.V., sendo que a SQR das estimativas de Bayes era maior que a SQR das estimativas de M.V., mas tomando os valores absolutos das diferenças para esses dois arranjos, nota-se que os valores absolutos das diferenças também diminuíram quando se aumentou o tamanho da progênie.

Para o arranjo $A 1$ do cruzamento $A B 3(8)$ a diferença entre a SQR das estimativas de M.V. e SQR das estimativas de Bayes aumentou quando se aumentou o tamanho da progênie de 50 para 100 (Tabela 14). Isso ocorreu, pois, quando se aumentou o tamanho da progênie a SQR das estimativas de Bayes teve uma redução maior que a SQR das estimativas de M.V., tornando a diferença maior quando o tamanho da progênie era 100. Também, para o arranjo $A 3$ do cruzamento $B 1 B 2(17)$, a diferença aumentou quando o tamanho da progênie era 100. Nesse caso isso pode ser devido aos dados simulados.

Tabela 14. SQR para as estimativas de máxima verossimilhança e Bayesianas da frequiência de recombinação em cruzamento do tipo $A B 3(8)$ (isto é, cruzamento em que um dos locos é do tipo $a b \times c d$ e o outro é do tipo $a b \times a b$ )

\begin{tabular}{ccccccc}
\hline & \multicolumn{3}{c}{$\mathrm{N}=50$} & \multicolumn{3}{c}{$\mathrm{N}=100$} \\
Arranjo & E.M.V. & E.B. & Diferença & E.M.V. & E.B. & Diferença \\
\hline A1 & 0,1226 & 0,1224 & 0,0002 & 0,0440 & 0,0323 & 0,0117 \\
A2 & 0,2166 & 0,1125 & 0,1041 & 0,0843 & 0,0647 & 0,0196 \\
A3 & 0,1000 & 0,1072 & $-0,0072$ & 0,0705 & 0,0699 & 0,0006 \\
A4 & 0,1564 & 0,1423 & 0,0141 & 0,0787 & 0,0684 & 0,0103 \\
\hline
\end{tabular}

E.M.V. - Estimativa de Máxima Verossimilhança; E.B. - Estimativa de Bayes 
Tabela 15. SQR para as estimativas de máxima verossimilhança e Bayesianas da freqüência de recombinação em cruzamento do tipo $B 1 B 3(10)$ (isto é, cruzamento em que um dos lcos é do tipo $a b \times a o$ e o outro é do tipo $a b \times a b$ )

\begin{tabular}{ccccccc}
\hline & \multicolumn{3}{c}{$\mathrm{N}=50$} & & \multicolumn{3}{c}{$\mathrm{N}=100$} \\
Arranjo & E.M.V. & E.B. & Diferença & E.M.V. & E.B. & Diferença \\
\hline A1 & 0,2040 & 0,1408 & 0,0632 & 0,1212 & 0,1026 & 0,0186 \\
A2 & 0,1942 & 0,1516 & 0,0426 & 0,0862 & 0,0747 & 0,0115 \\
A3 & 0,1471 & 0,1014 & $-0,0457$ & 0,1268 & 0,0873 & 0,0395 \\
A4 & 0,2461 & 0,1796 & 0,0665 & 0,1126 & 0,0871 & 0,0255 \\
\hline
\end{tabular}

E.M.V. - Estimativa de Máxima Verossimilhança; E.B. - Estimativa de Bayes

Tabela 16. SQR para as estimativas de máxima verossimilhança e Bayesianas de freqüência de recombinação em cruzamento do tipo $A C(12)$ (isto é, cruzamento em que um dos locos é do tipo $a b \times c d$ e o outro é do tipo $a o \times a o$ )

\begin{tabular}{ccccccc}
\hline & \multicolumn{3}{c}{ N=50 } & \multicolumn{3}{c}{$\mathrm{N}=100$} \\
Arranjo & E.M.V. & E.B. & Diferença & E.M.V. & E.B. & Diferença \\
\hline A1 & 0,1900 & 0,1642 & 0,0258 & 0,1259 & 0,1099 & 0,0160 \\
A2 & 0,3955 & 0,2362 & 0,1593 & 0,1382 & 0,1153 & 0,0229 \\
A3 & 0,2227 & 0,1155 & 0,1072 & 0,1129 & 0,1081 & 0,0048 \\
A4 & 0,2026 & 0,1411 & 0,0615 & 0,0890 & 0,0762 & 0,0128 \\
\hline
\end{tabular}

E.M.V. - Estimativa de Máxima Verossimilhança; E.B. - Estimativa de Bayes 
Tabela 17: SQR para as estimativas de máxima verossimilhança e Bayesianas de freqüência de recombinação em cruzamento do tipo $A B 1(13)$ (isto é, cruzamento em que um dos locos é do tipo $a b \times c d$ e o outro é do tipo $a b \times a o$ )

\begin{tabular}{ccccccc}
\hline & \multicolumn{3}{c}{ N=50 } & \multicolumn{3}{c}{$\mathrm{N}=100$} \\
Arranjo & E.M.V. & E.B. & Diferença & E.M.V. & E.B. & Diferença \\
\hline A1 & 0,0925 & 0,0892 & 0,0033 & 0,0397 & 0,0428 & $-0,0031$ \\
A2 & 0,0917 & 0,0851 & 0,0066 & 0,0385 & 0,0433 & $-0,0048$ \\
A3 & 0,1058 & 0,0972 & 0,0086 & 0,0430 & 0,0352 & 0,0078 \\
A4 & 0,1109 & 0,1032 & 0,0077 & 0,0443 & 0,0435 & 0,0008 \\
\hline
\end{tabular}

E.M.V. - Estimativa de Máxima Verossimilhança; E.B. - Estimativa de Bayes

Tabela 18. SQR para as estimativas de máxima verossimilhança e Bayesianas de freqüência de recombinação em cruzamento do tipo $B 1 B 2(17)$ (isto é, cruzamento em que um dos locos é do tipo $a b \times a o$ e o outro é do tipo $a o \times a b$ )

\begin{tabular}{ccccccc}
\hline & \multicolumn{3}{c}{$\mathrm{N}=50$} & & \multicolumn{3}{c}{$\mathrm{N}=100$} \\
Arranjo & E.M.V. & E.B. & Diferença & E.M.V. & E.B. & Diferença \\
\hline A1 & 0,1939 & 0,1548 & 0,0391 & 0,0723 & 0,0628 & 0,0095 \\
A2 & 0,1427 & 0,1223 & 0,0204 & 0,0616 & 0,0608 & 0,0008 \\
A3 & 0,1650 & 0,1553 & 0,0097 & 0,2415 & 0,2151 & 0,0264 \\
A4 & 0,1674 & 0,1414 & 0,0260 & 0,0844 & 0,0638 & 0,0206 \\
\hline
\end{tabular}

E.M.V. - Estimativa de Máxima Verossimilhança; E.B. - Estimativa de Bayes 
Freqüência de Recombinação

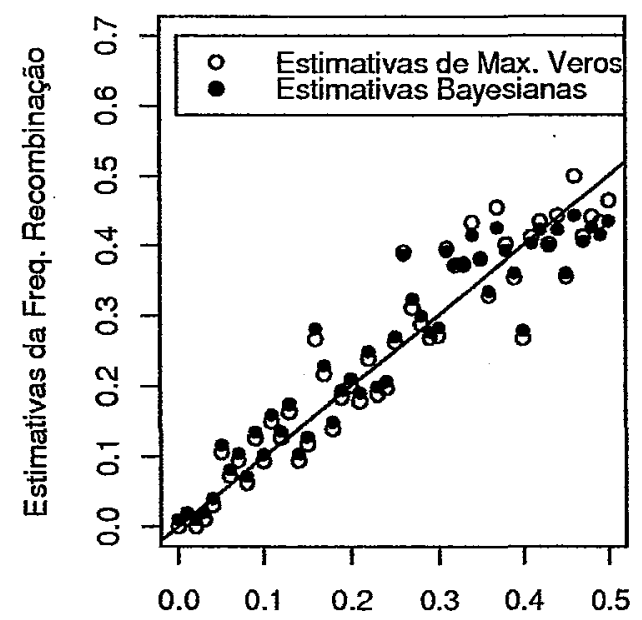

Freqũência de Recombinação

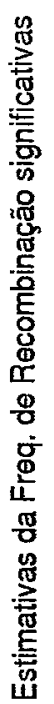

Freqüência de Recombinação

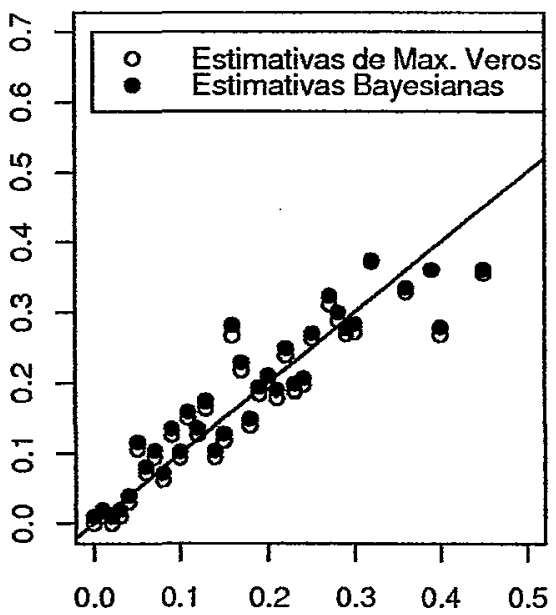

Freqüência de Recombinaçāo

Figura 22 - Estimativas das freqüûncias de recombinação - cruzamento AB3(8) - arranjo A1 - progênie de tamanho 50

Freqüência de Recombinação

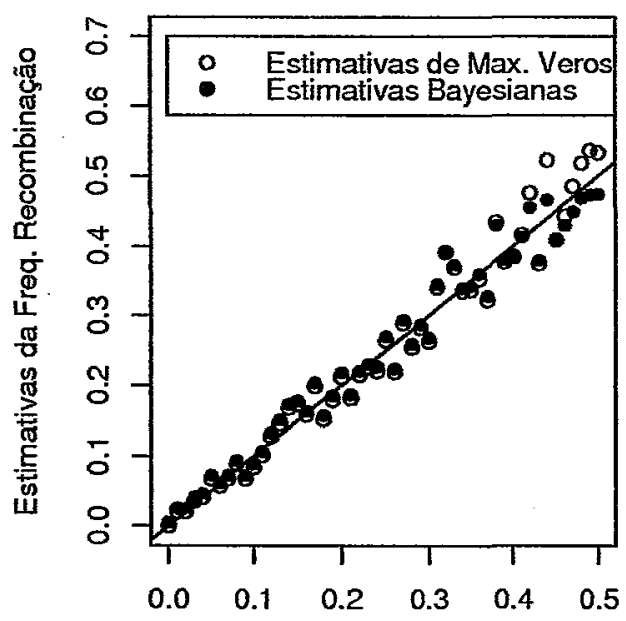

Freqüência de Recombinação

\section{Freqüência de Recombinação}

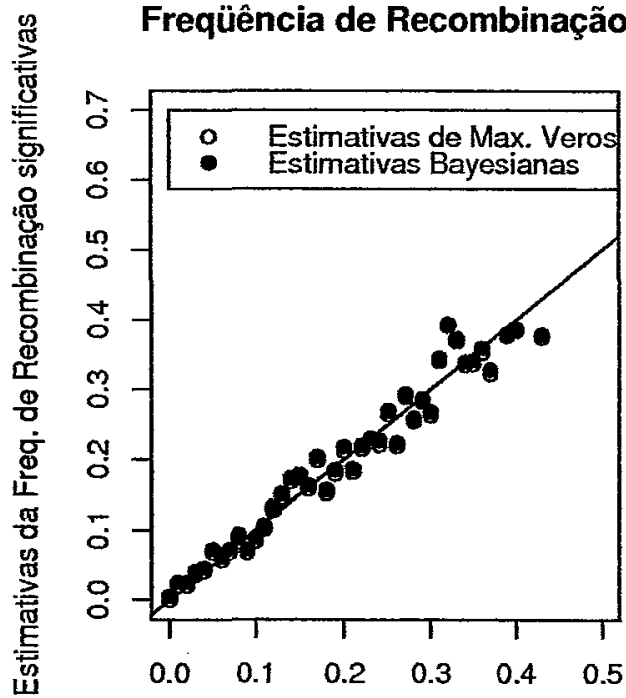

Freqüência de Recombinação

Figura 23 - Estimativas das freqüências de recombinação - cruzamento AB3(8) - arranjo A1 - progênie de tamanho 100 
maram umas das outras, e também dos verdadeiros valores de $r$, quando o tamanho da progênie aumentou de 50 para 100. As Figuras 22 e 23 mostram esses fatos no caso do cruzamento $A B 3(8)$, sob o arranjo $A 1$.

Os intervalos de confiança aproximados $95 \%$ e de credibilidade $95 \%$ foram calculados para cada um dos cruzamentos abordados aqui, sob cada um dos quatro arranjos. Nas Figuras 24 e 25 são apresentados os gráficos das estimativas de M.V. e de Bayes com os limites inferior e superior dos respectivos intervalos de confiança $95 \%$ e de credibilidade $95 \%$ para o cruzamento do tipo $A B 3(8)$, sob o arranjo $A 1$. Os valores de tais estimativas, juntamente com os valores dos limites inferiores e superiores de tais intervalos podem ser visto no Anexo A10.
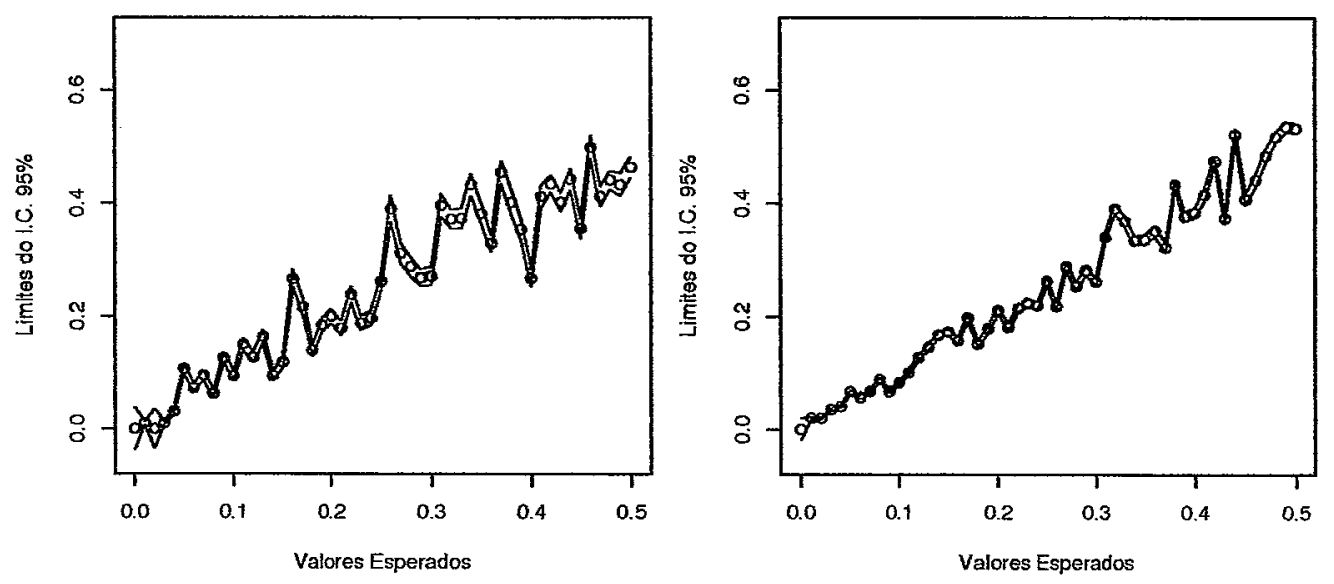

Figura 24 - Limires inferior e superior dos intervalos de confiança para as estimativas de M.V. das freqüências de recombinação - cruzamento $A B 3(8)$ - arranjo $A 1$ - progênie de tamanhos 50(à esquerda) e 100(à direita) 

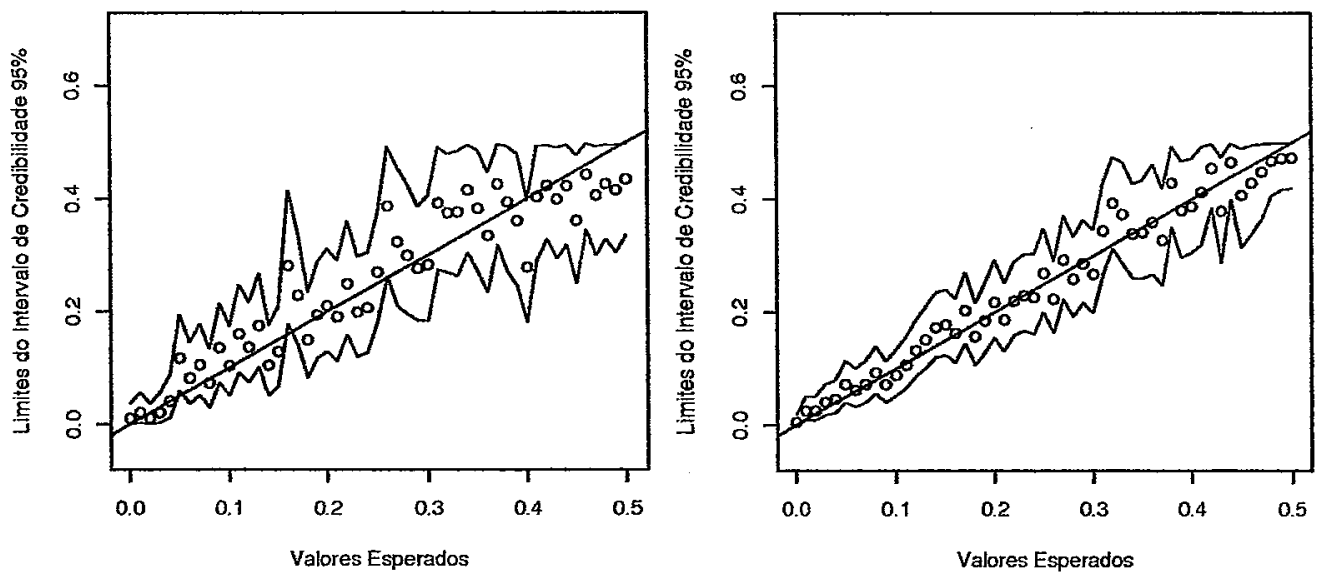

Figura 25 - Limites inferior e superior dos intervalos de credibilidade para as estimativas de Bayes das freqüências de recombinação - cruzamento $A B 3(8)$ arranjo $A 1$ - progênie de tamanhos 50(à esquerda) e 100(à direita)

\subsection{Considerações Gerais}

Na Figura 26 é apresentado o gráfico da SQR de todos os cruzamentos, para os quatro arranjos, a fim de se fazer uma comparação entre os tipos de cruzamentos e arranjos quanto a SQR das estimativas de Bayes e de M.V..

Deve ser observado com relação a Figura 26 que arranjos equivalentes e/ou cruzamentos equivalentes apresentam SQR diferentes, pois, diferentes conjuntos de dados foram simulados para cada cruzamento e cada arranjo. Por exemplo, nos cruzamentos de números 1 a 6 , os arranjos $A 1$ e $A 3$ são equivalentes aos arranjos $A 3$ e $A 4$ respectivamente, no entanto apresentaram SQR diferentes. Pode-se observar na Figura 26 que os tipos de cruzamentos menos informativos na análise de ligação, apresentam maiores SQR.

Os intervalos de confiança e de credibilidade apresentados, têm interpretações diferentes. Assim, não se pode concluir, por exemplo, que uma estimativa de M.V. é mais precisa do que uma estimativa de Bayes, porque o intervalo de confiança de uma é menor que o intervalo de credibilidade da outra e vice-versa.

Observou-se que os intervalos de confiança e de credibilidade, para 

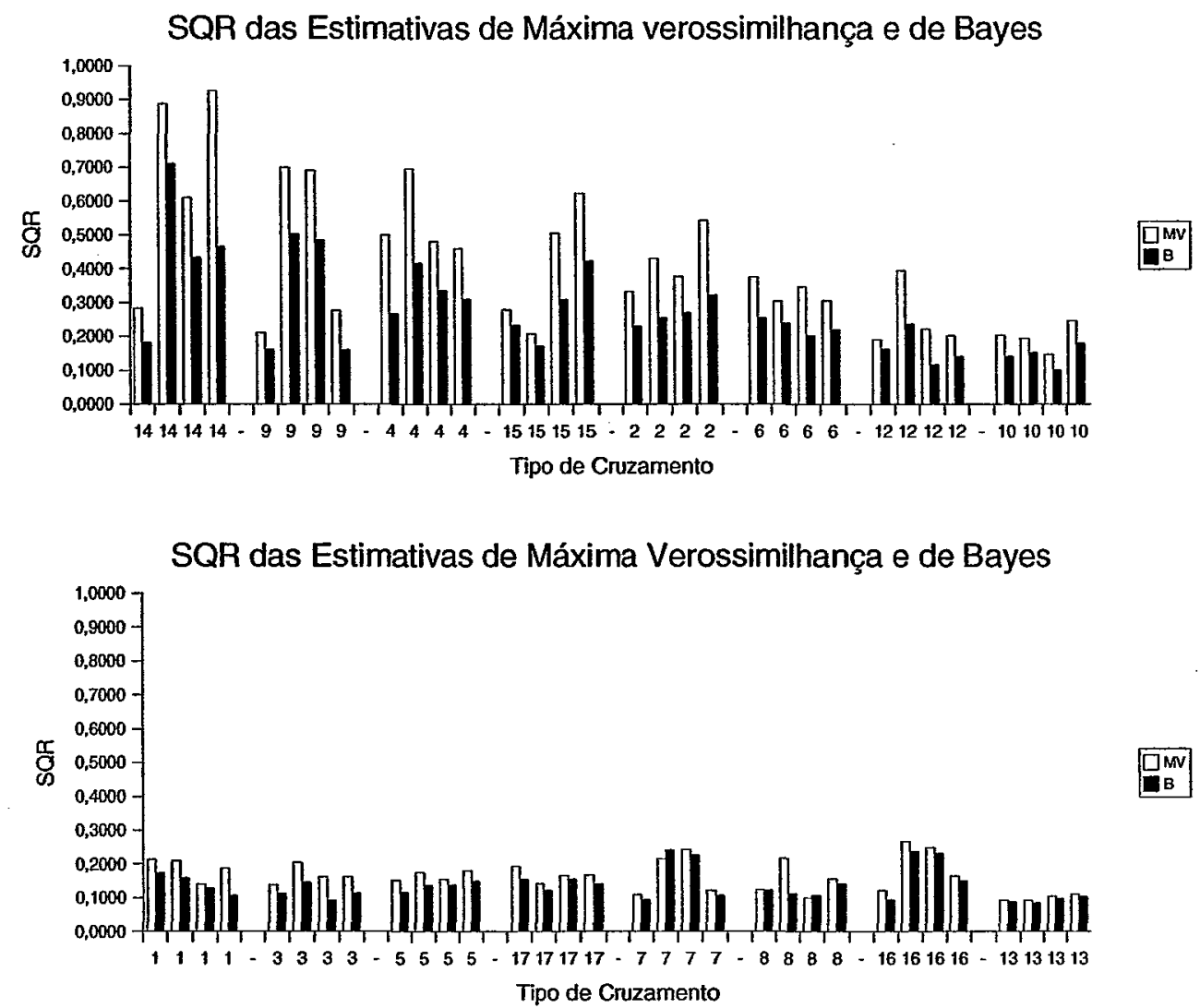

Figura 26 - SQR das estimativas das freqüências de recombinação das estimativas de Bayes e de máxima verossimilhança para progênies de tamanho 50. Os números sob o gráfico indicam o tipo de cruzamento e as quatro barras com números repetidos são os arranjos $A 1, A 2, A 3$, e $A 4$ nessa ordem

as estimativas de M.V. e de Bayes respectivamente, obtidos para uma progênie de tamanho 100, são sempre menores do que aqueles obtidos para uma progênie de tamanho 50, como esperado teoricamente.

Em geral, as SQR's das estimativas de M.V. e de Bayes obtidas de progênies de tamanho 100, são menores que as SQR's das estimativas obtidas de progênies de tamanho 50 .

Aumentando o tamanho da progênie de 50 para 100, as estimativas de 
M.V. e de Bayes, ficam mais precisas, ou seja, os valores estimados tornam-se mais próximos dos verdadeiros valores do parâmetro $r$; também, os comportamentos das estimativas obtidas pelos dois métodos ficam mais parecidos.

Em geral, as estimativas de Bayes apresentam SQR menor que as estimativas de M.V., indicando que as estimativas de Bayes têm menor variabilidade em relação aos valores verdadeiros da freqüência de recombinação que as estimativas de M.V..

O fato de estimar a freqüência de recombinação pelo método da M.V. ou pelo método Bayesiano, não influência na determinação do arranjo. A diferença entre os dois modos de se determinar o arranjo entre os alelos em dois locos é que, estimando a freqüência de recombinação pela M.V., o arranjo é determinado do seguinte modo: entre os arranjos para os quais as estimativas da freqüência de recombinação são admissíveis, aceita-se o que tem maior probabilidade a posteriori. Quando se estima a freqüência de recombinação pelo método Bayesiano, apenas a maior probabilidade a posteriori é suficiente para se determinar o arranjo. Além disso, esse segundo modo de abordar o problema é um método puramente Bayesiano, não fazendo uso da verossimilhança e da probabilidade a posteriori, como apresentado por Wu et al. (2002).

Como foi utilizada uma distribuição de probabilidade uniforme para a freqüência de recombinação (valores de $r$ igualmente prováveis) era esperado resultados semelhantes para os métodos Bayesiano e da máxima verossimilhança. Porém, o segundo têm diferenças conceituais, por exemplo, apresenta menor variabilidade nas estimativas, além de permitir a inclusão de informação a priori que pode ser interessante para o pesquisador. Cada vez mais os geneticistas têm informações sobre o genoma que poderiam ser incorporadas nos mapas, noentanto isso não tem sido feito diretamente usando a abordagem Bayesiana.

Considerando tudo o que foi discutido, nota-se que a metodologia Bayesiana para a análise de ligação, apresenta bons resultados, podendo ser recomendada para uso em situações práticas. 


\section{CONCLUSÕES}

Baseando-se nos resultados obtidos, é possível concluir que a abordagem bayesiana pode ser usada em situações práticas, pois:

i) a medida em que o tamanho da progênie aumenta, o comportamento das estimativas obtidas pelos métodos da máxima verossimilhança e de Bayes tornamse mais parecidos;

ii) a estimação do arranjo entre os alelos, não é afetada quando se usa um ou outro método de estimação para a freqüência de recombinação;

iii) a estimativas das freqüências de recombinação obtidas pelo método Bayesiano com o uso da priori uniforme, em geral, apresentam menor SQR que as estimativas de máxima veossimilhança, principalmente para progênies de tamanhos pequenos. 
Anexos 
A1 - Programa Maple para a obtenção das funções de verossimilhança

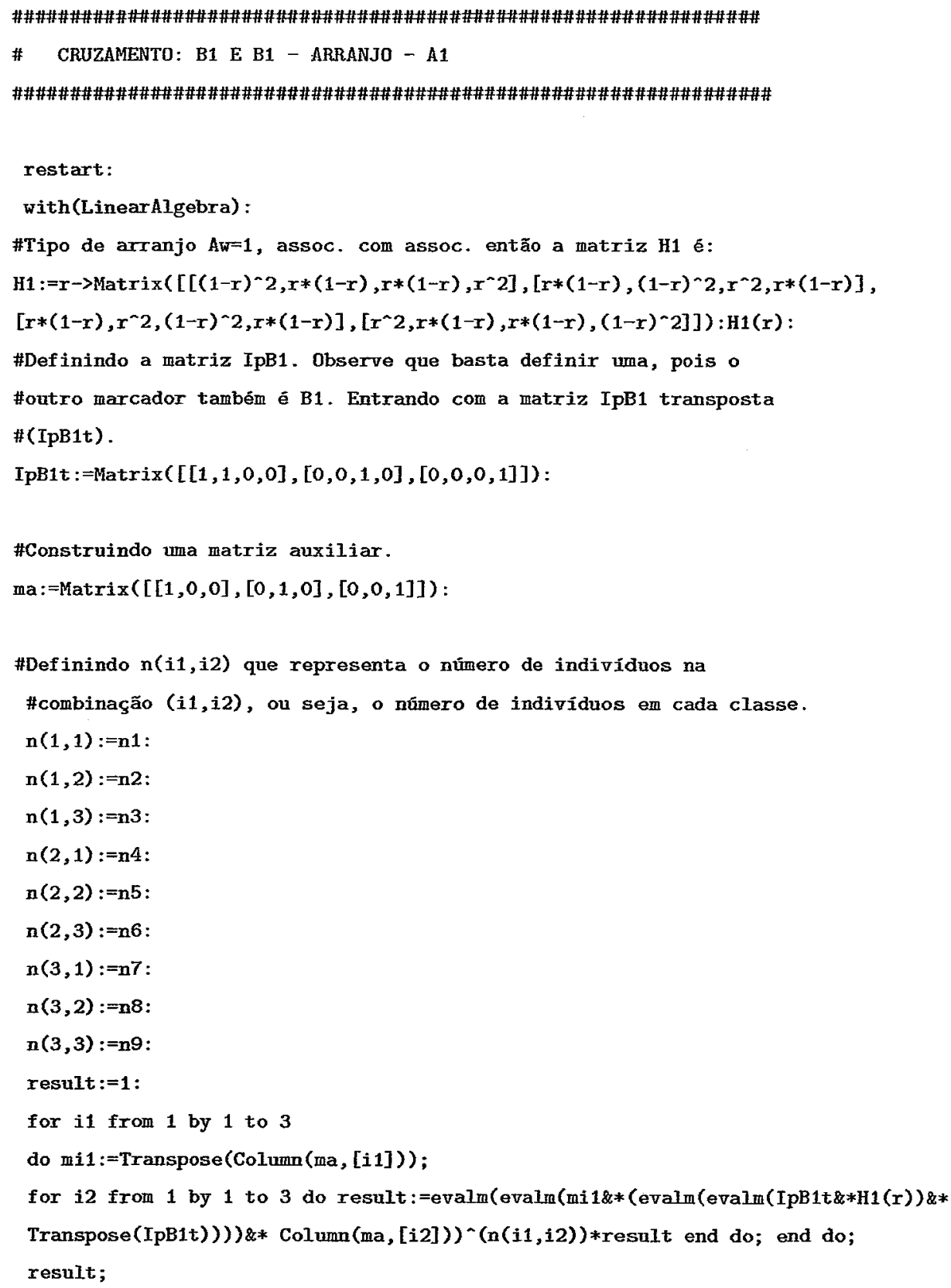

Observação: É fácil expandir o programa para os outros tipos de cruzamentos. 
A2 - Programa R para simulação do conjunto de dados

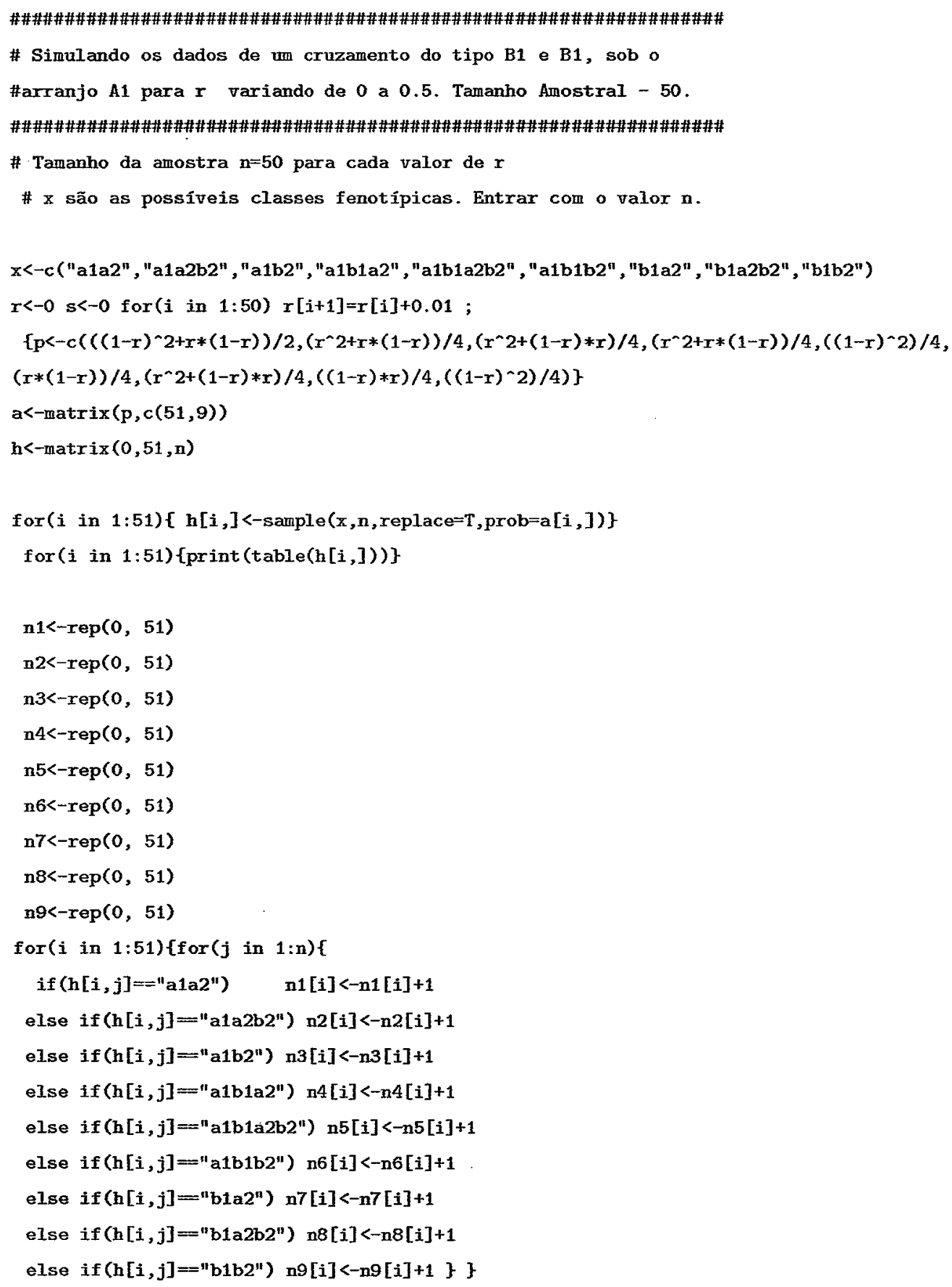


A3 - Programa R para estimação e teste de hipóteses

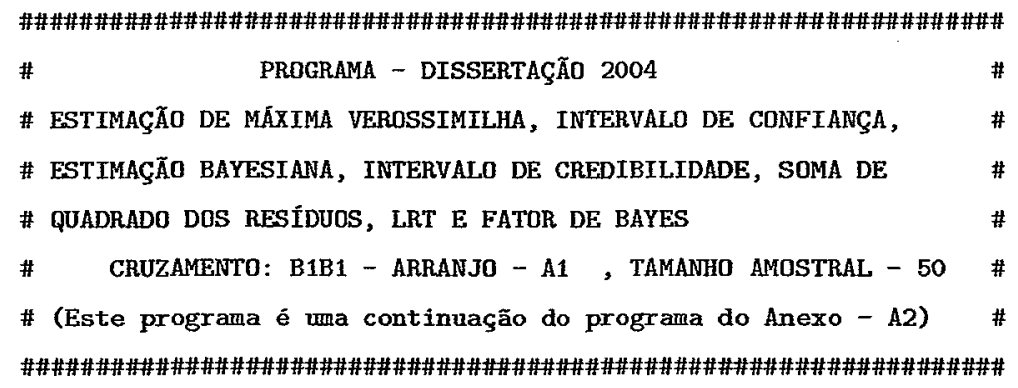




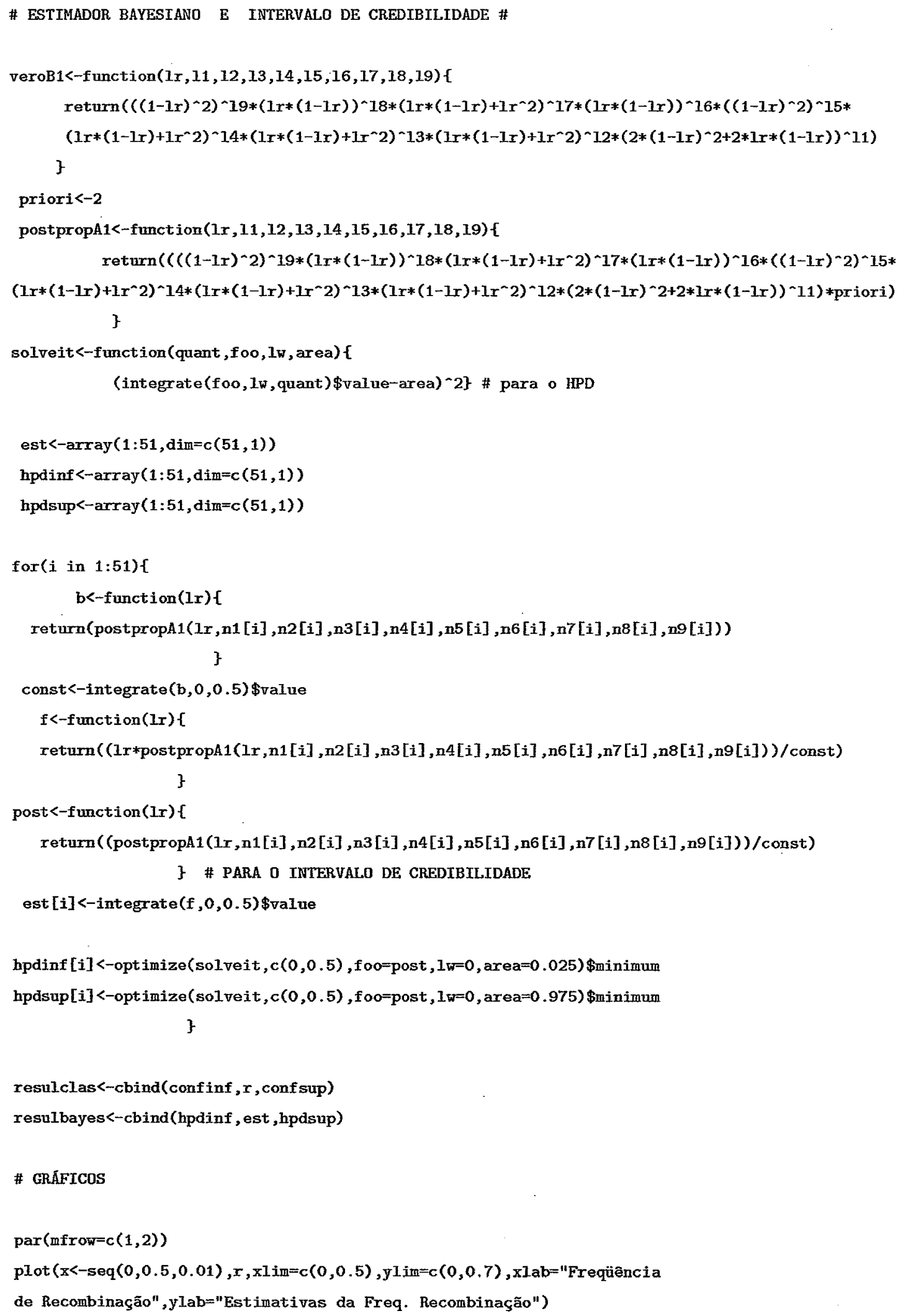


points ( $x$, est, col=2) title("Freqüência de Recombinação")

legend(0,0.7,1egend=c ("Estimativas de Max. Veros. ", "Estimativas

Bayesianas"), $\mathrm{pch}=1, \operatorname{col}=\mathrm{c}(1,2), \mathrm{pt}=1)$

\# SOMA dos quadrados dos RESÍduOS

sqev<-0 sqeb<-0 for $(i$ in $1: 51)$ \{ sqev<-(abs $(r[i]-x[i]))^{-2}+$ sqev

sqeb $\left.<-(\text { abs }(\text { est }[i]-x[i]))^{\sim 2+s q e b ~}\right\}$

sqev \# Soma dos quadrados dos residuos para o estimador de máxima verossimilhança

sqeb \# Soma dos quadrados dos residuos para o estimador de Bayes

\# LRT (Teste da Razão de Verossimilhanças)\#

$\operatorname{lrt}<-r e p(0,51)$

for $(i$ in 1:51) \{

$\operatorname{lrt}[i]<-(-2 * \log ((\operatorname{veroB} 1(0.5, \mathrm{n} 1[i], \mathrm{n} 2[\mathrm{i}], \mathrm{n} 3[\mathrm{i}], \mathrm{n} 4[\mathrm{i}], \mathrm{n} 5[\mathrm{i}], \mathrm{n} 6[\mathrm{i}], \mathrm{n} 7[\mathrm{i}], \mathrm{n} 8[\mathrm{i}], \mathrm{n} 9[\mathrm{i}])) /$

$(v e r \circ B 1(x[i], n 1[i], n 2[i], n 3[i], n 4[i], n 5[i], n 6[i], n 7[i], n 8[i], n 9[i])))$ )

if (Irt $[i]>3.841) \quad r[i]<-r[i]$ else $r[i]<-N A\}$

\#Fator de Bayes

pri<-function(1r) $\{2 * 1 r / 1 r\}$

pio<-(integrate(pri,0.45,0.5)\$value) \#prob. a priori da regiăo Ho

pi1<-(integrate(pri,0,0.45)\$value) \#prob. a priori da regiāo H1

roo<-function(1r) \{pri/pio\} ro $1<-$ function(lr) $\{\mathrm{pr} i / \mathrm{p} i 1\}$

fatbayes<-array $(1: 51, \operatorname{dim}=c(51,1))$

for $(i$ in $1: 51)$ r

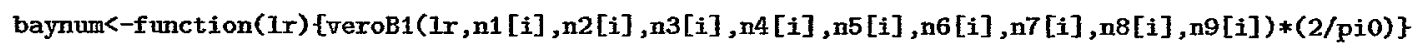

bayden<-function(1r) $[\operatorname{veroB1}(1 \mathrm{r}, \mathrm{n} 1[i], \mathrm{n} 2[\mathrm{i}], \mathrm{n} 3[\mathrm{i}], \mathrm{n} 4[\mathrm{i}], \mathrm{n} 5[\mathrm{i}], \mathrm{n} 6[\mathrm{i}], \mathrm{n} 7[\mathrm{i}], \mathrm{n} 8[\mathrm{i}], \mathrm{n} 9[\mathrm{i}]) *(2 / \mathrm{pi1})\}$

fatbayes $[i]<-($ integrate (baynum, 0.45,0.5)\$value)/(integrate(bayden, $0,0.45)$ \$value)

if (fatbayes $[i]<1$ ) est $[i]<-e s t[i]$ else est $[i]<-N A\}$

\# GRĀFICOS

$\operatorname{plot}(x<-\operatorname{seq}(0,0.5,0.01), x, x \lim =c(0,0.5), y l i m=c(0,0.7), x l a b=" F r e q u ̈ i e n c i a$

de Recombinação",ylab="Estimativas da Freq. de Recombinação

significativas") points $(x$, est, $\operatorname{col}=2)$

Iegend (0,0.7,Iegend=c("Estimativas de Max. Veros.", "Estimativas Bayesianas"),

pch=1, $\operatorname{col}=c(1,2), p t=1)$ title ("Freqüência de Recombinação") 
A4 - Programa R para a determinação da fase de ligação

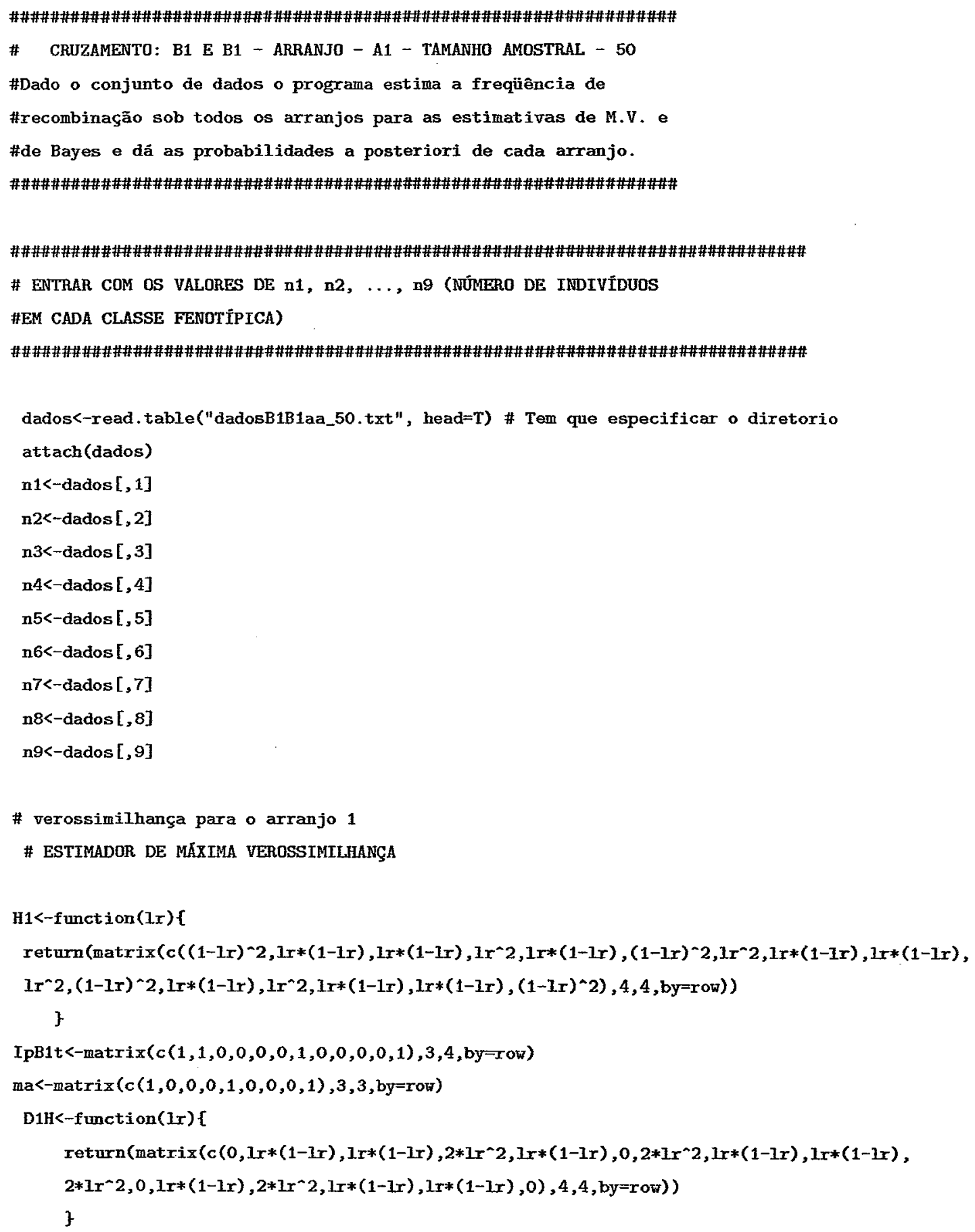




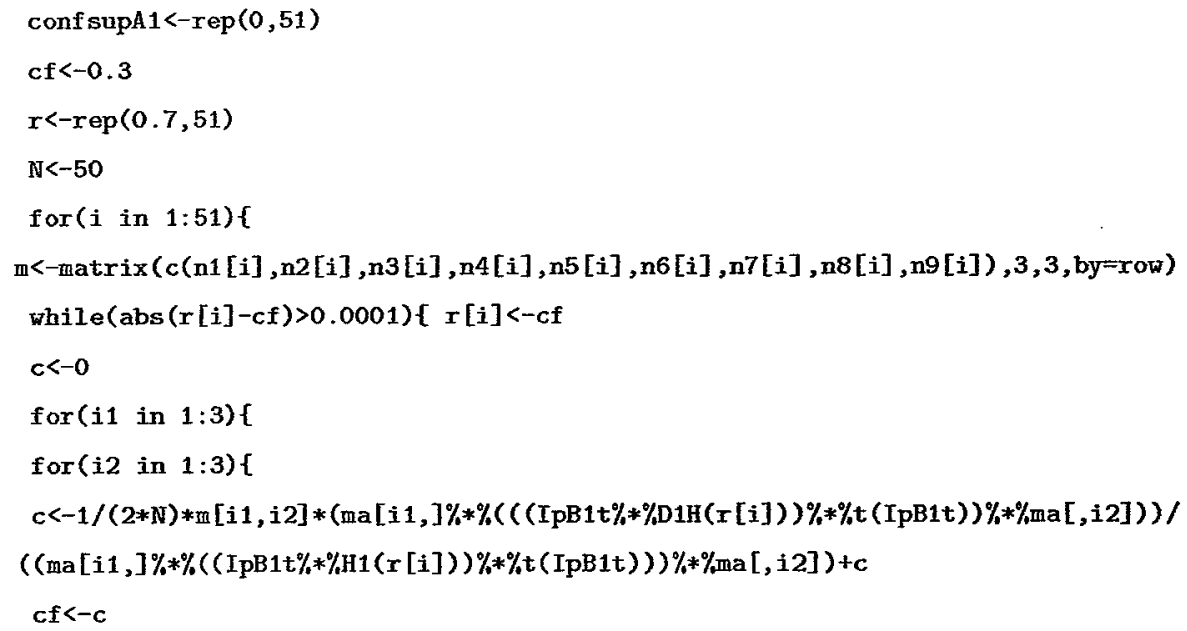




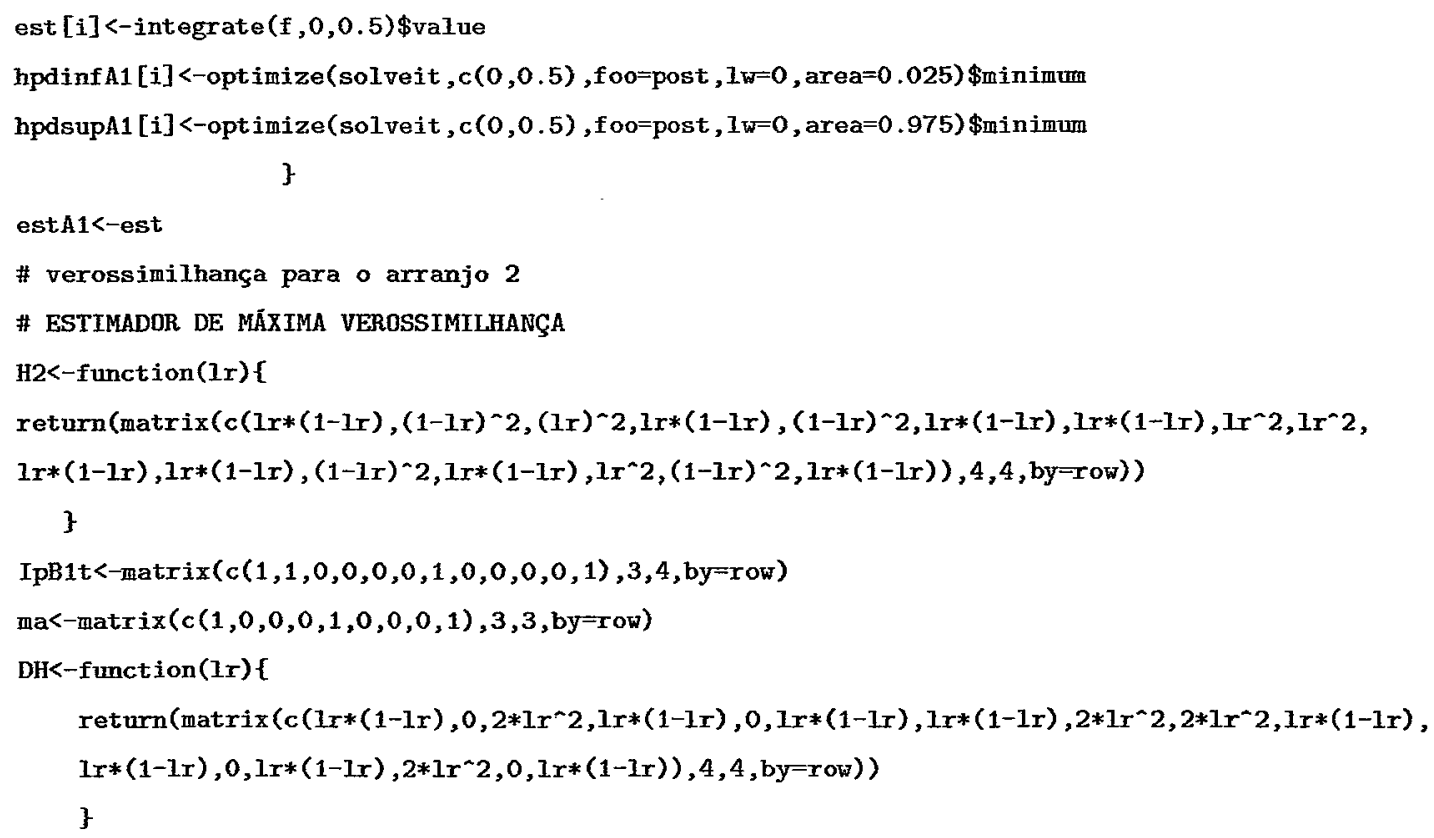


(integrate(foo, lw, quant)\$value-area)^2\} \# para o intervalo de credibilidade

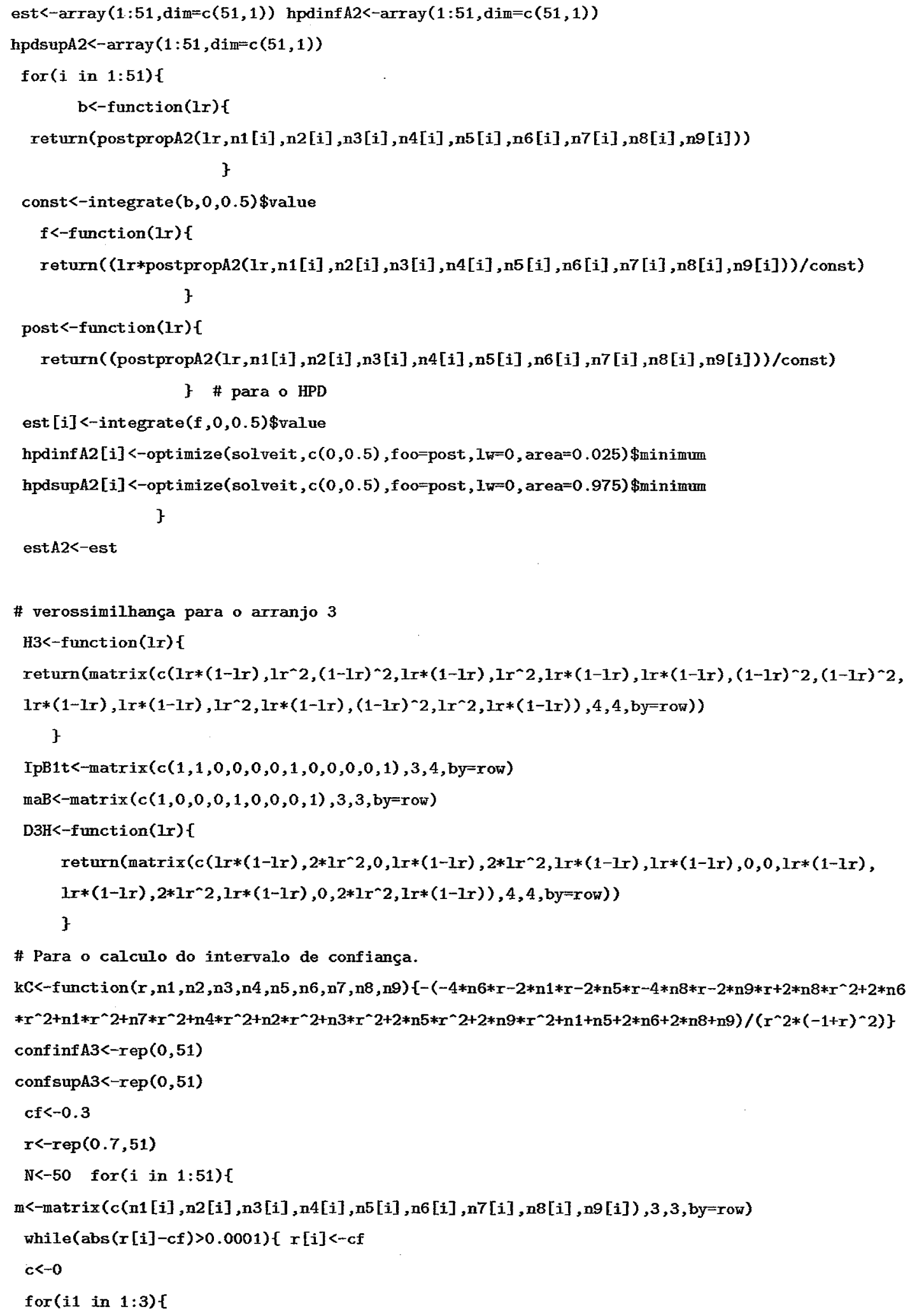




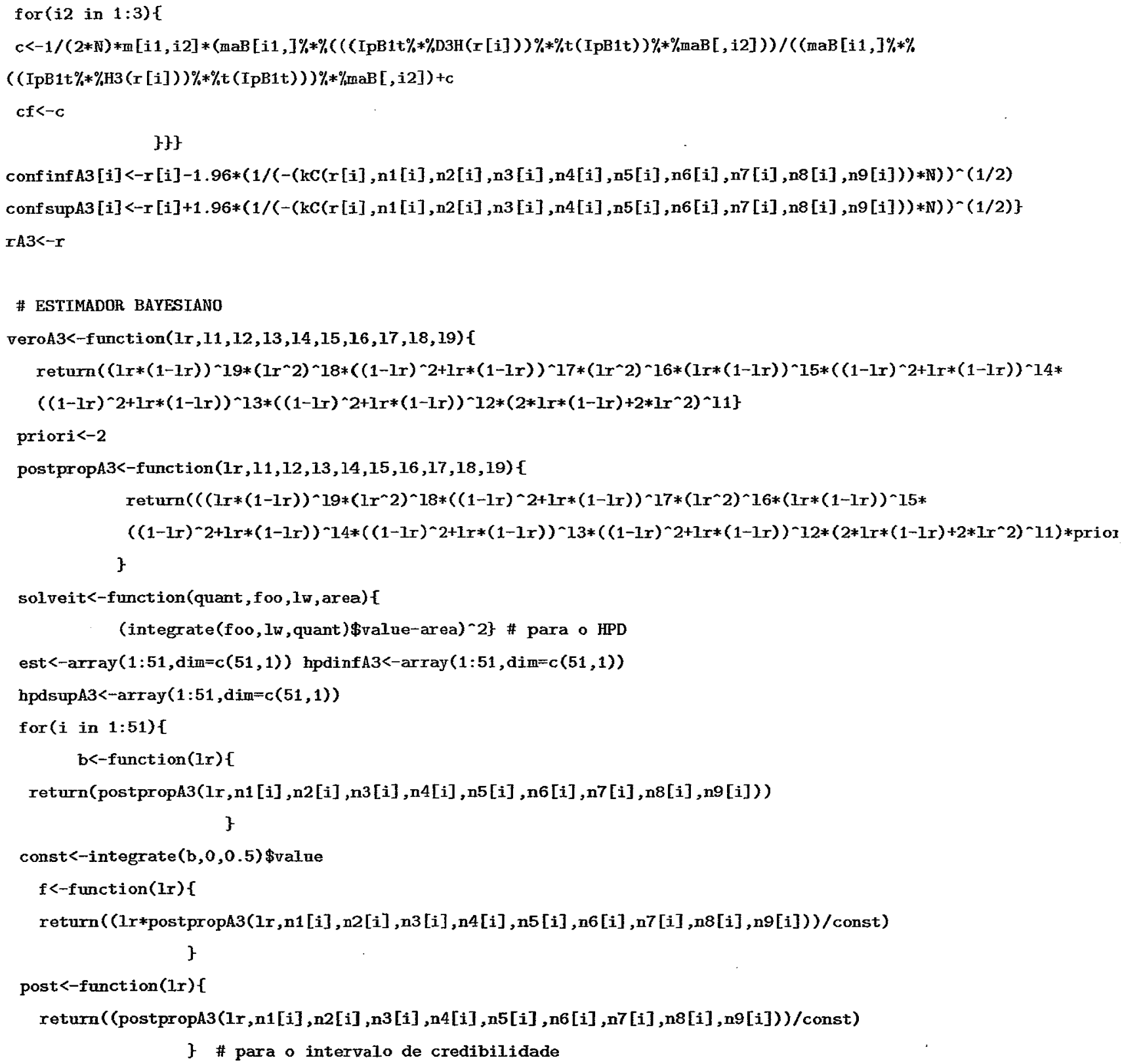




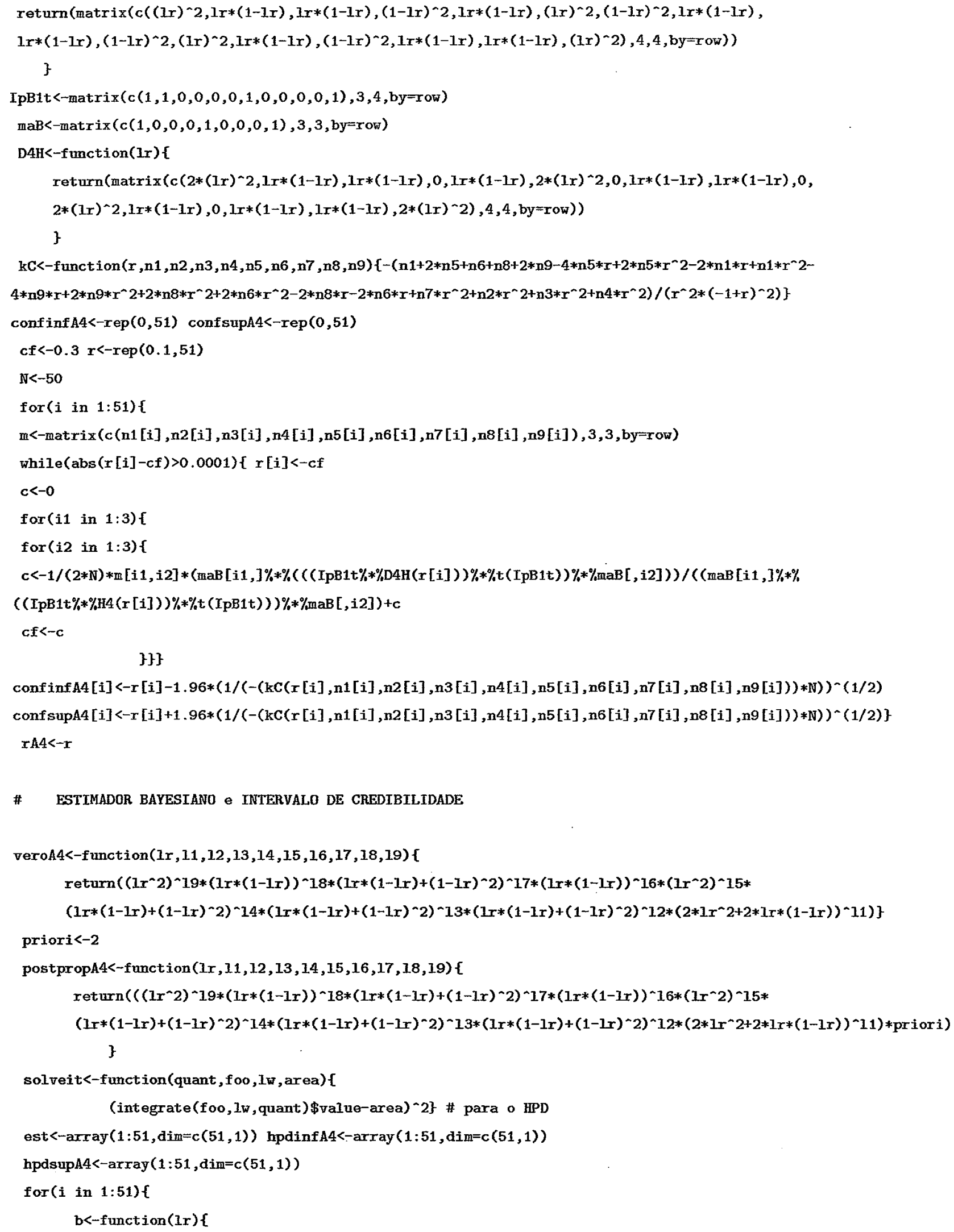




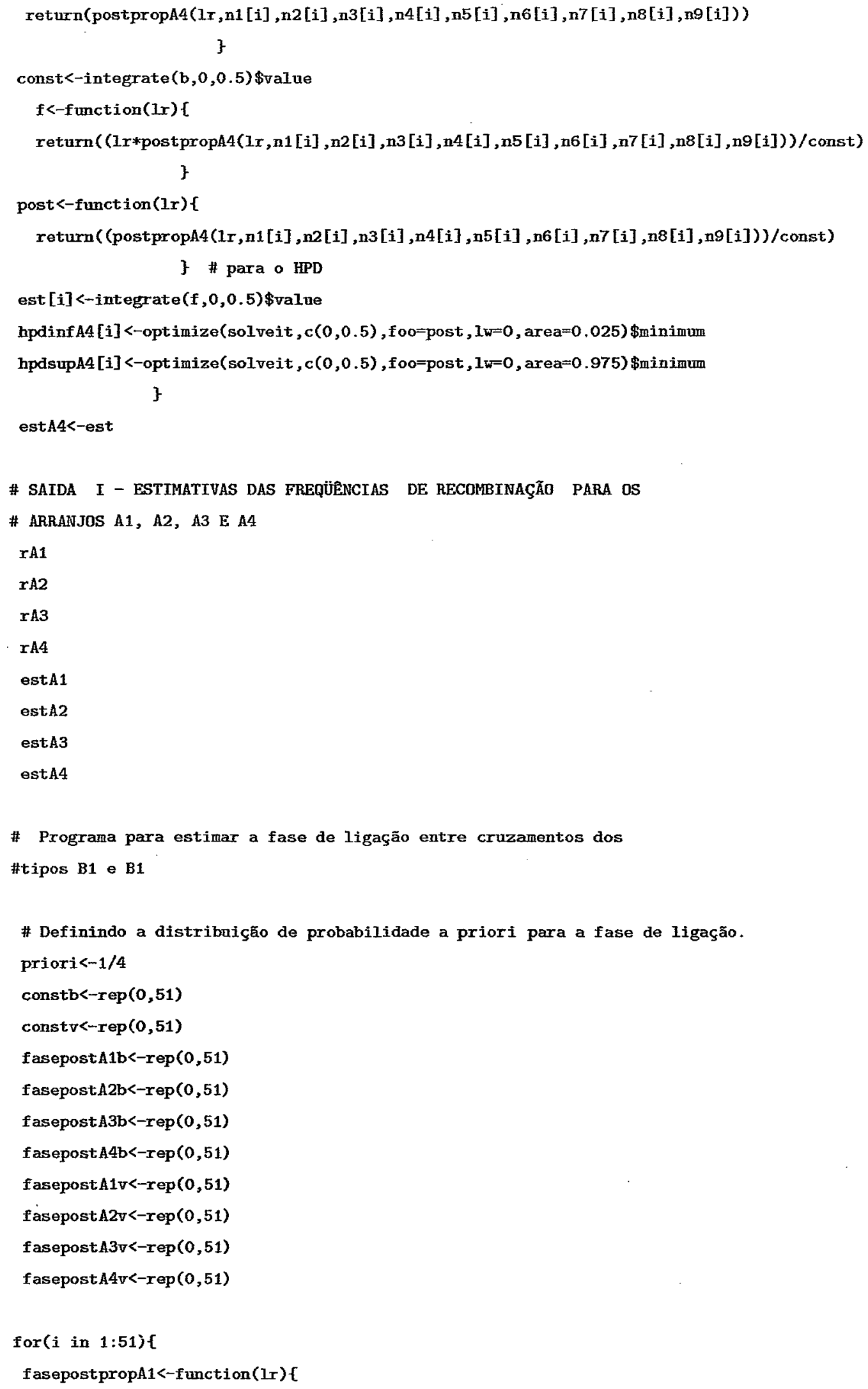




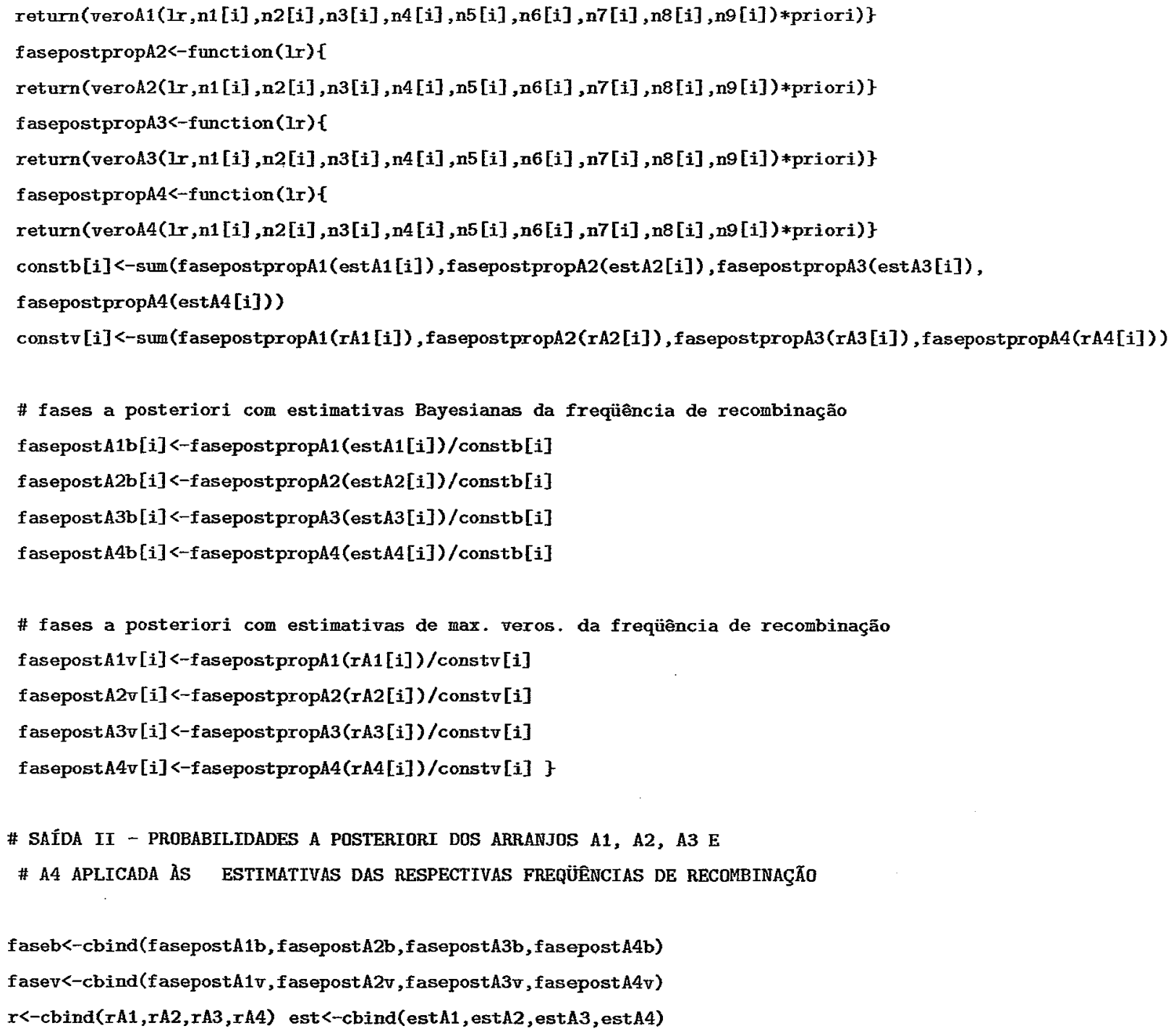


A5 - Gráficos referente aos cruzamentos $D 1 D 1(1), D 1 B 3(2), D 1 A(3), D 1 C(4)$, $D 1 B 1(5)$ e $D 2 B 1(6)$

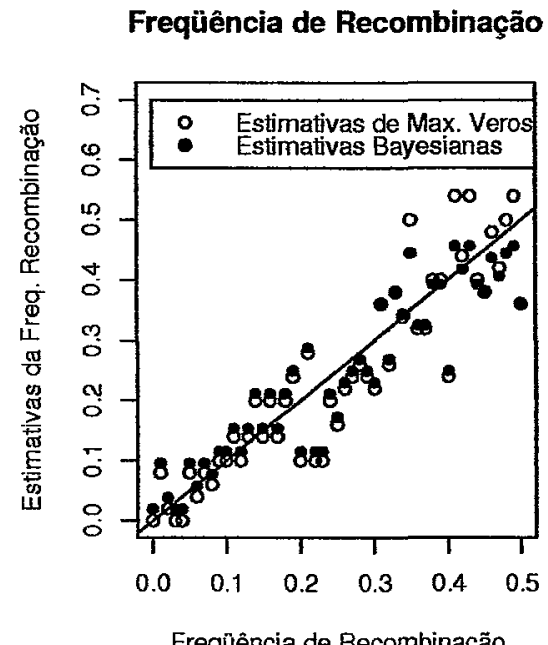

Frequêencia de Recombinação

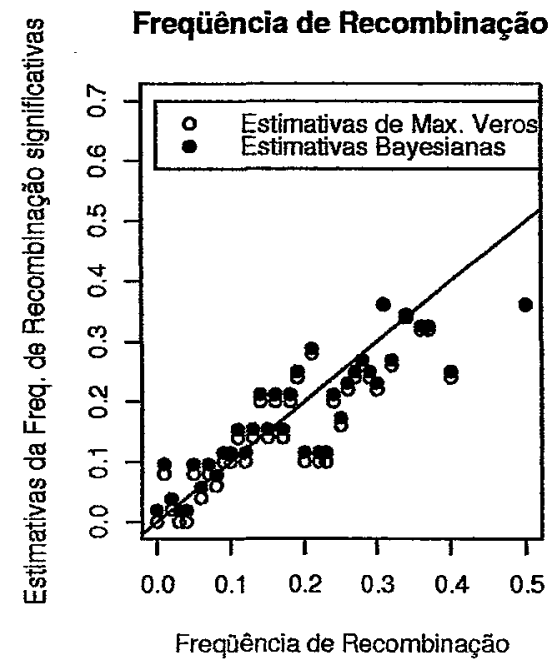

Frequuência de Recombinação

Figura 27 - Estimativas das freqüências de recombinação - cruzamento D1D1(1) arranjo A2 - progênie de tamanho 50

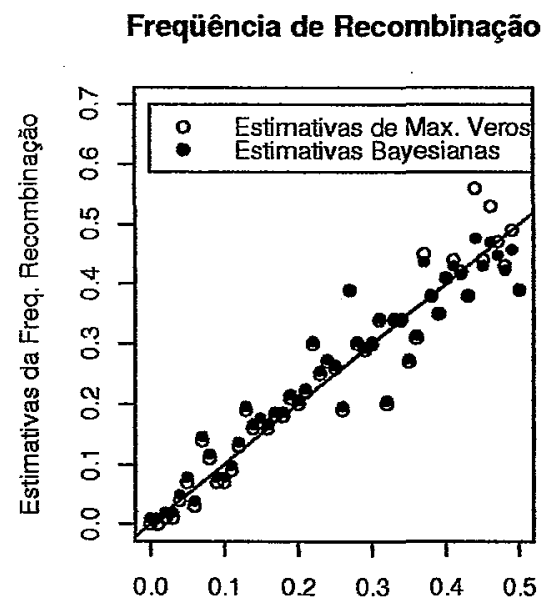

Freqüência de Recombinação

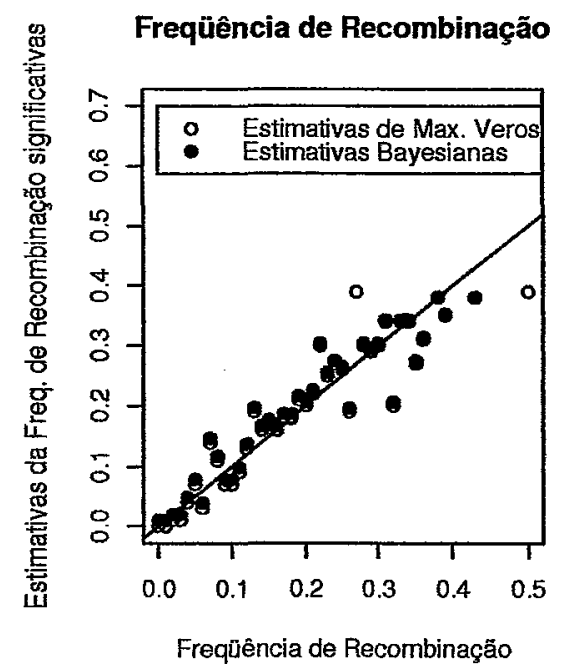

Freqüência de Recombinação

Figura 28 - Estimativas das freqüências de recombinação - cruzamento D1D1(1) arranjo A2 - progênie de tamanho 100 

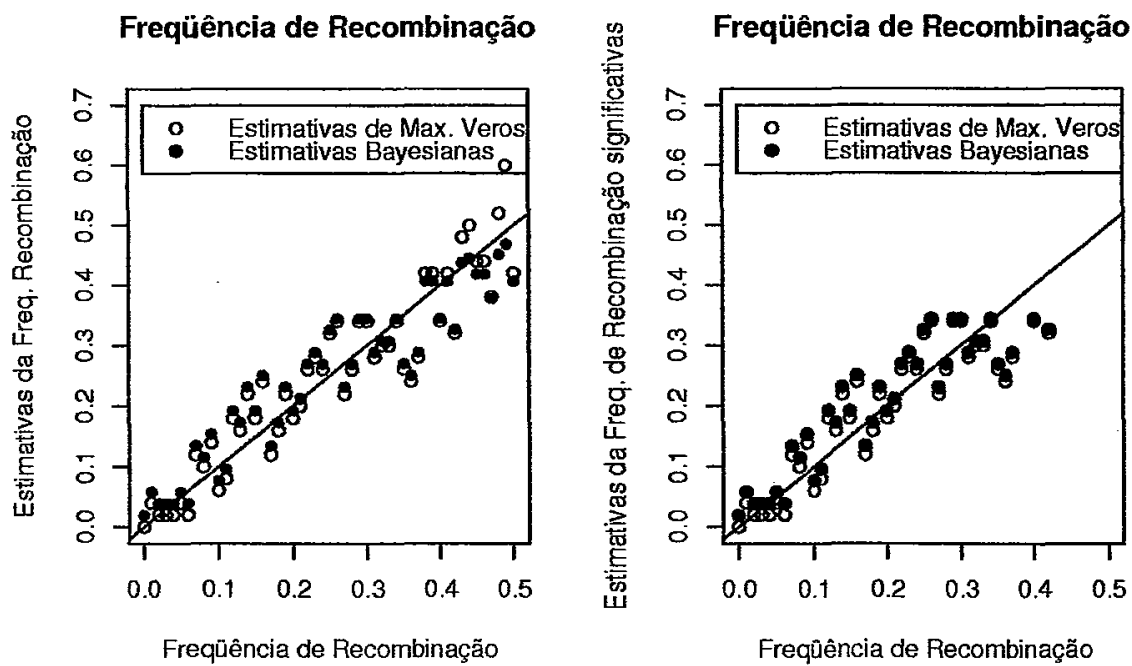

Figura 29 - Estimativas das freqüências de recombinação - cruzamento D1D1(1) arranjo A3 - progênie de tamanho 50

Freqüência de Recombinação

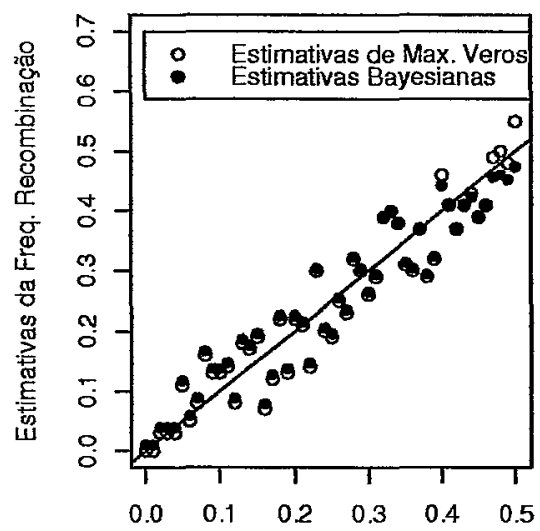

Freqüência de Recombinação
Freqüência de Recombinação
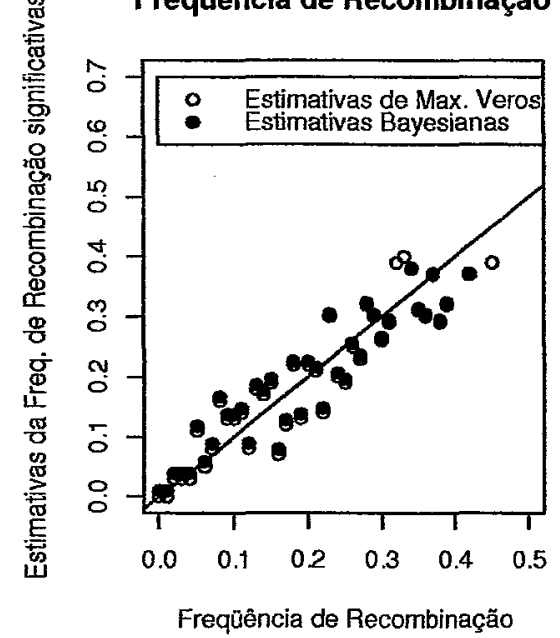

Figura 30 - Estimativas das freqüências de recombinação - cruzamento D1D1(1) arranjo A3 - progênie de tamanho 100 

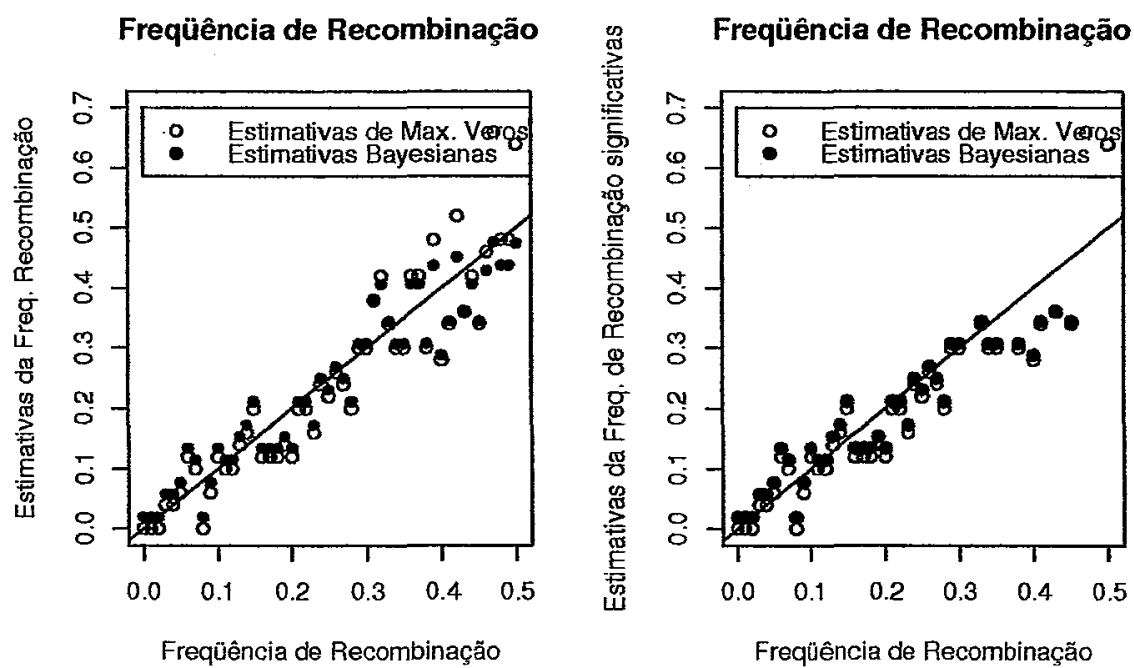

Figura 31 - Estimativas das freqüências de recombinação - cruzamento D1D1(1) arranjo A4 - progênie de tamanho 50

Freqüência de Recombinação

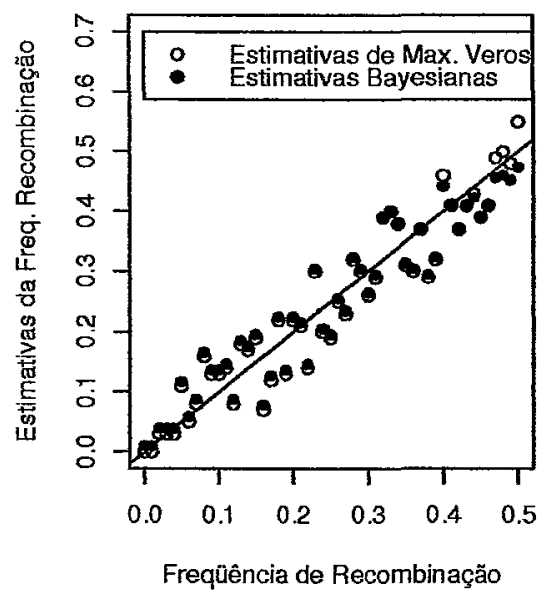

Freqüência de Recombinação
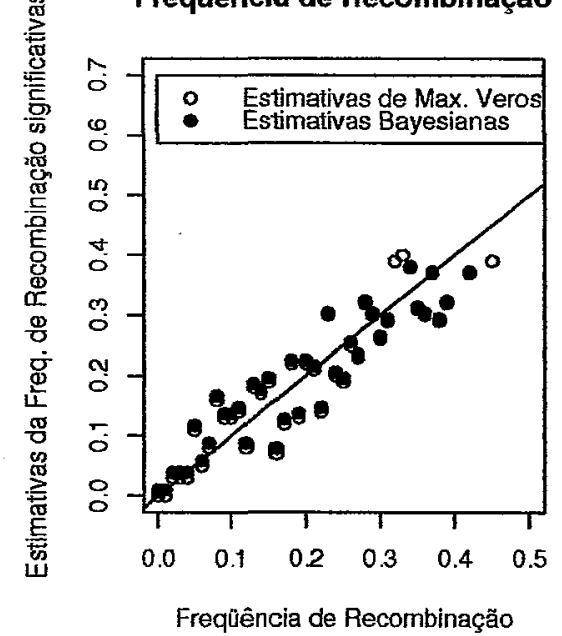

Figura 32 - Estimativas das freqüências de recombinação - cruzamento D1D1(1) arranjo A4 - progênie de tamanho 100 
A6 - Resultados de simulação - Estimativas de M.V. e de Bayes, intervalos de confiança e de credibilidade para o cruzamento do tipo $B 1 D 2(6)$ sob o arranjo $A 3$, tamanho de progênie 50

\begin{tabular}{|c|c|c|c|c|c|c|c|}
\hline I. C. Inf. & Est. M. V. & 1. C. Sup. & Est. M. V. Sig. & 1.Cred. Inf. & Est. Bayes & I. Cred. Sup. & Est. Bayes Sig. \\
\hline$-0,0551$ & 0,0003 & 0,0557 & 0,0003 & 0,0010 & 0,0370 & 0,1323 & 0,0370 \\
\hline$-0,0617$ & 0,0002 & 0,0622 & 0,0002 & 0,0012 & 0,0455 & 0,1611 & 0,0455 \\
\hline$-0,0564$ & 0,0002 & 0,0568 & 0,0002 & 0,0010 & 0,0385 & 0,1372 & 0,0385 \\
\hline$-0,0481$ & 0,0001 & 0,0484 & 0,0001 & 0,0007 & 0,0286 & 0,1028 & 0,0286 \\
\hline 0,0907 & 0,1069 & 0,1230 & 0,1069 & 0,0389 & 0,1333 & 0,2735 & 0,1333 \\
\hline 0,0582 & 0,0717 & 0,0852 & 0,0717 & 0,0219 & 0,1000 & 0,2277 & 0,1000 \\
\hline 0,0940 & 0,1108 & 0,1275 & 0,1108 & 0,0403 & 0,1379 & 0,2823 & 0,1379 \\
\hline 0,0710 & 0,0873 & 0,1037 & 0,0873 & 0,0265 & 0,1200 & 0,2700 & 0,1200 \\
\hline 0,0853 & 0,1048 & 0,1242 & 0,1048 & 0,0321 & 0,1428 & 0,3166 & 0,1428 \\
\hline 0,0627 & 0,0772 & 0,0918 & 0,0772 & 0,0235 & 0,1071 & 0,2429 & 0,1071 \\
\hline 0,0626 & 0,0771 & 0,0917 & 0,0771 & 0,0235 & 0,1071 & 0,2429 & 0,1071 \\
\hline 0,0245 & 0,0336 & 0,0428 & 0,0336 & 0,0079 & 0,0625 & 0,1670 & 0,0625 \\
\hline 0,0845 & 0,0997 & 0,1148 & 0,0997 & 0,0363 & 0,1250 & 0,2575 & 0,1250 \\
\hline 0,0710 & 0,0874 & 0,1037 & 0,0874 & 0,0265 & 0,1200 & 0,2700 & 0,1200 \\
\hline 0,2119 & 0,2377 & 0,2634 & 0,2377 & 0,1071 & 0,2585 & 0,4403 & 0,2585 \\
\hline 0,2004 & 0,2226 & 0,2448 & 0,2226 & 0,1069 & 0,2408 & 0,4067 & 0,2408 \\
\hline 0,1126 & 0,1293 & 0,1460 & 0,1293 & 0,0527 & 0,1515 & 0,2899 & 0,1515 \\
\hline 0,0910 & 0,1116 & 0,1322 & 0,1116 & 0,0338 & 0,1499 & 0,3307 & 0,1499 \\
\hline 0,1925 & 0,2140 & 0,2355 & 0,2140 & 0,1030 & 0,2330 & 0,3955 & 0,2330 \\
\hline 0,2460 & 0,2723 & 0,2986 & 0,2723 & 0,1316 & 0,2873 & 0,4598 & 0,2873 \\
\hline 0,2166 & 0,2403 & 0,2640 & 0,2403 & 0,1156 & 0,2580 & 0,4293 & 0,2580 \\
\hline 0,1428 & 0,1672 & 0,1916 & 0,1672 & 0,0605 & 0,1993 & 0,3916 & 0,1993 \\
\hline 0,4121 & 0,4396 & 0,4671 & NA & 0,2549 & 0,4001 & 0,4949 & NA \\
\hline 0,1459 & 0,1670 & 0,1882 & 0,1670 & 0,0683 & 0,1922 & 0,3601 & 0,1922 \\
\hline 0,2967 & 0,3211 & 0,3456 & NA & 0,1785 & 0,3269 & 0,4747 & 0,3269 \\
\hline 0,2029 & 0,2277 & 0,2525 & 0,2277 & 0,1022 & 0,2485 & 0,4284 & 0,2485 \\
\hline$-0,0551$ & 0,0003 & 0,0557 & 0,0003 & 0,0010 & 0,0370 & 0,1323 & 0,0370 \\
\hline 0,1106 & 0,1300 & 0,1494 & 0,1300 & 0,0474 & 0,1599 & 0,3234 & 0,1599 \\
\hline
\end{tabular}


A6 - Resultados de simulação - Estimativas de M.V. e de Bayes, intervalos de confiança e de credibilidade para o cruzamento do tipo $B 1 D 2(6)$ sob o arranjo $A 3$, tamanho de progênie 50

\begin{tabular}{|c|c|c|c|c|c|c|c|}
\hline 1. C. Inf. & Est. M. V. & 1. C. Sup. & Est. M. V. Sig. & 1. Cred. Inf. & Est. Bayes & I. Cred. Sup. & Est. Bayes Sig. \\
\hline 0,2021 & 0,2269 & 0,2516 & 0,2269 & 0,1022 & 0,2485 & 0,4284 & 0,2485 \\
\hline 0,2075 & 0,2304 & 0,2533 & 0,2304 & 0,1111 & 0,2492 & 0,4180 & 0,2492 \\
\hline 0,2716 & 0,2960 & 0,3203 & 0,2960 & 0,1583 & 0,3063 & 0,4642 & 0,3063 \\
\hline 0,3063 & 0,3330 & 0,3596 & NA & 0,1781 & 0,3350 & 0,4814 & 0,3350 \\
\hline 0,1066 & 0,1254 & 0,1441 & 0,1254 & 0,0454 & 0,1538 & 0,3121 & 0,1538 \\
\hline 0,4490 & 0,4779 & 0,5067 & NA & 0,2720 & 0,4134 & 0,4963 & NA \\
\hline 0,2868 & 0,3106 & 0,3344 & 0,3106 & 0,1723 & 0,3180 & 0,4689 & 0,3180 \\
\hline 0,3317 & 0,3568 & 0,3819 & NA & 0,2048 & 0,3540 & 0,4853 & NA \\
\hline 0,4298 & 0,4580 & 0,4862 & NA & 0,2634 & 0,4069 & 0,4956 & NA \\
\hline 0,4545 & 0,4812 & 0,5078 & NA & 0,2879 & 0,4200 & 0,4966 & NA \\
\hline 0,2362 & 0,2596 & 0,2830 & 0,2596 & 0,1321 & 0,2743 & 0,4396 & 0,2743 \\
\hline 0,3566 & 0,3884 & 0,4202 & NA & 0,1956 & 0,3649 & 0,4914 & $\mathrm{NA}$ \\
\hline 0,3884 & 0,4163 & 0,4442 & NA & 0,2361 & 0,3874 & 0,4934 & NA \\
\hline 0,4115 & 0,4439 & 0,4764 & NA & 0,2299 & 0,3914 & 0,4947 & NA \\
\hline 0,4341 & 0,4612 & 0,4883 & NA & 0,2721 & 0,4109 & 0,4959 & NA \\
\hline 0,3098 & 0,3336 & 0,3575 & NA & 0,1913 & 0,3367 & 0,4777 & 0,3367 \\
\hline 0,3725 & 0,3996 & 0,4268 & NA & 0,2278 & 0,3794 & 0,4920 & NA \\
\hline 0,3797 & 0,4087 & 0,4378 & NA & 0,2243 & 0,3810 & 0,4929 & NA \\
\hline 0,4701 & 0,4996 & 0,5292 & NA & 0,2807 & 0,4194 & 0,4968 & NA \\
\hline 0,5606 & 0,5860 & 0,6113 & NA & 0,3501 & 0,4513 & 0,4984 & NA \\
\hline 0,4922 & 0,5188 & 0,5455 & NA & 0,3097 & 0,4324 & 0,4975 & NA \\
\hline 0,6242 & 0,6517 & 0,6793 & NA & 0,3556 & 0,4549 & 0,4987 & NA \\
\hline 0,3356 & 0,3641 & 0,3925 & NA & 0,1935 & 0,3546 & 0,4881 & NA \\
\hline
\end{tabular}

"NA": indica que o valor estimado é não significativo. 
A7 - Gráficos referente ao cruzamento $B 3 C(9)$, sob os arranjos $A 1$ e $A 3$
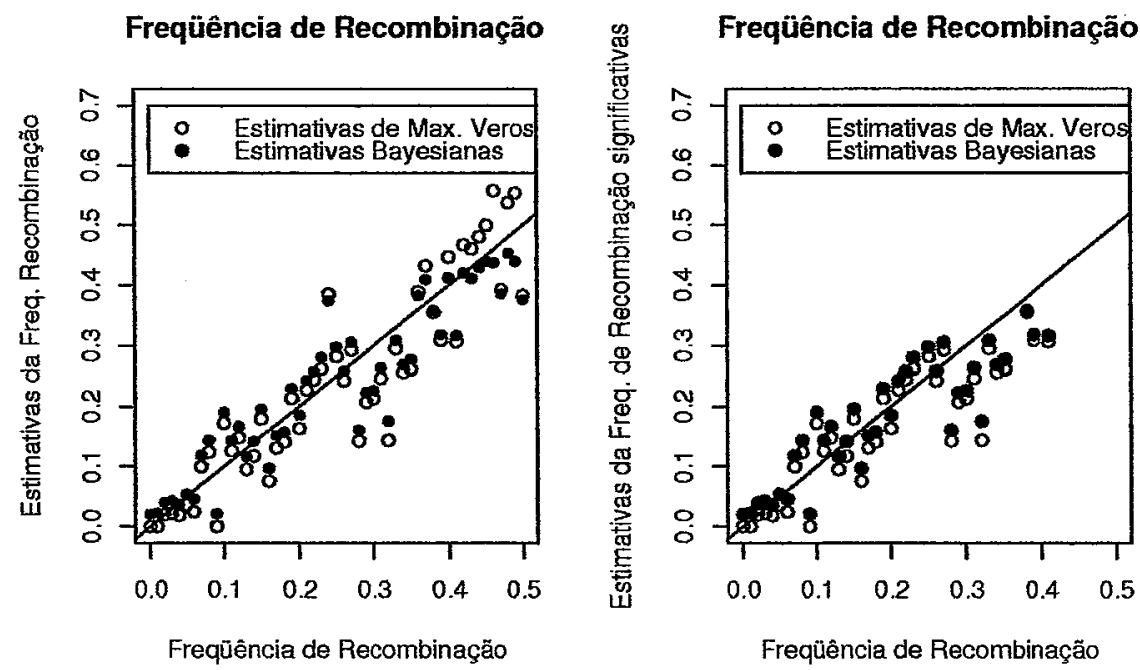

Figura 33 - Estimativas das freqüências de recombinação - cruzamento B3C(9) - arranjo A1 - progênie de tamanho 50

Freqüência de Recombinação

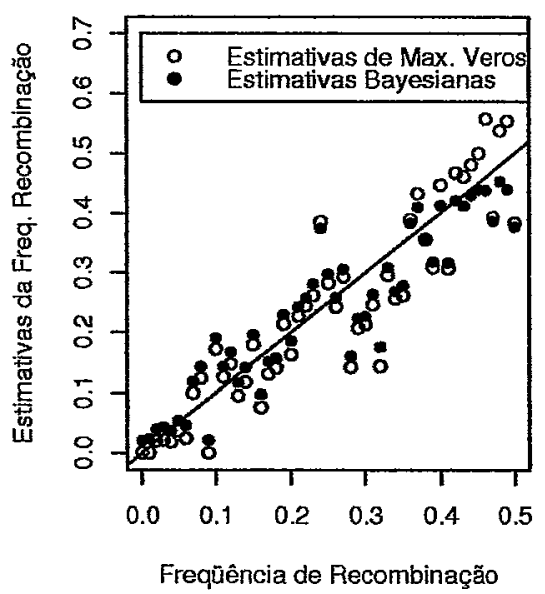

Freqüência de Recombinação

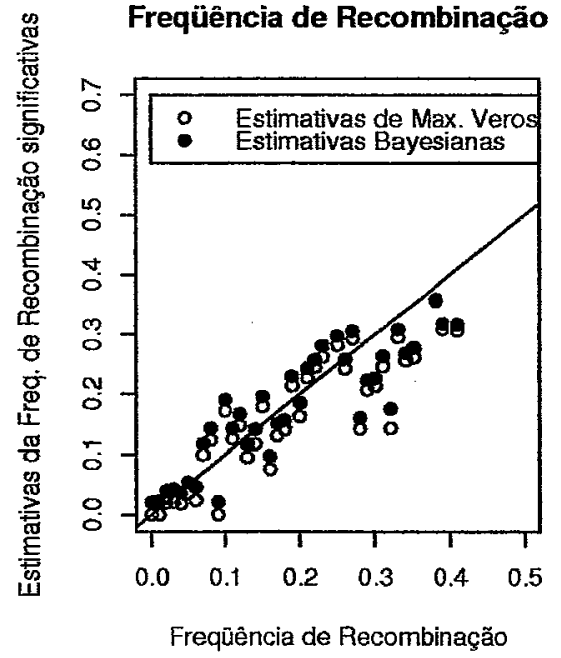

Figura 34 - Estimativas das freqüências de recombinação - cruzamento B3C(9) - arranjo A1 - progênie de tamanho 100 
Freqüêência de Recombinação

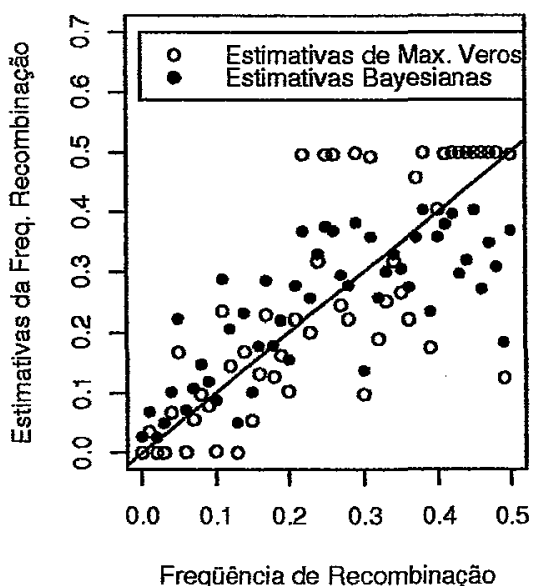

Freqüência de Recombinação

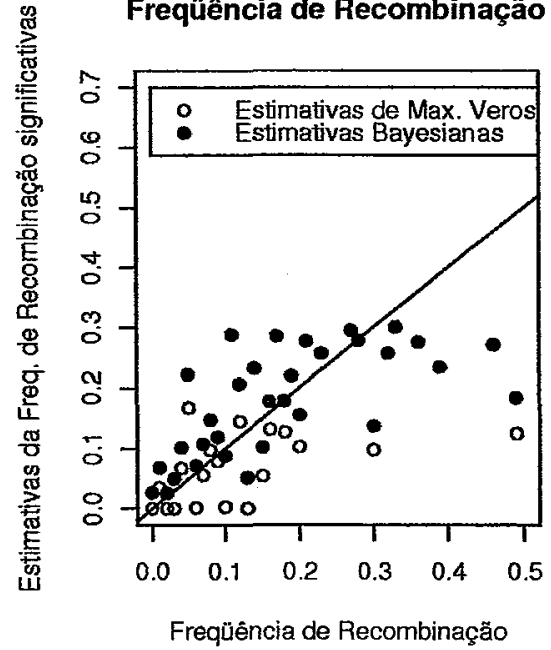

Figura 35 - Estimativas das freqüências de recombinação - cruzamento B3C(9) - arranjo A3 - progênie de tamanho 50

Freqüência de Recombinação

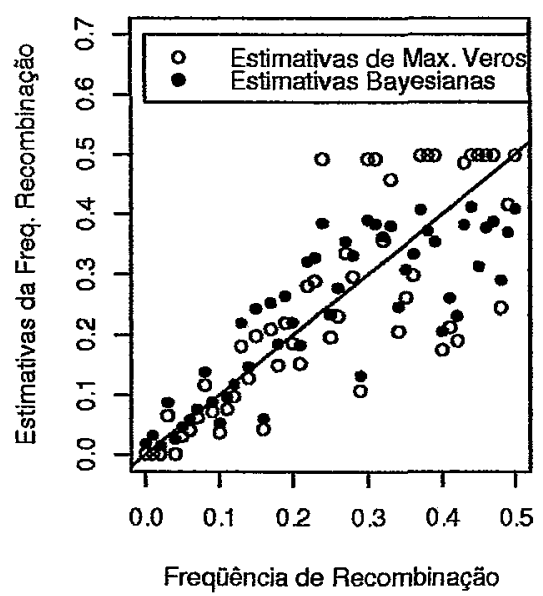

Freqüência de Recombinação
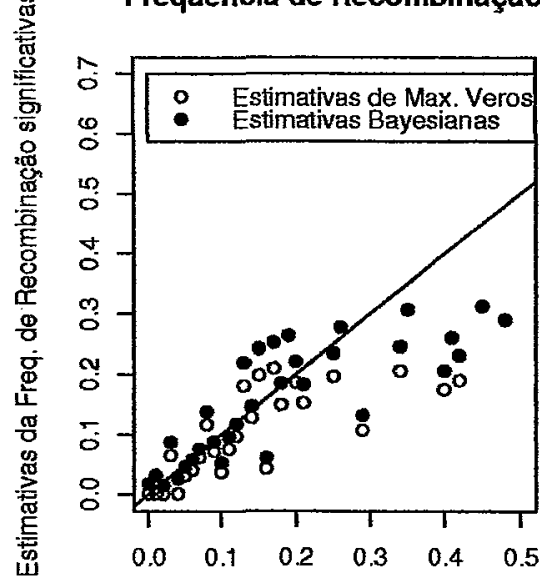

Frequeência de Recombinação

Figura 36 - Estimativas das freqüências de recombinação - cruzamento B3C - arranjo A3 - progênie de tamanho 100 
A8 - Resultados de simulação - Estimativas de M.V. e de Bayes, intervalos de confiança e de credibilidade para o cruzamento do tipo $B 3 B 3(7)$ sob o arranjo $A 3$, tamanho de progênie 50

\begin{tabular}{|c|c|c|c|c|c|c|c|}
\hline I. C. Inf. & Est. M. V. & I. C. Sup. & Est. M. V. Sig. & I.Cred. Inf. & Est. Bayes & 1. Cred. Sup. & Est. Bayes Sig. \\
\hline - & 0,0000 & - & 0,0000 & 0,0002 & 0,0100 & 0,0370 & 0,0100 \\
\hline - & 0,0000 & - & 0,0000 & 0,0002 & 0,0100 & 0,0370 & 0,0100 \\
\hline 0,0164 & 0,0204 & 0,0244 & 0,0204 & 0,0063 & 0,0307 & 0,0743 & 0,0307 \\
\hline 0,0567 & 0,0640 & 0,0713 & 0,0640 & 0,0301 & 0,0755 & 0,1427 & 0,0755 \\
\hline 0,0260 & 0,0310 & 0,0359 & 0,0310 & 0,0113 & 0,0415 & 0,0914 & 0,0415 \\
\hline 0,0462 & 0,0528 & 0,0593 & 0,0528 & 0,0233 & 0,0638 & 0,1254 & 0,0638 \\
\hline 0,0789 & 0,0877 & 0,0964 & 0,0877 & 0,0451 & 0,1000 & 0,1791 & 0,1000 \\
\hline 0,0569 & 0,0642 & 0,0715 & 0,0642 & 0,0301 & 0,0755 & 0,1427 & 0,0755 \\
\hline 0,0790 & 0,0877 & 0,0964 & 0,0877 & 0,0451 & 0,1000 & 0,1791 & 0,1000 \\
\hline 0,0905 & 0,0999 & 0,1093 & 0,0999 & 0,0532 & 0,1130 & 0,1985 & 0,1130 \\
\hline 0,0791 & 0,0878 & 0,0965 & 0,0878 & 0,0451 & 0,1000 & 0,1791 & 0,1000 \\
\hline 0,1149 & 0,1258 & 0,1366 & 0,1258 & 0,0708 & 0,1409 & 0,2416 & 0,1409 \\
\hline 0,0678 & 0,0758 & 0,0838 & 0,0758 & 0,0374 & 0,0876 & 0,1606 & 0,0876 \\
\hline 0,1149 & 0,1258 & 0,1366 & 0,1258 & 0,0708 & 0,1409 & 0,2416 & 0,1409 \\
\hline 0,1550 & 0,1682 & 0,1815 & 0,1682 & 0,1006 & 0,1897 & 0,3301 & 0,1897 \\
\hline 0,1695 & 0,1837 & 0,1979 & 0,1837 & 0,1116 & 0,2088 & 0,3714 & 0,2088 \\
\hline 0,1695 & 0,1837 & 0,1979 & 0,1837 & 0,1116 & 0,2088 & 0,3714 & 0,2088 \\
\hline 0,1846 & 0,1998 & 0,2151 & 0,1998 & 0,1233 & 0,2295 & 0,4143 & 0,2295 \\
\hline 0,2175 & 0,2353 & 0,2530 & 0,2353 & 0,1486 & 0,2741 & 0,4676 & 0,2741 \\
\hline 0,1279 & 0,1395 & 0,1511 & 0,1395 & 0,0802 & 0,1560 & 0,2666 & 0,1560 \\
\hline
\end{tabular}


A8 - Resultados de simulação - Estimativas de M.V. e de Bayes, intervalos de confiança e de credibilidade para o cruzamento do tipo $B 3 B 3(7)$ sob o arranjo $A 3$, tamanho de progênie 50

\begin{tabular}{|c|c|c|c|c|c|c|c|}
\hline I. C. Inf. & Est. M. V. & I. C. Sup. & Est. M. V. Sig. & 1.Cred. Inf. & Est. Bayes & I. Cred. Sup. & Est. Bayes Sig. \\
\hline 0,2175 & 0,2353 & 0,2530 & 0,2353 & 0,1486 & 0,2741 & 0,4676 & 0,2741 \\
\hline 0,1552 & 0,1685 & 0,1818 & 0,1685 & 0,1006 & 0,1897 & 0,3301 & 0,1897 \\
\hline 0,2547 & 0,2761 & 0,2975 & NA & 0,1764 & 0,3176 & 0,4853 & 0,3176 \\
\hline 0,1849 & 0,2002 & 0,2154 & 0,2002 & 0,1233 & 0,2295 & 0,4143 & 0,2295 \\
\hline 0,2006 & 0,2170 & 0,2334 & 0,2170 & 0,1356 & 0,2515 & 0,4475 & 0,2515 \\
\hline 0,3236 & 0,3579 & 0,3922 & NA & 0,2201 & 0,3686 & 0,4931 & NA \\
\hline 0,1413 & 0,1537 & 0,1662 & 0,1537 & 0,0902 & 0,1722 & 0,2955 & 0,1722 \\
\hline 0,3339 & 0,4708 & 0,6077 & NA & 0,2477 & 0,3916 & 0,4950 & NA \\
\hline 0,1696 & 0,1839 & 0,1981 & 0,1839 & 0,1116 & 0,2088 & 0,3714 & 0,2088 \\
\hline 0,2006 & 0,2170 & 0,2334 & 0,2170 & 0,1356 & 0,2515 & 0,4475 & 0,2515 \\
\hline 0,4283 & 0,4976 & 0,5668 & NA & 0,2606 & 0,4005 & 0,4955 & NA \\
\hline 0,3244 & 0,3592 & 0,3939 & NA & 0,2201 & 0,3686 & 0,4931 & NA \\
\hline 0,3507 & 0,3988 & 0,4469 & NA & 0,2342 & 0,3811 & 0,4942 & NA \\
\hline 0,2551 & 0,2766 & 0,2981 & NA & 0,1764 & 0,3176 & 0,4853 & 0,3176 \\
\hline 0,3507 & 0,3987 & 0,4468 & NA & 0,2342 & 0,3811 & 0,4942 & NA \\
\hline 0,4283 & 0,4975 & 0,5667 & NA & 0,2606 & 0,4005 & 0,4955 & NA \\
\hline 0,2760 & 0,3003 & 0,3245 & NA & 0,1909 & 0,3369 & 0,4891 & NA \\
\hline 0,3236 & 0,3580 & 0,3923 & NA & 0,2201 & 0,3686 & 0,4931 & NA \\
\hline 0,4735 & 0,4997 & 0,5259 & NA & 0,3195 & 0,4323 & 0,4972 & NA \\
\hline 0,4730 & 0,4998 & 0,5264 & NA & 0,2477 & 0,3916 & 0,4950 & NA \\
\hline- & 0,4998 & - & NA & 0,2342 & 0,3811 & 0,4942 & NA \\
\hline 0,4508 & 0,4998 & 0,5488 & $\mathrm{NA}$ & 0,2725 & 0,4080 & 0,4960 & NA \\
\hline 0,4508 & 0,4998 & 0,5488 & NA & 0,2725 & 0,4080 & 0,4960 & NA \\
\hline 0,4651 & 0,4998 & 0,5344 & NA & 0,2938 & 0,4199 & 0,4966 & NA \\
\hline- & 0,4998 & - & $\mathrm{NA}$ & 0,2201 & 0,3686 & 0,4931 & NA \\
\hline - & 0,4998 & - & NA & 0,1764 & 0,3176 & 0,4853 & 0,3176 \\
\hline- & 0,4998 & - & NA & 0,1909 & 0,3369 & 0,4891 & $\mathrm{NA}$ \\
\hline - & 0,4997 & - & NA & 0,2201 & 0,3686 & 0,4931 & NA \\
\hline- & 0,4997 & - & NA & 0,2201 & 0,3686 & 0,4931 & NA \\
\hline- & 0,4997 & - & NA & 0,2342 & 0,3811 & 0,4942 & $\mathrm{NA}$ \\
\hline- & 0,4997 & - & NA & 0,1622 & 0,2965 & 0,4789 & 0,2965 \\
\hline
\end{tabular}

"-" : indica que não foi possível calcular; "NA": indica que o valor estimado é não significativo. 
A9 - Resultados de simulação - Estimativas de M.V. e de Bayes, intervalos de confiança e de credibilidade para o cruzamento do tipo $B 1 B 1(16)$ sob o arranjo $A 1$, tamanho de progênie 100

\begin{tabular}{|c|c|c|c|c|c|c|c|}
\hline I. C. Inf. & Est. M. V. & I. C. Sup. & Fist. M. V. Sig. & 1.Cred. Inf. & Est. Bayes & I. Cred. Sup. & Est. Bayes Sig. \\
\hline$-0,0161$ & 0,0001 & 0,0163 & 0,0001 & 0,0002 & 0,0067 & 0,0246 & 0,0067 \\
\hline$-0,0161$ & 0,0000 & 0,0161 & 0,0000 & 0,0002 & 0,0067 & 0,0244 & 0,0067 \\
\hline$-0,0160$ & 0,0000 & 0,0160 & 0,0000 & 0,0002 & 0,0066 & 0,0241 & 0,0066 \\
\hline 0,0252 & 0,0279 & 0,0306 & 0,0279 & 0,0114 & 0,0345 & 0,0696 & 0,0345 \\
\hline 0,0435 & 0,0469 & 0,0503 & 0,0469 & 0,0233 & 0,0530 & 0,0938 & 0,0530 \\
\hline 0,0573 & 0,0612 & 0,0650 & 0,0612 & 0,0329 & 0,0671 & 0,1123 & 0,0671 \\
\hline 0,0183 & 0,0206 & 0,0229 & 0,0206 & 0,0075 & 0,0270 & 0,0585 & 0,0270 \\
\hline 0,0855 & 0,0902 & 0,0948 & 0,0902 & 0,0538 & 0,0959 & 0,1484 & 0,0959 \\
\hline 0,0492 & 0,0528 & 0,0563 & 0,0528 & 0,0272 & 0,0584 & 0,1004 & 0,0584 \\
\hline 0,0705 & 0,0747 & 0,0790 & 0,0747 & 0,0426 & 0,0805 & 0,1291 & 0,0805 \\
\hline 0,1112 & 0,1164 & 0,1216 & 0,1164 & 0,0742 & 0,1216 & 0,1787 & 0,1216 \\
\hline 0,0541 & 0,0577 & 0,0614 & 0,0577 & 0,0310 & 0,0633 & 0,1060 & 0,0633 \\
\hline 0,1187 & 0,1240 & 0,1294 & 0,1240 & 0,0802 & 0,1293 & 0,1878 & 0,1293 \\
\hline 0,0944 & 0,0993 & 0,1043 & 0,0993 & 0,0604 & 0,1049 & $\mathbf{0 , 1 5 9 9}$ & 0,1049 \\
\hline 0,0736 & 0,0781 & 0,0825 & 0,0781 & 0,0444 & 0,0839 & 0,1344 & 0,0839 \\
\hline 0,1105 & 0,1158 & 0,1212 & 0,1158 & 0,0729 & 0,1214 & 0,1802 & 0,1214 \\
\hline 0,1410 & 0,1470 & 0,1529 & 0,1470 & 0,0975 & 0,1522 & 0,2164 & 0,1522 \\
\hline 0,1990 & 0,2058 & 0,2126 & 0,2058 & 0,1466 & 0,2101 & 0,2817 & 0,2101 \\
\hline 0,1907 & 0,1972 & 0,2038 & $\mathbf{0 , 1 9 7 2}$ & 0,1402 & 0,2014 & 0,2704 & 0,2014 \\
\hline 0,1354 & 0,1410 & 0,1466 & 0,1410 & 0,0943 & 0,1457 & 0,2060 & 0,1457 \\
\hline 0,1932 & 0,1999 & 0,2067 & 0,1999 & 0,1414 & 0,2044 & 0,2755 & 0,2044 \\
\hline 0,1825 & 0,1889 & 0,1953 & 0,1889 & 0,1333 & 0,1931 & 0,2609 & 0,1931 \\
\hline 0,1653 & 0,1717 & 0,1781 & 0,1717 & 0,1174 & 0,1765 & 0,2446 & 0,1765 \\
\hline 0,1961 & 0,2028 & 0,2095 & 0,2028 & 0,1444 & 0,2071 & 0,2778 & 0,2071 \\
\hline 0,2231 & 0,2301 & 0,2371 & 0,2301 & 0,1682 & 0,2340 & 0,3071 & 0,2340 \\
\hline 0,3117 & 0,3199 & 0,3281 & 0,3199 & 0,2447 & 0,3228 & 0,4063 & 0,3228 \\
\hline
\end{tabular}


A9 - Resultados de simulação - Estimativas de M.V. e de Bayes, intervalos de confiança e de credibilidade para o cruzamento do tipo $B 1 B 1(16)$ sob o arranjo $A 1$, tamanho de progênie 100

\begin{tabular}{|c|c|c|c|c|c|c|c|}
\hline I. C. Inf. & Est. M. V. & I. C. Sup. & Est. M. V. Sig. & I.Cred. Inf. & Est. Bayes & I. Cred. Sup. & Est. Bayes Sig. \\
\hline 0,2938 & 0,3015 & 0,3092 & 0,3015 & 0,2307 & 0,3043 & 0,3833 & 0,3043 \\
\hline 0,2938 & 0,3015 & 0,3092 & 0,3015 & 0,2307 & 0,3043 & 0,3833 & 0,3043 \\
\hline 0,2755 & 0,2829 & 0,2902 & 0,2829 & 0,2158 & 0,2857 & 0,3611 & 0,2857 \\
\hline 0,3417 & 0,3495 & 0,3573 & 0,3495 & 0,2763 & 0,3517 & 0,4309 & 0,3517 \\
\hline 0,2781 & 0,2858 & 0,2935 & 0,2858 & 0,2158 & 0,2889 & 0,3679 & 0,2889 \\
\hline 0,3580 & 0,3663 & 0,3745 & 0,3663 & 0,2888 & 0,3683 & 0,4510 & 0,3683 \\
\hline 0,2781 & 0,2858 & 0,2935 & 0,2858 & 0,2158 & 0,2889 & 0,3679 & 0,2889 \\
\hline 0,2902 & 0,2978 & 0,3053 & 0,2978 & 0,2286 & 0,3007 & 0,3781 & 0,3007 \\
\hline 0,3945 & 0,4028 & 0,4112 & 0,4028 & 0,3235 & 0,4030 & 0,4802 & NA \\
\hline 0,3279 & 0,3359 & 0,3439 & 0,3359 & 0,2614 & 0,3382 & 0,4195 & 0,3382 \\
\hline 0,3377 & 0,3457 & 0,3538 & 0,3457 & 0,2704 & 0,3481 & 0,4301 & 0,3481 \\
\hline 0,3724 & 0,3809 & 0,3893 & 0,3809 & 0,3007 & 0,3823 & 0,4656 & 0,3823 \\
\hline 0,3706 & 0,3789 & 0,3871 & 0,3789 & 0,3005 & 0,3802 & 0,4622 & 0,3802 \\
\hline 0,4834 & 0,4921 & 0,5008 & NA & 0,3971 & 0,4621 & 0,4984 & NA \\
\hline 0,4097 & 0,4180 & 0,4264 & NA & 0,3372 & 0,4162 & 0,4878 & NA \\
\hline 0,3734 & 0,3817 & 0,3901 & 0,3817 & 0,3029 & 0,3830 & 0,4650 & 0,3830 \\
\hline 0,3697 & 0,3779 & 0,3861 & 0,3779 & 0,3004 & 0,3793 & 0,4605 & 0,3793 \\
\hline 0,4832 & 0,4920 & 0,5007 & NA & 0,3963 & 0,4618 & 0,4984 & NA \\
\hline 0,4071 & 0,4155 & 0,4240 & NA & 0,3337 & 0,4139 & 0,4872 & NA \\
\hline 0,4439 & 0,4529 & 0,4619 & NA & 0,3625 & 0,4408 & 0,4961 & NA \\
\hline 0,4588 & 0,4676 & 0,4764 & $\mathrm{NA}$ & 0,3772 & 0,4503 & 0,4973 & NA \\
\hline 0,4791 & 0,4878 & 0,4966 & NA & 0,3930 & 0,4600 & 0,4983 & NA \\
\hline 0,4709 & 0,4797 & 0,4886 & NA & 0,3861 & 0,4561 & 0,4979 & NA \\
\hline 0,4648 & 0,4734 & 0,4819 & NA & 0,3841 & 0,4540 & 0,4976 & NA \\
\hline 0,3963 & 0,4048 & 0,4134 & 0,4048 & 0,3228 & 0,4044 & 0,4824 & NA \\
\hline
\end{tabular}

"NA": indica que o valor estimado é não significativo. 
A10 - Resultados de simulação - Estimativas de M.V. e de Bayes, intervalos de confiança e de credibilidade para o cruzamento do tipo $A B 3(8)$ sob o arranjo $A 1$, tamanho de progênie 50

\begin{tabular}{|c|c|c|c|c|c|c|c|}
\hline I. C. Inf. & Est. M. V. & I. C. Sup. & Est. M. V. Sig. & I.Cred. Inf. & Est. Bayes & I. Cred. Sup. & Est. Bayes Sig. \\
\hline$-0,0377$ & 0,0000 & 0,0377 & 0,0000 & 0,0002 & 0,0099 & 0,0364 & 0,0099 \\
\hline 0,0072 & 0,0100 & 0,0128 & 0,0100 & 0,0024 & 0,0200 & 0,0555 & 0,0200 \\
\hline$-0,0352$ & 0,0000 & 0,0352 & 0,0000 & 0,0002 & 0,0099 & 0,0363 & 0,0099 \\
\hline 0,0072 & 0,0100 & 0,0128 & 0,0100 & 0,0024 & 0,0199 & 0,0550 & 0,0199 \\
\hline 0,0256 & 0,0305 & 0,0353 & 0,0305 & 0,0111 & 0,0403 & 0,0878 & 0,0403 \\
\hline 0,0972 & 0,1063 & 0,1155 & 0,1063 & 0,0587 & 0,1166 & 0,1936 & 0,1166 \\
\hline 0,0648 & 0,0722 & 0,0796 & 0,0722 & 0,0358 & 0,0817 & 0,1452 & 0,0817 \\
\hline 0,0861 & 0,0947 & 0,1033 & 0,0947 & 0,0508 & 0,1047 & 0,1772 & 0,1047 \\
\hline 0,0553 & 0,0623 & 0,0693 & 0,0623 & 0,0293 & 0,0723 & 0,1340 & 0,0723 \\
\hline 0,1163 & 0,1261 & 0,1358 & 0,1261 & 0,0735 & 0,1353 & 0,2142 & 0,1353 \\
\hline 0,0854 & 0,0938 & 0,1023 & 0,0938 & 0,0503 & 0,1033 & 0,1741 & 0,1033 \\
\hline 0,1395 & 0,1503 & 0,1611 & 0,1503 & 0,0910 & 0,1599 & 0,2469 & 0,1599 \\
\hline 0,1172 & 0,1271 & 0,1370 & 0,1271 & 0,0739 & 0,1365 & 0,2168 & 0,1365 \\
\hline 0,1526 & 0,1641 & 0,1755 & 0,1641 & 0,1009 & 0,1744 & 0,2674 & 0,1744 \\
\hline 0,0860 & 0,0945 & 0,1031 & 0,0945 & 0,0507 & 0,1043 & 0,1764 & 0,1043 \\
\hline 0,1083 & 0,1180 & 0,1277 & 0,1180 & 0,0669 & 0,1284 & 0,2095 & 0,1284 \\
\hline 0,2506 & 0,2667 & 0,2828 & 0,2667 & 0,1769 & 0,2816 & 0,4140 & 0,2816 \\
\hline 0,2036 & 0,2172 & 0,2308 & 0,2172 & 0,1406 & 0,2288 & 0,3394 & 0,2288 \\
\hline 0,1294 & 0,1399 & 0,1503 & 0,1399 & 0,0829 & 0,1497 & 0,2351 & 0,1497 \\
\hline 0,1727 & 0,1846 & 0,1965 & 0,1846 & 0,1173 & 0,1940 & 0,2883 & 0,1940 \\
\hline 0,1873 & 0,2000 & 0,2126 & 0,2000 & 0,1284 & 0,2102 & 0,3115 & 0,2102 \\
\hline 0,1669 & 0,1792 & 0,1914 & 0,1792 & 0,1115 & 0,1904 & 0,2910 & 0,1904 \\
\hline 0,2245 & 0,2385 & 0,2525 & 0,2385 & 0,1583 & 0,2491 & 0,3597 & 0,2491 \\
\hline 0,1761 & 0,1884 & 0,2008 & 0,1884 & 0,1193 & 0,1988 & 0,2981 & 0,1988 \\
\hline 0,1846 & 0,1970 & 0,2093 & 0,1970 & 0,1267 & 0,2065 & $\mathbf{0}, 3040$ & 0,2065 \\
\hline 0,2487 & 0,2624 & 0,2761 & 0,2624 & 0,1805 & 0,2701 & 0,3737 & 0,2701 \\
\hline
\end{tabular}


A10 - Resultados de simulação - Estimativas de M.V. e de Bayes, intervalos de confiança e de credibilidade para o cruzamento do tipo $A B 3(8)$ sob o arranjo $A 1$, tamanho de progênie 50

\begin{tabular}{|c|c|c|c|c|c|c|c|}
\hline I. C. Inf. & Est. M. V. & I. C. Sup. & Est. M. V. Sig. & I.Cred. Inf. & Est. Bayes & I. Cred. Sup. & Est. Bayes Sig. \\
\hline 0,3674 & 0,3905 & 0,4137 & NA & 0,2613 & 0,3868 & 0,4915 & NA \\
\hline 0,2933 & 0,3110 & 0,3287 & 0,3110 & 0,2110 & 0,3237 & 0,4559 & 0,3237 \\
\hline 0,2716 & 0,2878 & 0,3040 & 0,2878 & 0,1949 & 0,2998 & 0,4264 & 0,2998 \\
\hline 0,2543 & 0,2686 & 0,2828 & 0,2686 & 0,1840 & 0,2770 & 0,3856 & 0,2770 \\
\hline 0,2558 & 0,2713 & 0,2868 & 0,2713 & 0,1827 & 0,2833 & 0,4061 & 0,2833 \\
\hline 0,3758 & 0,3963 & 0,4168 & NA & 0,2741 & 0,3921 & 0,4910 & NA \\
\hline 0,3557 & 0,3720 & 0,3884 & 0,3720 & 0,2694 & 0,3746 & 0,4788 & 0,3746 \\
\hline 0,3549 & 0,3732 & 0,3915 & NA & 0,2630 & 0,3761 & 0,4841 & NA \\
\hline 0,4131 & 0,4331 & 0,4532 & NA & 0,3047 & 0,4154 & 0,4948 & NA \\
\hline 0,3639 & 0,3819 & 0,3999 & NA & 0,2714 & 0,3827 & 0,4859 & NA \\
\hline 0,3134 & 0,3288 & 0,3442 & 0,3288 & 0,2343 & 0,3350 & 0,4464 & 0,3350 \\
\hline 0,4344 & 0,4549 & 0,4754 & NA & 0,3184 & 0,4259 & 0,4962 & NA \\
\hline 0,3796 & 0,4023 & 0,4251 & NA & 0,2712 & 0,3940 & 0,4924 & NA \\
\hline 0,3352 & 0,3539 & 0,3726 & NA & 0,2449 & 0,3607 & 0,4790 & 0,3607 \\
\hline 0,2527 & 0,2678 & 0,2829 & 0,2678 & 0,1806 & 0,2787 & 0,3974 & 0,2787 \\
\hline 0,3928 & 0,4123 & 0,4318 & NA & 0,2907 & 0,4035 & 0,4927 & NA \\
\hline 0,4189 & 0,4345 & 0,4501 & NA & 0,3281 & 0,4234 & 0,4944 & NA \\
\hline 0,3855 & 0,4025 & 0,4194 & NA & 0,2937 & 0,3990 & 0,4897 & NA \\
\hline 0,4240 & 0,4428 & 0,4616 & NA & 0,3181 & 0,4229 & 0,4955 & NA \\
\hline 0,3376 & 0,3553 & 0,3730 & 0,3553 & 0,2495 & 0,3611 & 0,4762 & 0,3611 \\
\hline 0,4789 & 0,4998 & 0,5207 & NA & 0,3445 & 0,4430 & 0,4977 & NA \\
\hline 0,3953 & 0,4129 & 0,4306 & NA & 0,2993 & 0,4058 & 0,4920 & $\mathrm{NA}$ \\
\hline 0,4249 & 0,4415 & 0,4580 & NA & 0,3288 & 0,4262 & 0,4953 & NA \\
\hline $0, \mathbf{4 1 3 4}$ & 0,4335 & 0,4536 & NA & 0,3047 & 0,4154 & 0,4948 & NA \\
\hline 0,4460 & 0,4643 & 0,4827 & NA & 0,3360 & 0,4347 & 0,4968 & $\mathrm{NA}$ \\
\hline
\end{tabular}

"NA": indica que o valor estimado é nấo significativo. 
A11 - Cruzamentos da Tabela 2, sua notação em termos dos grupos da Tabela 1 e notação utilizada neste trabalho

\begin{tabular}{|c|c|c|}
\hline Cruzamentos da Tabela 2 & Notaçāo Tabela 1 & Notação Utilizada \\
\hline 1 & $D 1 D 1$ & $D 1 D 1(1)$ \\
\hline (1) & $D 2 D 2$ & $D 2 D 2(2)$ \\
\hline 2 & $D 1 B 3$ & $D 1 B 3(2)$ \\
\hline (2) & $D 2 B 3$ & $D 2 B 3(2)$ \\
\hline 3 & $D 1 A$ & $D 1 A(3)$ \\
\hline (3) & $D 2 A$ & $D 2 A(3)$ \\
\hline 4 & $D 1 C$ & $D 1 C(4)$ \\
\hline (4) & $D 2 C$ & $D 2 C(4)$ \\
\hline 5 & $D 1 B 1$ & $D 1 B 1(5)$ \\
\hline (5) & $D 2 B 2$ & $D 2 B 2(5)$ \\
\hline 6 & $D 1 B 2$ & $D 1 B 2(6)$ \\
\hline (6) & $D 2 B 1$ & $D 2 B 1(6)$ \\
\hline 7 & $B 3 B 3$ & $B 3 B 3(7)$ \\
\hline 8 & $B 3 A$ & $B 3 A(8)$ \\
\hline 9 & $B 3 C$ & $B 3 C(9)$ \\
\hline 10 & $B 3 B 1$ & $B 3 B 1(10)$ \\
\hline (10) & $B 3 B 2$ & $B 3 B 2(10)$ \\
\hline 11 & $A A$ & $A A(11)$ \\
\hline 12 & $A C$ & $A C(12)$ \\
\hline 13 & $A B 1$ & $A B 1(13)$ \\
\hline (13) & $A B 2$ & $A B 2(13)$ \\
\hline 14 & $C C$ & $C C(14)$ \\
\hline 15 & $C B 1$ & $C B 1(15)$ \\
\hline (15) & $C B 2$ & $C B 2(15)$ \\
\hline 16 & $B 1 B 1$ & $B 1 B 1(16)$ \\
\hline 17 & $B 1 B 2$ & $B 1 B 2(17)$ \\
\hline (17) & $B 2 B 2$ & $B 2 B 2(17)$ \\
\hline
\end{tabular}




\section{REFERÊNCIAS BIBLIOGRÁFICAS}

BOX, G.E.P.; TIAO, G.C. Bayesian inference in statistical analysis. New York: Wiley, 1992. 588p.

CRISTOFANI, M. Mapas de ligação de Citrus sunki Hort. ex. Tan. e Poncirus trifoliata (L.) Raf. cv. Rubidoux e localização do gene de resistência ao vírus da tristeza. Piracicaba, 1997. 140 p. Tese (Doutorado) - Escola Superior de Agricultura "Luiz de Queiroz", Universidade de São Paulo.

GRATTAPAGLIA, D.; SEDEROFF, R., Genetic linkage maps of Eucalyptus grandis and Eucalyptus urophylla using a pseudo-testcross: mapping strategy and RAPD markers. Genetics, v. 137, p. 1121-1137, 1994.

GELMAN, A.; CARLIN, J.B.; STERN, H.S.; RUBIN, D.B. Bayesian data analysis. 2. ed. London: Chapman and Hall, 2003. 668p.

GRIFFITHS, A.J.F.; MILLER, J.H.; SUZUKI, D.T.; LEWONTIN, R.C.; GELBART,W.M. Introdução à Genética. 7.ed. Rio de Janeiro: Guanabara Koogan, 2002. 794p.

JEFFREYS, H. Theory of probability, 3.ed. Oxford: Clarendon Press, 1961. 447p.

KALBFLEISCH, J.G. Probability and statistics inference. 2.ed. New York: Springer - Velarg, 1985. 2v. 343p.

LANGE, K.S. Statistics for biology and health: Mathematical and statistical methods for genetic analysis. New York: Springer, 1997. 265p. 
LEANDRO, R.A. Introdução à estatística Bayesiana. Piracicaba: Escola Superior de Agricultura Luiz de Queiroz, Universidade de São Paulo, Departamento de Ciências Exatas, 2001. 51p.

LEE, P.M. Bayesian statistics: an introduction. 2.ed. London: Euston Road, 1997. $338 \mathrm{p}$.

LIU, B.H. Statistical genomics: Linkage, Mapping and QTL Analysis, Boca Raton: CRC Press, 1998. 611p.

MALIEPAARD, C.; JASEN, J.; VAN, O. Linkage analysis in a full-sib family of an outbreeding plant species: overview and consequences for apllications. Genetics Research , v.70, p.237-250, 1997.

NORDHEIM,E.V.; O'MALLEY,D.M.; GURIES,R.P. Estimation of recombination frequency in genetic linkage studies. Teoretical Applied and Genetics, v 66, p. 313-321, 1983.

PASTINA, M.M. Construção de um mapa genético para cana-de-açúcar com marcador RFLP usando os programas computacionais MAPMAKER/EXP E JOINMAP Simultaneamente. Piracicaba, 2002. 13 p. Trabalho de Iniciação Científica - Escola Superior de Agricultura "Luiz de Queiroz"- Universidade de São Paulo.

SMITH, A.F.M. Bayesian methods in Reliability. In SANDER, P.; BADEUX, R. Topics in safety, reliability and quality. London: Kleiwer Academic Publishers (ed)., 1991, p.34-79.

WU, R.; MA,C.-X.; PAINTER, I.; ZENG,Z.-B. Simultaneous maximum likelihood estimation of linkage and linkage phases in outcrossing species. Teoretical Population Biology, v.61, p.349-363, 2002. 